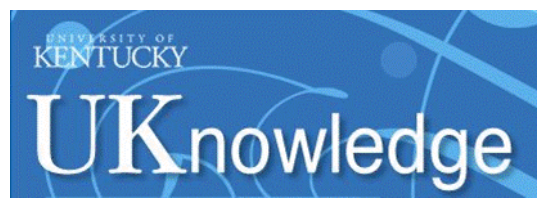

University of Kentucky

UKnowledge

2016

\title{
How The Prospect of Fault Influences Managers' Compliance
}

\author{
Matthew T. Sooy \\ University of Kentucky, matthew.sooy@uky.edu \\ Digital Object Identifier: http://dx.doi.org/10.13023/ETD.2016.135
}

Right click to open a feedback form in a new tab to let us know how this document benefits you.

\section{Recommended Citation}

Sooy, Matthew T., "How The Prospect of Fault Influences Managers' Compliance" (2016). Theses and Dissertations--Accountancy. 5.

https://uknowledge.uky.edu/accountancy_etds/5

This Doctoral Dissertation is brought to you for free and open access by the Accountancy at UKnowledge. It has been accepted for inclusion in Theses and Dissertations--Accountancy by an authorized administrator of UKnowledge. For more information, please contact UKnowledge@lsv.uky.edu. 


\section{STUDENT AGREEMENT:}

I represent that my thesis or dissertation and abstract are my original work. Proper attribution has been given to all outside sources. I understand that I am solely responsible for obtaining any needed copyright permissions. I have obtained needed written permission statement(s) from the owner(s) of each third-party copyrighted matter to be included in my work, allowing electronic distribution (if such use is not permitted by the fair use doctrine) which will be submitted to UKnowledge as Additional File.

I hereby grant to The University of Kentucky and its agents the irrevocable, non-exclusive, and royalty-free license to archive and make accessible my work in whole or in part in all forms of media, now or hereafter known. I agree that the document mentioned above may be made available immediately for worldwide access unless an embargo applies.

I retain all other ownership rights to the copyright of my work. I also retain the right to use in future works (such as articles or books) all or part of my work. I understand that I am free to register the copyright to my work.

\section{REVIEW, APPROVAL AND ACCEPTANCE}

The document mentioned above has been reviewed and accepted by the student's advisor, on behalf of the advisory committee, and by the Director of Graduate Studies (DGS), on behalf of the program; we verify that this is the final, approved version of the student's thesis including all changes required by the advisory committee. The undersigned agree to abide by the statements above.

Matthew T. Sooy, Student

Dr. Sean Peffer, Major Professor

Dr. Dan Stone, Director of Graduate Studies 
HOW THE PROSPECT OF FAULT

INFLUENCES MANAGERS' COMPLIANCE

\section{DISSERTATION}

A dissertation submitted in partial fulfillment of requirements for the degree of Doctor or Philosophy in the

College of Business and Economics at the University of Kentucky

By

Matthew Sooy

Lexington, Kentucky

Director: Dr. Sean Peffer, Associate Professor of

Accounting, Lexington, Kentucky

2016

Copyright (C Matthew Sooy 2016 


\title{
ABSTRACT OF DISSERTATION
}

\author{
HOW THE PROSPECT OF FAULT \\ INFLUENCES MANAGERS' COMPLIANCE
}

The SEC relies heavily on 'no-fault' settlements in its enforcement, where targets avoid costly litigation by accepting sanctions without admitting or denying fault. This policy is argued to enable the agency to pursue greater numbers of violators. However, opponents argue that nofault sanctions may be less effective, reducing fines to a 'cost of business'. In an experiment, I examine the effects of fault assignment on managers' cost perceptions, ethical framing and compliance. I manipulate the presence of fault assignment in prospective sanctions, and additionally manipulate sanction strength and sanction target - attributes that commonly vary in sanctions and which may interact with fault assignment. I find that all manipulated sanction attributes increase managers' cost perceptions, and that managers' cost perceptions are associated with greater compliance frequency and compliance quality. I also find that managers facing fault assignment in manager-targeted sanction conditions perceive their compliance differently - as an ethical, rather than economic choice. Consequently, these managers comply more frequently with costly regulations and select higher quality compliance than do managers in managertargeted no-fault conditions. Targeting firms with sanctions also increases managers' ethical perceptions, but adding fault to firm-targeted sanctions does not further increase ethical perceptions or compliance. My findings are consistent with sanctions facilitating greater ethical awareness and compliance when fault targets managers or when sanctions target firms, and with ethical awareness facilitating greater compliance. Supplementary analysis suggests that results are stronger among individuals high in 'dark triad' personality traits (narcissism, machiavellianism, and psychopathy), suggesting that findings generalize to subpopulations thought to be high in dark triad traits such as firm managers (O'Reilly et al. 2014).

KEYWORDS: Accounting, Fault, Compliance, Social Sanctions, Decision Frames

Matthew T. Sooy

Author

$4 / 26 / 2016$

Date 
HOW THE PROSPECT OF FAULT

INFLUENCES MANAGERS' COMPLIANCE

By

Matthew T. Sooy
Dr. Sean Peffer

Director of Dissertation

Dr. Dan Stone

Director of Graduate Studies

$4 / 26 / 2016$

Date 


\section{ACKNOWLEDGEMENTS}

My dissertation reflects the collective effort, input and support of many individuals and institutions. I thank the Von Allmen School of Accountancy, the Gatton College of Business and Economics, and the University of Kentucky for the opportunity and resources to pursue my doctoral degree. I especially thank my dissertation chair, Sean Peffer, and members of my dissertation committee, Jason Brown, Bob Ramsay, and Richard Smith for their insight and patience. I also thank the many faculty members at the University of Kentucky who have assisted in my growth and the many colleagues and faculty members who have been a part of previous chapters of my journey - at Georgia State University, KPMG, Emory University, and Indiana University. I have learned much from all of you. I hope that you can share in this achievement.

My greatest thanks go to my family, for their constant love, support, and encouragement. They have sacrificed much so that I may pursue my dream. Thank you. Lastly, I would also like to acknowledge the many readers who have taken extra time from their schedules to give insightful feedback on this project. Among others, this manuscript and its previous iterations has benefitted from the insightful feedback of Nigel Barradale, Jean Bedard, Willie Choi, Ben Commerford, Jing Davis, Kun Huo, Sean Dennis, Dick Riley, Pinky Rusli, Dan Stone, Jay Thibodeau, Russell Williamson, brownbag participants in the Managerial Experimental Accounting Research Brownbag series, and workshop participants at Bentley University, the University of Kentucky, University of Western Ontario, and West Virginia University. All errors are my own. 


\section{TABLE OF CONTENTS}

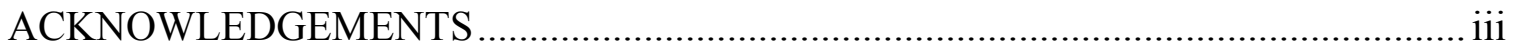

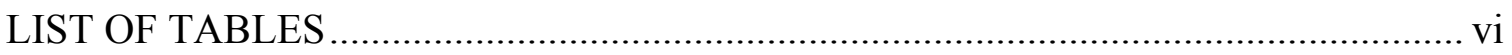

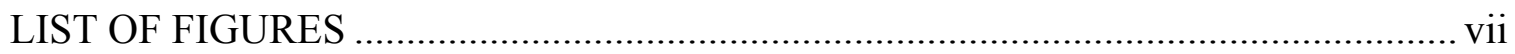

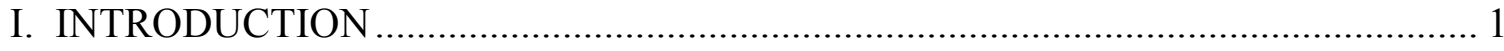

II. BACKGROUND \& HYPOTHESIS DEVELOPMENT............................................ 7

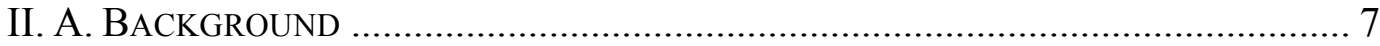

No-Fault Settlements .......................................................................... 7

Compliance, Sanctioning Systems, and Decision Frames .......................... 9

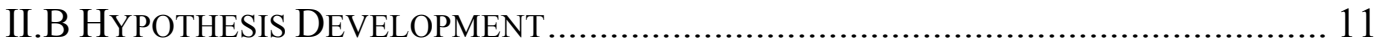

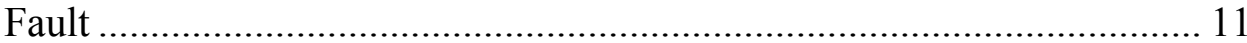

Sanction Strength \& Sanction Target ................................................ 13

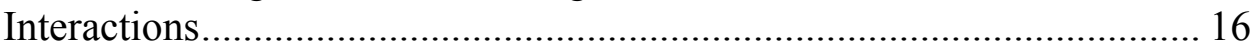

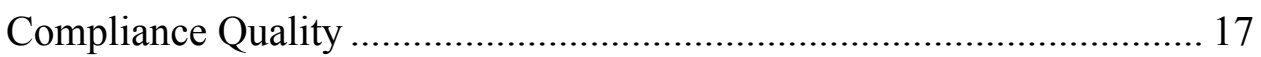

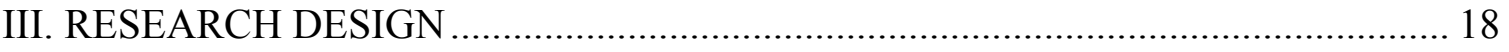

III.A PARTICIPANTS ……………………………................................... 18

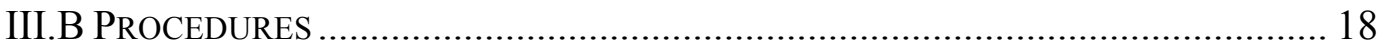

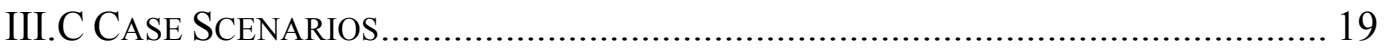

III.D MANIPULATED AND MEASURED VARIABLES …………………………........ 21

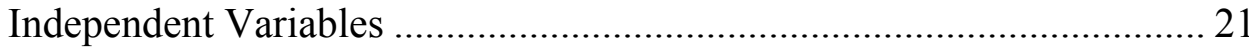

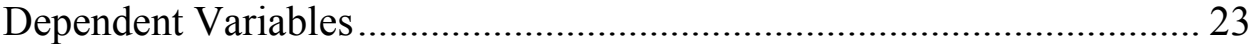

Mediating Variables................................................................................ 24

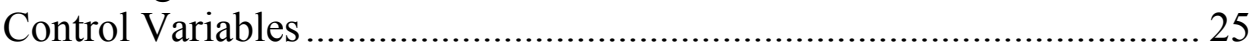

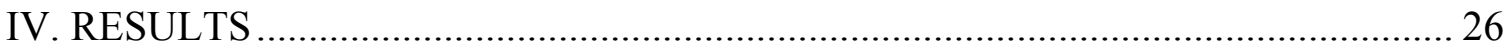

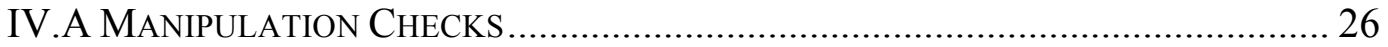

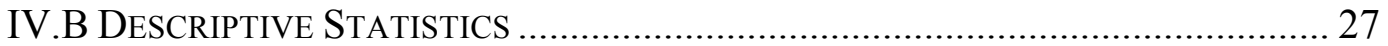

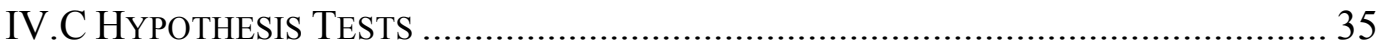

The Effects of Fault on Perceived Costs (H1a) and Ethical Frames (H1b)

The Effects of Sanction Strength on Perceived Costs and Ethical Frames

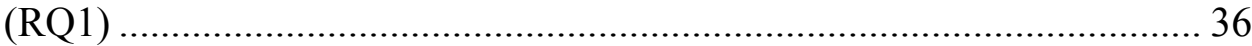

The Interactive Effects of Fault and Sanction Target on Ethical Frames

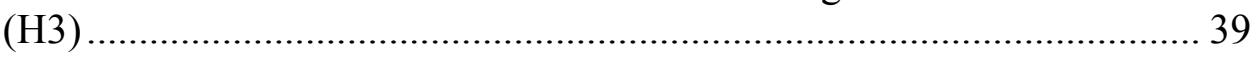

The Interactive Effects of Sanction Strength and Sanction Target on

Perceived Costs (H4) ............................................................................ 40

The Interactive Effects of Fault and Sanction Strength on Perceived Costs

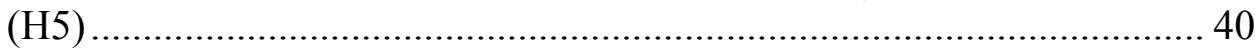

The Effects of Perceived Costs and Ethical Frames on Managers'

Compliance Frequency (H6a) and Compliance Level (H6b) ..................... 41

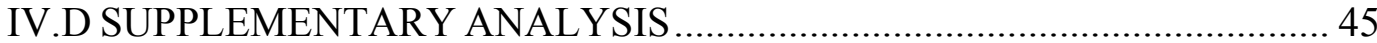

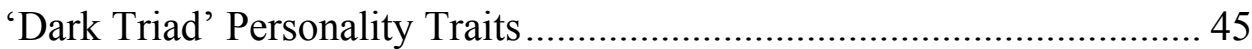

Cost Source and Compliance Level.......................................................... 49

Pairwise Comparisons of Regulatory Regimes.......................................... 50 
Private Fault ................................................................................. 54

V. CONCLUSION, LIMITATIONS, \& FUTURE RESEARCH ................................ 56

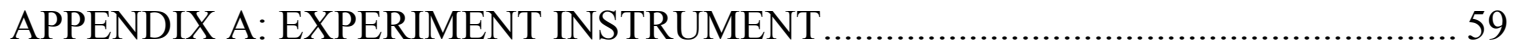

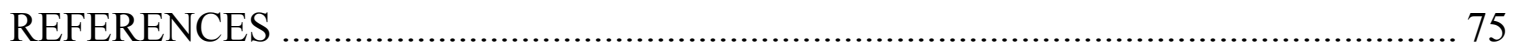

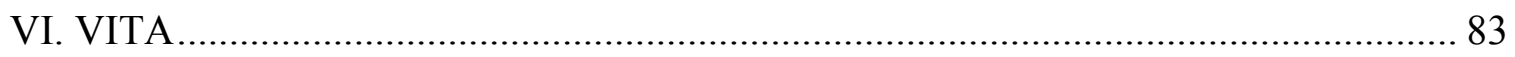




\section{LIST OF TABLES}

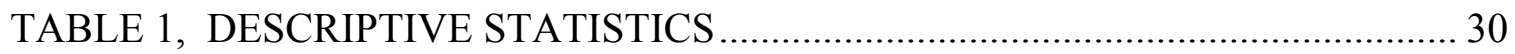

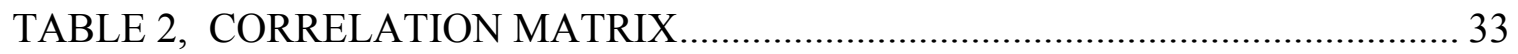

TABLE 3, MEDIATOR - COST PERCEPTIONS ("PROCESSING”) ........................ 37

TABLE 4, MEDIATOR - DECISION FRAME (“SIGNALING”) ............................... 38

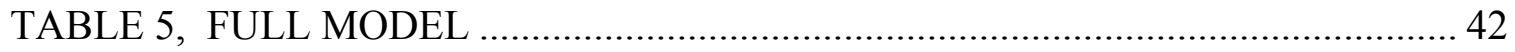

TABLE 6, SUPPLMENTAL ANALYSIS: BY DARK TRIAD PARTITION .............. 47

TABLE 7, SUPPLEMENTAL ANALYSIS: SOURCE OF PERCEIVED COSTS ....... 51

TABLE 8, SUPPLEMENTAL ANALYSIS: PAIRWISE COMPARISONS ................ 53

TABLE 9, SUPPLEMENTAL ANLYSIS: PRIVATE FAULT .................................... 55 


\section{LIST OF FIGURES}

FIGURE 1, BASE THEORETICAL MODEL ........................................................ 9

FIGURE 2, DETAILED MODEL \& PREDICTIONS ............................................... 13

FIGURE 3, HISTOGRAM OF COMPLIANCE CHOICES ......................................... 24 


\section{INTRODUCTION}

In this study I examine if and how the prospect of fault influences managers' compliance with protective regulations. The SEC resolves virtually all of its enforcement actions through 'no-fault' settlements (90\% from 2012 - 2014), where enforcement targets forgo costly litigation by agreeing to penalties without admitting or denying fault in the matter (Eaglesham \& Ackerman 2013, White 2013). SEC leaders argue that these settlements expedite enforcement, enabling more enforcement actions (White 2013, Khuzami 2012). However, critics argue that sanctions without fault may be ineffective, transforming sanctions into 'just another cost of business' (Ackerman \& Rexrode 2014, Eaglesham \& Ackerman 2013). I hypothesize that managers perceive compliance differently when faced with fault - as an ethical rather than economic choice. Absent fault, I expect managers to treat fines as a price, comparing the economic gains of noncompliance to the economic penalties of sanctions (Gneezy \& Rustichini 2000). Consequently, managers' compliance should be more frequent and higher quality when sanctions include fault than when they include only economic penalties (i.e., 'no-fault').

Regulators compel compliance through sanctions, which are typically discussed in terms of their financial penalties. However, financial penalties and compliance share a complicated relationship. The presence of financial penalties suggests that managers do not voluntarily comply with regulations (reducing compliance), but may nevertheless motivate managers to comply if sufficiently strong (increasing compliance) (Christ 2013, Cialdini et al. 2004, Gneezy \& Rustichini 2000, Tenbrunsel \& Messick 1999). Thus, research concludes broadly that financial penalties increase compliance only when strong enough to offset the decreases in compliance that they provoke. However, recent research 
acknowledges that sanctions may also include social penalties, triggering distrust, disapproval and loss of respect. Social penalties heighten cooperation and compliance, leading managers to sometimes comply with rules even when illicit financial gains exceed risk-weighted fines (Dugar 2010, Noussair \& Tucker 2005, Rege \& Telle 2004, Masclet et al. 2003).

In this study, I hypothesize that fault assignment is a social penalty, and that social penalties increase compliance by leading managers to construe their compliance differently - as an ethical rather than economic choice (Tenbrunsel \& Smith-Crowe 2008, Weber et al. 2004, Tenbrunsel \& Messick 1999). ${ }^{1}$ When managers perceive that their compliance is an ethical choice, they assign greater weight to social consequences and less weight to individual cost-benefit comparisons (Weber et al. 2004, Tenbrunsel \& Messick 1999). Thus, I predict that managers faced with fault will be more willing to comply with costly regulations and more willing to exceed minimum compliance thresholds - similar to distinctions between 'letter of the law' versus 'spirit of the law' compliance (Garcia et al. 2014, McBarnet 2001, McBarnet \& Whelan 1991). I

additionally investigate whether this relationship depends on the risk-weighted magnitude of fines ('sanction strength'), a factor that regulators suggest will be greater under nofault regimes (Khuzami 2012), or dependent on the target of enforcement settlements, manager or firm.

I test my hypotheses in a laboratory experiment where participants complete one of two scenarios adapted from research and SEC litigation. In the scenarios, managers choose between complying with costly protective regulations or earning greater profits

\footnotetext{
${ }^{1}$ For the purposes of this study, fault is an unambiguous record explicating a violation of a legal norm and the identity of the violator. This definition conforms to comments made by SEC Chair Mary Jo White (White 2013).
} 
and compensation in the scenario. One scenario is managerial, where plant managers choose if and how much to run pollution control equipment that is costly to operate but necessary to protect health and the environment (Tenbrunsel \& Messick 1999). The other scenario is financial, where financial managers must choose if and how to disclose unfavorable IPO information that would lower profits but is necessary to protect investors from damaging misrepresentation of the issue's true value. In both scenarios, managers are informed of the presence of sanctions for violations, which take the form of a settlement agreement that imposes fines and may also require managers to admit fault. Managers choose if and how they wish to comply, where higher levels of compliance increase social benefits (lower pollution, less mispricing), but also impose greater individual costs.

I utilize a $2 \times 2 \times 2$ between-participants design, manipulating attributes of the regulatory sanctions that managers expect to face for violating regulations. ${ }^{2}$ I manipulate whether managers are required to admit fault in the settlement (assigned-fault or nofault). Additionally, I manipulate the sanction strength of fines, where strong (weak) fines impose financial penalties that exceed (do not exceed) the financial benefits of noncompliance and sanction target, where manager-targeted sanctions impose penalties on the manager him/herself and firm-targeted sanctions impose penalties on the manager's firm. My primary dependent variable is participants' compliance choice, measured in three levels: full compliance (i.e., high quality, 'spirit of the law' compliance), minimal

\footnotetext{
${ }^{2}$ Compared to archival methods, an experimental approach is better-suited to explore managers' internal decision processes and disentangle jointly operative theories. Additionally, no-fault settlements and the quality of compliance they compel have no credible real-world counterfactual (Coffee 2007), complicating archival analyses. The experiments employed in this study disentangle these naturally confounded effects, using hypothetical conditions with known parameters and choice options, enabling the study to test constructs separately (see Libby, Bloomfield, Nelson 2002).
} 
compliance (i.e., low quality, 'letter of the law' compliance), and non-compliance (i.e., violation). Both minimal and full compliance satisfy regulatory requirements, eliminating the threat of sanctions. Full compliance imposes additional individual economic costs in the form of additional lost profit and bonus compensation, but also provides additional social benefits by either fully eliminating pollution (managerial case) or fully eliminating mispricing (financial case). I measure two mediating variables, relating to participants' perceived costs and their decision frame - the perception that compliance reflects either an ethical or economic dilemma. I also measure participants' expectations for job loss and subsequent litigation to control for collateral consequences that lead sanction strength to be greater when penalties include fault, separate from any social awareness that fault brings.

Results with a sample of 480 experienced participants partially support my hypotheses. I find that managers more frequently perceive their compliance choice to be ethical in nature when fault assignment is combined with manager-targeted sanctions, relative to manager-targeted no-fault sanctions. And, managers who perceive their compliance choice to be ethical in nature comply more frequently with costly regulations, and with higher quality compliance. I also find that managers in firm-targeted sanction conditions are more likely to perceive their compliance to be ethical in nature relative to manager-targeted no-fault sanctions; however, fault assignment does not facilitate incrementally greater ethical perceptions among managers in firm-targeted sanction conditions.

I also find that all manipulated sanction attributes - fault assignment, increased sanction strength, and targeting managers with sanctions - separately lead managers to 
perceive greater costs associated with accepting settlements, and that greater cost perceptions are associated with more frequent and higher quality compliance. However, I also observe that interactions of manipulated sanction attributes are negatively related to cost perceptions, consistent with decreasing incremental benefits of additional sanction attributes with regard to managers' cost perceptions. In regressions that control for managers' cost perceptions and ethical framing, I observe that conditions with managertargeted sanctions that assign fault still demonstrate greater overall compliance, consistent with partial mediation.

On the whole, my findings support the idea that sanctions facilitate greater compliance both by directly assigning costs to violations and by indirectly facilitating greater ethical decision frames. In my study, ethical decision frames are higher in conditions that trigger greater social sanctions, either by assigning managers the socially deleterious label 'fault', or by assigning penalties to the managers' coworkers such as through firm-targeted sanctions. Managers' ethical decision frames result in greater and higher quality compliance relative to the compliance compelled through financial penalties alone.

In supplemental analysis, I make several additional observations. First, in subsample analyses of participants who are either high or low in 'dark triad' personality traits (narcissism, machiavellianism, subclinical psychopathy - see Paulhaus \& Williams 2002), I find that my results are stronger for the high triad subsample than for the low triad subsample. Research suggests that the senior-most leaders of organizations, who commonly make compliance choices, are higher in dark triad personality traits than the general population (O'Reilly et al. 2014). I additionally decompose managers' cost 
perceptions into costs arising from economic sources (e.g. financial penalties) and those arising from social sources (e.g. reputation and relationship loss). I find that social costs are associated with both more frequent and higher quality compliance, but economic costs are positively associated only with more frequent compliance, and negatively associated with high quality compliance. Lastly, in a supplemental condition with privately resolved manager-targeted settlements, I find that privately assigned fault is also associated with an increased prevalence of ethical decision frames but that this does not translate into greater compliance for privately assigned sanctions. This suggests that expectations for social consequences may be important for translating ethical perceptions into ethical behavior.

My study makes several important contributions to policy-makers and researchers. Foremost, my study is the first to my knowledge to document the compliance consequences of fault, an active policy matter. In my study, when fault is combined with manager-targeted sanctions, managers' ethical decision frames and compliance are greater than when managers were targeted with no-fault sanctions. That is, managers perceive sanctions with manager-targeted fault differently - fault does not simply increase the perceived strength of sanctions. I also find that managers' ethical decision frames and compliance are greater when sanctions target the firm rather than managers. One interpretation of these findings is that managers are more likely to perceive compliance choices to be ethical in nature when they expect social sanctions, triggered by the fault label or by coworkers being penalized for the managers' own misdeeds. This contributes to experimental research suggesting that the notion of sanctions should be broadened to include social penalties (Dugar 2010, Noussair \& Tucker 2005, Rege \& 
Telle 2004, Masclet et al. 2003), and also compliments archival research suggesting that economic penalties are weak predictors of compliance (Williams \& Hawkins 1989, Pratt \& Cullen 2005). On the whole, my study suggests that the compliance compelled through fines is not always equivalent to the compliance compelled through social sanctions, such as manager-targeted fault (Dugar 2010, Noussair \& Tucker 2005, Mascelet et al. 2003, Tenbrunsel \& Messick 1999).

My study also makes a methodological contribution by allowing for differences in compliance quality, a distinction of importance to regulators, researchers, and the public. Compliance quality in this study reflects participants' willingness to incur greater individual costs to effect greater social benefits, consistent with arguments for 'spirit of the law' versus 'letter of the law' compliance. In this study, I find that many participants select high quality compliance when given the option; more do so in the presence of manager-targeted fault.

This study proceeds as follows. Section II lays out relevant background and motivates the hypotheses. Section III outlines the research design. Section IV discusses tests of hypotheses and supplementary analysis. Section V concludes the study.

\section{BACKGROUND \& HYPOTHESIS DEVELOPMENT}

\section{A. Background}

\section{No-Fault Settlements}

The SEC is an active regulatory enforcer, averaging 722 enforcement actions per year and \$3.53 B in financial sanctions annually, from 2012 through 2014 (SEC 2015, 
see also Coffee 2007). ${ }^{3,4}$ The SEC relies heavily on 'no-fault settlements,' where enforcement targets agree to penalties without admitting to or denying fault. ${ }^{5}$ Settlements avoid costly and protracted litigation for both the SEC and enforcement targets, enabling the SEC to pursue roughly twice as many cases as it might otherwise (Eaglesham \& Ackerman 2013). However, the SEC's emphasis of no-fault settlements is also contentious. Opponents argue that removing fault from enforcement reduces financial violations to a 'cost of business', enabling offenders to 'buy their way out of a violation' (Ackerman \& Rexrode 2014, Eaglesham \& Ackerman 2013). That is, removing fault from sanctions may diminish the salience of ethical aspects of violations - reducing compliance and sanctions to a price (Gneezy \& Rustichini 2000).

Although accounting research does not directly inform the consequences of assigning fault in enforcement actions, it finds evidence of several types of 'collateral consequences' that are plausibly linked to fault - indirect economic penalties that add to fines imposed by the SEC. ${ }^{6}$ Several studies note that firms and managers targeted by the SEC may experience additional civil lawsuits (Bowen, Call, \& Rajgopal 2010; Karpoff,

\footnotetext{
${ }^{3}$ The SEC is a regulatory agency. Thus, the SEC's enforcement actions are civil rather than criminal in nature. The primary differences for the purpose of this study are a) that SEC cases, although public, do not influence one's criminal record (i.e. 'felon', etc.) and b) that the SEC cannot sanction guilty parties with prison sentences. The Department of Justice enforces criminal law. Some, but not all, of the SEC's administrative regulations overlap with related criminal law and investigations.

${ }^{4}$ For perspective, the UK's equivalent agency (FSA, which is also the SEC's nearest peer) initiated 52 enforcement actions per year over the same period, triggering a comparatively modest $£ 308.97 \mathrm{M}$ (\$475.81M) in sanctions (KL Gates 2015 - see also Coffee 2007).

${ }^{5}$ SEC Chair Mary Jo White and Director of Enforcement Robert Khuzami have recently made statements indicating the SEC intends to pursue fault in some cases (Mahoney 2014, Eaglesham \& Ackerman 2013, Kuzami 2012). However, both representatives also indicate that no-fault settlements would remain the primary mode of sanctioning for the SEC, seeking fault from individuals who have already been assigned fault in other venues.

${ }^{6}$ Most SEC fines are capped at 'ill-gotten gains' (typically excluding punative fines and/or damages). Thus, SEC penalties are by definition weak in that the risk-weighted value of fines are legally capped at the benefits of violation; their risk-weighted value is likely to be lower given that enforcement may not be perfect. Follow-up litigation adds to financial penalties, but are outside the control of regulators and not the subject of this investigation.
} 
Lee, \& Martin 2008b) and, in the case of managers, job loss (Karpoff, Lee, \& Martin 2008a; Desai, Hogan, \& Wilkins 2006). In the present study, I argue that fault assignment alters how managers perceive their compliance, separate from any economic consequences (including collateral consequences). That is, fault does more than increase sanction strength; it increases the tendency of managers to perceive their compliance as an ethical choice. Consequently, when faced with fault, managers' compliance is less dependent on the magnitude of direct and indirect economic penalties. I expand on this argument below.

\section{Compliance, Sanctioning Systems, and Decision Frames}

In this study, I examine managers' compliance, a form of ethical behavior rooted in ethical decision-making as defined by Tenbrunsel \& Smith-Crowe (2008). Following Tenbrunsel \& Smith-Crowe (2008), an individual has complied with legal and social norms when s/he has selected a decision that is both legally and socially acceptable. I additionally distinguish high quality compliance from low quality compliance, acknowledging that managers sometimes prefer to minimally satisfy legal requirements. Minimally satisfying legal compliance avoids sanctions, but may also offer fewer social FIGURE 1: BASE THEORETICAL MODEL

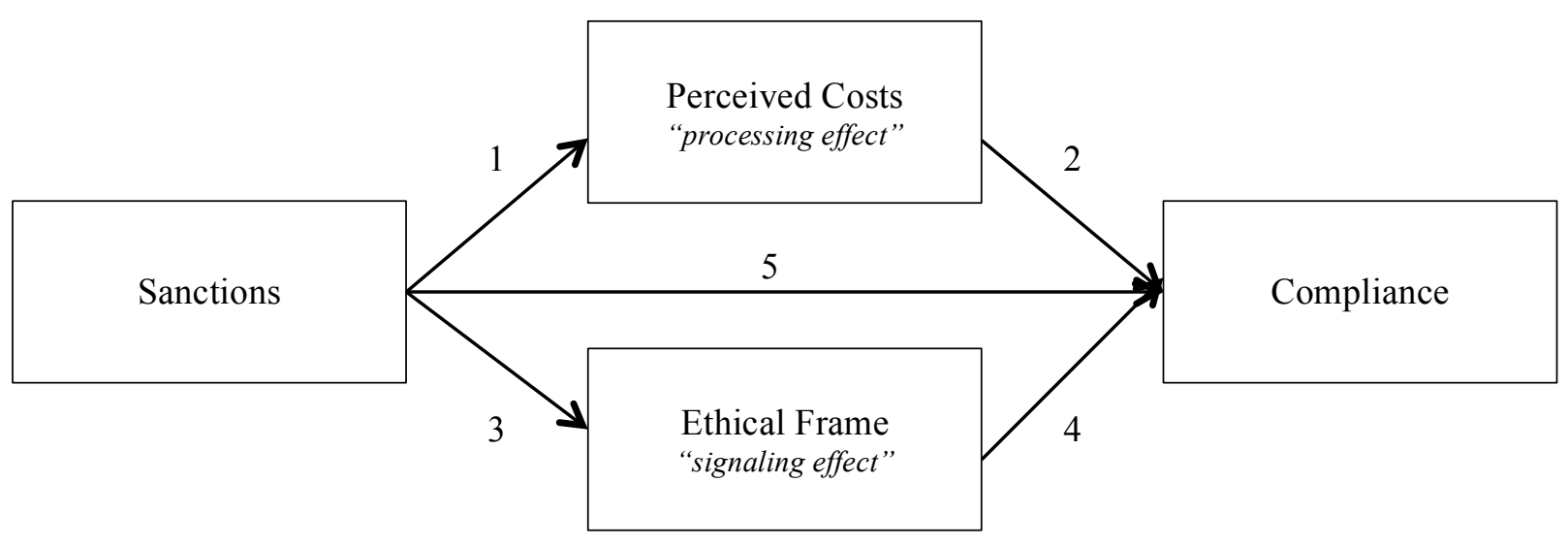


benefits than fully complying with the intent of the law (Garcia et al. 2014, Mulder et al. 2006, McBarnet 2001, McBarnet \& Whelan 1991). I deem cases when an individual complies only with minimal legal requirements, in spite of the opportunity to provide greater social benefits, to be low quality compliance; I define high quality compliance as cases where an individual exceeds minimum legal requirements, providing greater social benefits.

Individuals are compelled to comply with legal and social norms through a variety of formal and informal incentive systems that may be either economic or social in nature. That is, individuals care about and seek to avoid economic sanctions such as fines and/or imprisonment (Sefton et al. 2006, Grasmick \& Bryjak 1980). They also care about and seek to avoid social sanctions, such as the discomfort of losing self-respect, or losing the respect of and relationships with others (Dugar 2010, Noussair \& Tucker 2005, Bandura 1991, Grasmick \& Bursik 1990, see also Rankin et al. 2008).

Regulators compel compliance through formal sanctions, which are typically discussed in terms of the financial penalties they impose. Financial penalties increase compliance by reducing the economic benefits of violating regulations (deemed a 'processing effect', Figure 1, Links 1 \& 2) (Karpoff et al. 2008a, 2008b, Mulder et al. 2006, Gneezy \& Rustichini 2000, Tenbrunsel \& Messick 1999). However, financial penalties also decrease compliance by reducing the prevalence of cooperative norms that underlie voluntary compliance (deemed a 'signaling effect', Figure 1, Links 3 \& 4). Financial sanctions signal that others do not comply with regulations voluntarily, leading more managers to adopt individualistic strategies based on cost-benefit calculus (Christ 2013, Tayler \& Bloomfeld 2011, Falk \& Kosfeld 2006, Fehr \& Rockenbach 2003, 
Tenbrunsel \& Messick 1999). Research across several studies supports the processing / signaling model, finding that financial penalties lead individuals to suspect that selfinterested behavior is appropriate, and to also behave in a self-interested manner - which results in greater compliance when sanctions are sufficiently strong, but lower compliance otherwise (Tayler \& Bloomfield 2011, Rankin et al. 2008, Weber et al. 2004, Towry 2003, Tenbrunsel \& Messick 1999).

Lastly, research has linked the compliance-decreasing signaling effect to managers' decision frames, which can be thought of as groups of social norms that individuals invoke depending on their present setting (Tenbrunsel \& Smith-Crowe 2008, Weber et al. 2004, Tenbrunsel \& Messick 1999). Research theorizes that managers possess different categorical definitions for decision-making settings, which differently emphasize managerial norms and objectives such as social versus individual welfare. Managers invoke categorical definitions for their decisions based on social cues in the setting. When managers observe signals of trust or cooperation, they are more likely to invoke ethical decision frames that emphasize social outcomes, and are consequently more likely to incur individual costs to cooperate (e.g. complying with costly regulations) (Figure 1, Links $3 \& 4$ ); when managers observe signals of distrust or defection, they are more likely to invoke self-interested 'economic' decision frames, and are consequently less likely to incur individual costs to comply.

\section{II.B Hypothesis Development}

\section{Fault}

This study investigates a penalty that is sometimes conveyed in sanctions - fault. For the purposes of this study, fault is an unambiguous record explicating a violation of a 
legal norm and the identity of the violator. Fault has at least two primary consequences, one financial in nature (relating to sanctions' processing effect) and one social in nature (relating to sanctions' signaling effect). First, as accounting research implies, fault triggers indirect financial penalties by increasing the prospect of costly follow-up litigation and job loss ('collateral consequences', Bowen, Call, \& Rajgopal 2010; Karpoff, Lee, \& Martin 2008a, 2008b, Desai, Hogan, \& Wilkins 2006). To the extent that fault is more likely to be sought in cases of gross violations, fault may also directly coincide with greater financial penalties. Consequently, I predict that managers will perceive the cost of sanctions to be greater when fault is assigned in sanctions.

H1a: Managers will perceive costs to be greater under a sanctioning regime that assigns fault to sanctions than under a regime that imposes sanctions with only economic penalties.

Traditional notions of sanctions as instruments of financial penalty would predict that fault matters in compliance, but only to the extent that it triggers greater financial penalties (i.e., greater sanction strength). However, fault also has a second function relating to its signaling effects. Fault serves as a social penalty, explicitly assigning responsibility for a social violation and facilitating social recourse (e.g. reputation and relationship loss). That is, fault assignment also signals that the manager's choice is occurring in a context where social outcomes matter, fostering expectations for social penalties such as disassociation, distrust, and/or loss of respect (Mulder et al. 2009, Grasmick \& Bursik 1990, Williams \& Hawkins 1986). Moreover, fault assignment also reduces managers' 'moral wriggle room' in the face of violations by increasing the certainty of the link between self-interested choices and their social costs (Dana, Weber, $\&$ Kuang 2007). Thus, managers are more likely to perceive and weight social 
dimensions in their decision-making, leading managers to increasingly invoke ethical decision frames in the presence of fault.

H1b: More managers will invoke ethical decision frames under a sanctioning regime that assigns fault to sanctions than under a regime that imposes sanctions with only economic penalties.

FIGURE 2: DETAILED MODEL \& PREDICTIONS

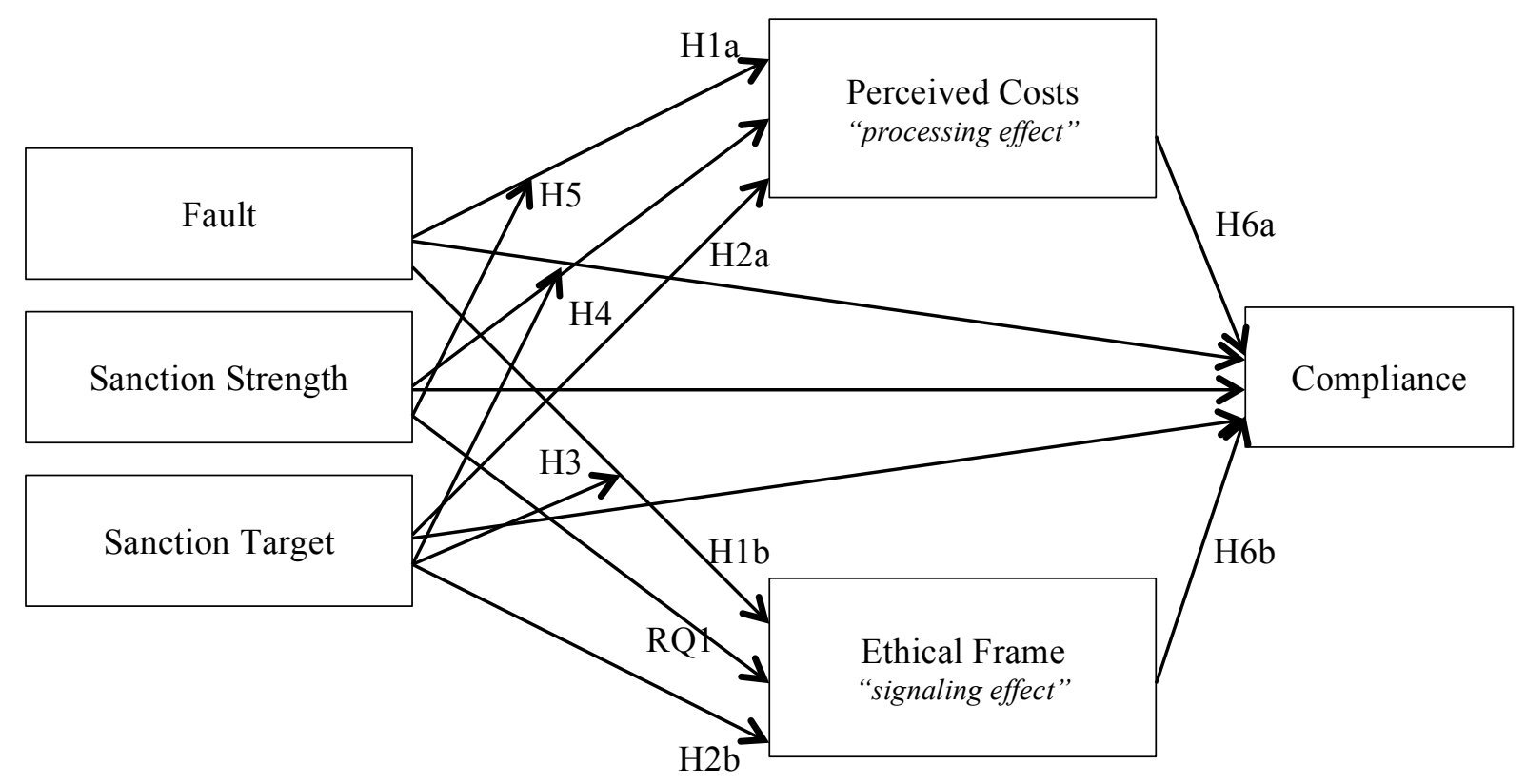

\section{Sanction Strength \& Sanction Target}

The effects of fault on compliance may depend on factors that sometimes vary in sanctions. In particular, regulators may increase the strength of sanctions by imposing larger fines and/or pursuing greater numbers of enforcement actions. And, regulators may target firms rather than managers in their enforcement actions. These possibilities are discussed further below. 
Regulators justify their emphasis of no-fault settlements on the basis of increased enforcement expediency (White 2013, Khuzami 2012). No-fault settlements enable the SEC to investigate greater numbers of enforcement actions because enforcement targets offer less resistance to no-fault sanctions, freeing regulatory resources to pursue additional cases. This increases sanction strength by increasing the risk that noncompliant managers will face sanctions for violations, leading the risk-weighted magnitude of fines to be greater. Managers should perceive costs to be greater when sanction strength greater because costs are in reality greater. I test this relationship but advance no hypothesis.

Prior research presents conflicting theory and evidence on what effect sanction strength should have on the signaling portion of the sanction-compliance relationship. Stronger financial penalties may be perceived as both signaling the presence of stronger descriptive norms of violation (reducing ethical frames) and also signaling stronger injunctive norms of compliance (increasing ethical frames) (Mulder et al. 2009). This is because stronger penalties suggest that violating managers are not deterred by weak penalties. On the contrary, penalties also signal the comparative importance of the issue to regulators, with stronger penalties being assigned to issues where compliance is more important (Shalvi et al. 2012, Mulder et al. 2009, Tyran \& Feld 2002). Because theory offers competing predictions for the effects of sanction strength on managers' ethical decision frames, I state my investigation of sanction strength on managers' ethical decision frames in the form of a research question.

RQ1: Will more managers invoke ethical decision frames under a sanctioning regime that assigns strong financial penalties than under a regime that assigns weak financial penalties? 
Sanctions sometimes target firms rather than managers, going so far as to withhold perpetrating managers' identities from enforcement fact patterns even when the managers' names appear to be known (e.g. Citigroup - see Zamensky 2011). With regard to the processing path of the sanction-compliance relationship, targeting firms with sanctions assigns responsibility for paying fines to the firm. Agency theory asserts that managers will be less concerned with costs that they do not personally bear. Consequently, I predict that managers will perceive the costs of sanctions to be lower when sanctions target firms rather than managers, for any level of sanction strength.

H2a: Managers will perceive costs to be lower under a sanctioning regime that targets firms than under a regime that targets managers.

Targeting firms with sanctions also influences the signaling portion of the sanction-compliance relationship. Relative to manager-targeted sanctions, firm-targeted sanctions may tend to foster managers' ethical decision frames for two reasons. First, when sanctions target firms, violations potentially injure an additional party - the managers' coworkers - making social outcomes salient. When the firm faces penalties, coworkers may experience job hardship, embarrassment, and/or job loss. In addition to any altruistic concern that managers experience for coworkers, they may also feel concern for social retribution from coworkers who are likely to know and blame perpetrating managers for bringing hardship on the firm. Secondly, when sanctions target managers, the managers are likely to perceive the presence of protective regulations as being more restrictive and adversarial in nature, potentially undermining managers' perceptions that compliance reflects an ethical choice (Cialdini et al. 2004, Brehm 1972). Consequently, I predict that managers will be more likely to invoke ethical decision frames when sanctions target the firm than when they target managers. 
H2b: More managers will invoke ethical decision frames under a sanctioning regime that targets firms than under a regime that targets managers.

\section{Interactions}

The effects of fault on managers' ethical decision frames may increase when sanctions target managers relative to when they target firms. In particular, the social awareness and ethical perceptions triggered by fault may depend on the expectation that the fault label will be assigned to the manager him/herself. When fault is assigned to the firm, the manager may expect fewer reputational and relationship consequences because the assignment of fault to an external party creates plausible deniability that can be exploited by the manager, and may also create 'moral wriggle room' in the manager's own mind (Dana et al. 2007). I therefore predict that the signaling effects of fault will be greater when sanctions target managers than when they target firms.

H3: The effects of fault on managers' ethical decision frames will be greater under a sanctioning regime that targets managers than under a regime that targets firms.

Likewise, increased sanction strength may matter more to managers who are themselves targeted by the sanctions than to managers who expect fines to be paid by the firm. That is, even when managers are aware of and concerned with the magnitude of financial penalties, they may nevertheless be less sensitive to differences in the magnitude of penalties that they will not be held personally liable for. Thus, I predict that the perceived differences between strong and weak sanction strength will be greater when sanctions target managers than when sanctions target firms.

H4: The effects of sanction strength on perceived costs will be greater under a sanctioning regime that targets managers than under a regime that targets firms. 
Lastly, to the extent that fault and sanction strength are substitutes, it is possible that managers' perceptions and compliance will be subject to ceiling effects: once penalties are made sufficiently strong - either through fault assignment or through prohibitive financial penalties - then managers' perceptions and compliance may be less sensitive to the presence of additional sanction dimensions. That is, to the extent that fault increases sanction strength, combining fault with strong sanctions may not be perceived differently than strong sanctions would be perceived in isolation. Consequently, I predict that the effects of fault will be weaker in the presence of strong sanctions than in the presence of weak sanctions, reflecting the tendency of fault to increase managers' perceptions of sanction strength.

H5: The effects of sanction strength on managers' perceived costs will be weaker under a sanctioning regime that assigns fault to sanctions than under a regime that imposes sanctions with only economic penalties.

\section{Compliance Quality}

As discussed in Section II.A, research finds that managers can be compelled to comply through stronger sanctions; and, that managers who adopt ethical decision frames demonstrate a greater willingness to incur individual costs to cooperate, such as by complying with costly protective regulations (Tenbrunsel \& Messick 1999, Messick 1999). However, prior research does not speak to whether compliance compelled through penalties and/or ethical decision frames is likely to be of low quality (similar to impression management and cost minimization) or of high quality (similar to altruism or risk aversion). That is, self-interested managers can eliminate substantially all possible social penalties by minimally 
satisfying regulatory requirements and thus avoiding penalties (including the stigma of 'fault'). But, they can also achieve greater social benefits and possibly reduce the chances of triggering sanctions through higher quality compliance. I therefore hypothesize that managers' compliance will be at least as frequent when faced with sanctions perceived to be costly or when invoking ethical decision frames, and may be of higher quality.

H6a: Managers who perceive greater costs to sanctions will comply more frequently and will be more likely to select high quality compliance.

H6b: Managers adopting ethical decision frames will comply more frequently and will be more likely to select high quality compliance.

\section{RESEARCH DESIGN}

\section{III.A Participants}

Participants are 480 experienced participants recruited through Amazon's Mechanical Turk marketplace. ${ }^{7} 48.5 \%$ of participants are male and participants' average age is 36.4 (std. dev. 11.1 yrs, range $19-83$ yrs). Participants report an average of 13.9 years of work experience (std. dev.12.1 yrs), 67.6\% report having supervisory experience. Participants are compensated $\$ 1.00$ for completing the electronic case, which takes an average of 27.5 minutes.

\section{III.B Procedures}

Each case consists of five basic parts, all completed electronically: a) background \& information, b) knowledge check, c) case scenario, d) retention check, and e) exit survey. Participants first receive instructions and background information relating to the

\footnotetext{
${ }^{7} 523$ participants complete the instrument. 12 responses are removed for failing attention check questions. 31 responses are removed for failing retention check questions. Results are qualitatively similar when these observations are included. 'Attention checks' and 'retention checks' are described in Section III.B.
} 
case, including descriptions of the managers' role and the regulatory environment. Before proceeding, participants must complete a short 'knowledge check' ensuring they understand important information about the study; participants may not proceed until they have correctly completed all of the knowledge check questions but may review the case information and retake incorrect questions. Participants then receive the remaining case information, which includes a description of the manager's present scenario, choice options and consequences, as described below. Immediately following case choices, participants complete 'retention check' questions that ask participants to recall important case information (e.g. sanction target, sanction amounts, fault admission, etc.). Lastly, participants complete demographic and psychometric scales in exit questions and receive a code used for payment. Embedded within exit questions are three 'attention checks' that prompt participants to select a specific response (e.g. 'please select disagree'). These questions serve to identify participants who may be answering questions without first reading corresponding questions completely.

\section{III.C Case Scenarios}

Participants complete one of two scenarios - either a managerial case where participants assume the role of a plant manager in a manufacturing firm, or a financial case where participants assume the role of an underwriting manager in a financial services firm. ${ }^{8}$ In both cases, managers choose between complying with costly protective

\footnotetext{
${ }^{8}$ I use two cases (rather than one) to reduce internal validity concerns relating to inferences drawn from a single case (e.g. results may be case-specific). To the extent that results hold across cases/settings, I have greater confidence that they reflect the constructs of interest.
} 
regulations or earning greater profit, where higher quality compliance imposes greater individual costs but also provides greater social benefits. ${ }^{9}$

In the managerial case, participants act as a plant manager of a facility that generates a toxic gas as a by-product of its production. The gas is harmful to health and the environment but costly pollution control equipment can reduce or eliminate the gas (depending on how much it is operated). Regulations mandate that managers run the pollution control equipment at least $80 \%$ of the time, which lowers the volume of emitted gas to a level deemed acceptable by health and environmental experts. ${ }^{10}$ Managers choose if and how much to run the costly equipment.

In the financial case, participants act as an underwriting manager in a financial services firm who has received unfavorable information about an important IPO client her firm is underwriting. Regulations mandate that the underwriter disclose the unfavorable information to avoid misrepresenting the IPO's actual value to investors. However, doing so reduces the expected IPO price, and thus the firm's profit and the manager's own profit-sharing bonus. Managers choose if and how to disclose the information, which can be communicated fully and transparently (eliminating predictable investor losses and the manager's expected bonus), communicated with intentionally confusing language and fine print (partially reducing investor losses and bonus

\footnotetext{
${ }^{9}$ The present case partly relates to social penalties that individuals expect for violating legal and/or social norms. Relative to abstract laboratory tasks, cases have the advantage of evoking concerns for reputation and relationship loss among participants' external, long-standing and naturally developed relationships. ${ }^{10}$ In addition to employing a different context, the managerial case differs in at least two ways from the financial case, and thus does not (and was not intended to) serve as an additional manipulation. First, the case additionally includes a cooperative element, noting that the entire industry faces stricter and more costly regulation if fewer than $80 \%$ of all manufacturing plants comply. Second, the negative externalities created by non-compliance in the managerial scenario are largely borne by the environment (rather than by people, in the financial scenario). These differences tend to weaken the appeal of ethical frames and compliance relative to the financial case; the differences tend to increase the internal validity of inferences drawn from the effects of sanction attributes such as fault on managers' perceptions and compliance.
} 
compensation), or not disclosed (reducing neither the manager's bonus nor investors losses, but exposing the manager to enforcement risks).

Both scenarios include information about regulatory enforcement that impacts the manager's hypothetical welfare, but does not impact participants' actual compensation for participating. The cases describe the probability and nature of future sanctions expected in the scenario (greater detail below). In the scenarios, managers may be audited by regulators who launch publicly recorded investigations of managers appearing to have violated regulations. Scenarios explain that investigations typically conclude with a settlement that avoids costly and protracted litigation for both sides; settlements impose the same financial penalties as would be imposed after trial, and may also require enforcement targets to admit fault, depending on condition. Thus, managers' compliance choices are made with knowledge of expected penalties. This knowledge influences the expected financial consequences of non-compliance and may also influence managers' ethical frames.

\section{III.D Manipulated and Measured Variables}

\section{Independent Variables}

I employ a $2 \times 2 \times 2$ between participants design, manipulating three attributes of the settlement sanctions that individuals face for violating regulations - fault, sanction strength, and target. I manipulate fault at two levels - assigned-fault or no-fault. Fault is a dimension of sanctions where, in addition to economic penalties such as fines, managers are required to admit to violating a legal norm in an unambiguous public record. Fault assignment is manipulated within case information, immediately following a discussion of financial penalties imposed on managers found to have violated 
regulations. Participants in the no-fault condition are informed that the settlement includes language stating that managers do not admit or deny fault in the matter. In the fault condition, participants are instead informed that managers are required to admit fault in the settlement.

I also manipulate sanction strength at two levels - weak or strong. Sanction strength is the risk-weighted economic cost of sanctions relative to the economic benefits gained from violating regulations. Strong (weak) sanctions impose risk-weighted costs that exceed (do not exceed) the financial gains derived from violating regulations. Sanction strength is manipulated within case information, by influencing the probability and magnitude of fines imposed in settlements. Sanctions are either weak (in the financial scenario, a $5 \%$ chance of receiving a $\$ 25,000$ fine) or strong (greater than $50 \%$ chance of receiving a $\$ 2,000,000$ fine). ${ }^{11}$ From a purely economic perspective, violation is a dominant strategy under weak sanctions, but minimal compliance is a dominant strategy under strong sanctions.

Lastly, I manipulate sanction target at two levels - firm or manager. Sanction target reflects the party held legally accountable in enforcement actions. When sanctions target the firm, financial penalties and fault (when applicable) are assigned to the firm. When sanctions target the manager, he or she is personally liable to regulators for payment of financial penalties and any admission of fault. Target is manipulated within case information, through a statement indicating that either the manager or the firm will be subject to investigation and any resulting penalties.

\footnotetext{
${ }^{11}$ Computations for net costs benefits are as follows. Weak Sanctions: $\$ 25,000$ of lost compensation for minimal disclosure less $\$ 5,000$ risk-weighted cost of sanctions $=\$ 20,000$ net benefit. Strong Sanctions: $\$ 25,000$ of lost compensation for minimal disclosure less $\$ 1,000,000$ risk-weighted cost of sanctions $=$ $\$ 975,000$ net loss
} 


\section{Dependent Variables}

The primary dependent variable in the study is managers' compliance level measured at three levels. Participants in the managerial case are asked how much they would like to run pollution control equipment ( $0 \%$ to $100 \%$, using a slider); participants in the financial case are asked to select one of three options for disclosing the unfavorable IPO information: a) full update (fully and transparently communicating the unfavorable information), b) minimal update (employing complex and legalistic language that is difficult to understand) or c) no update (corresponding to violation). In the managerial case, responses below $80 \%$ operating time are coded as non-compliant (reflecting violation), responses of $80 \%-82 \%$ are coded as minimally compliant (reflecting lowquality compliance that meets legal requirements but withholds some social benefits), and responses exceeding $82 \%$ are coded as fully compliant (reflecting high-quality compliance that offers greater social benefits than the legal lower threshold). ${ }^{12}$ See Figure 2. In the financial case, the no update option is coded as non-compliant, the minimal update option is coded as minimally compliant, and the full update option is coded as fully compliant.

In analyses relating to the overall frequency of compliance ('total compliance'), I convert compliance level into a dichotomous variable that is coded 1 when participants select either minimal compliance or full compliance, and 0 when participants choose not

\footnotetext{
${ }^{12}$ Results are robust to all alternative thresholds for differentiating minimal and full compliance, from $81 \%$ to $99 \%$. I employ an $82 \%$ threshold. This maps to construct definitions by setting a narrow range for minimal compliance levels $(80 \%-82 \%)$ to reflect the notion that higher quality compliance offers more than minimal compliance. The $82 \%$ threshold also maps to participants' actual choices, where most compliance choices were for $80 \%$ scrubber time (152 of 251 ), $81 \%$ scrubber time (18 or 251 ), or for $100 \%$ scrubber time ( 49 of 251), with few responses selecting compliance levels between $82 \%$ and $99 \%$. See Figure 2
} 
to comply. This measure reflects the amount of compliance observed, without regard to variations in the quality of the compliance.

\section{Mediating Variables}

I measure two mediating variables, relating to the processing and signaling paths in the sanction-compliance relationship. First I measure managers' perceived costs, which is predicted to correspond with increased compliance through the 'processing' portion of the sanction-compliance relationship. Participants' perceived costs are elicited through two Likert (7 point) questions embedded in a set of questions that follow the

\section{FIGURE 3: HISTOGRAM OF COMPLIANCE CHOICES}

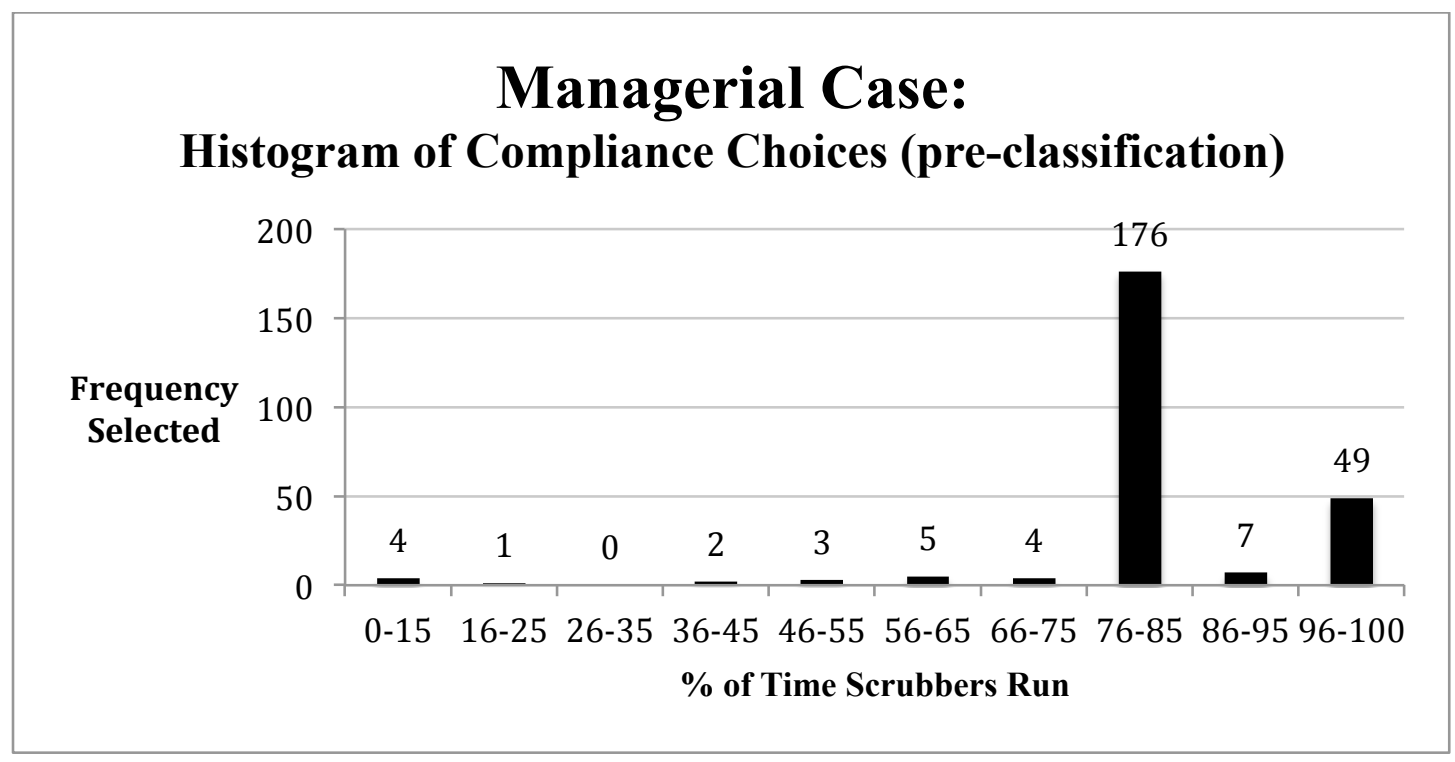

compliance choice question. The questions prompt participants to indicate their agreement with the belief that the overall costs of sanctions to the manager and to the firm are high $(1=$ strongly disagree, $7=$ strongly agree $) .{ }^{13}$ Perceived costs is the average

\footnotetext{
${ }^{13}$ The exact language of the two questions is: 1) "Considering all of the possible risks and costs - the potential downside of violating pollution control/misrepresentation regulations is high for you (the plant manager/underwriter)" 2) "Considering all of the possible risks and costs - the potential downside of violating pollution control/misrepresentation regulations is high for your firm"
} 
of participants' responses to the two questions, where higher scores indicate greater perceptions that the cost of settlements are high.

I also measure managers' ethical frame, which is predicted to correspond with increased compliance through the 'signaling' portion of the sanction-compliance relationship. Participants' decision frame is elicited immediately following their compliance choice, through a question that prompts participants to select the option that best describes the choice that participants were asked to make in the case (order randomized) - 'an economic choice', 'an ethical choice', 'a legal choice', 'a personal choice', or 'other (please elaborate)'. In the managerial case, participants are given an additional option: 'an environmental choice'. The options are taken from Tenbrunsel and Messick (1999) and are intended to provide insight on the categorical definition that participants invoked in their decision-making. Participants' responses are categorized as one of 'ethical', 'economic/legal', or 'other'.

\section{Control Variables}

I measure and control for three factors that may influence managers' cost perceptions and ethical frames (my mediating measures) and/or compliance (my dependent measure). First, I code participants' self-reported gender - a factor sometimes noted in research to influence cooperation and compliance (Charness \& Rustichini 2011, Croson \& Gneezy 2009). Participants' self-report identified gender with other demographic information at the conclusion of the survey. I code participants who identify as male as 1 , and those who identify as female as 0 .

I also control for the possibility that individuals expect greater indirect economic penalties when faced with fault assignment, deemed collateral consequences. Participants 
allocate points to 10 decision-making concerns according to how much each influenced their compliance decision (order randomized). Collateral Consequences is the averaged and standardized amount that each participant assigns to (1) Possibility of being sued if caught, and (2) the possibility of getting fired, with other options reflecting direct economic (e.g. probability and magnitude of fines) or social (e.g. reputation and relationship loss) consequences.

Lastly, to control for differences in context-dependent perceptions evoked by the financial or managerial nature of the case, I include an indicator variable for case in my analyses. I code participants receiving the financial case as 1 , and code participants receiving the managerial case as 0 .

\section{RESULTS}

\section{IV.A Manipulation Checks}

I employ three manipulation checks, corresponding to my three independent measures. After making their compliance choices, participants respond to several Likert questions $(1=$ strongly disagree, $7=$ strongly agree $)$ reflecting the perceived magnitude of social, financial and overall costs associated with accepting settlements. ${ }^{14}$ Participants in assigned fault conditions perceive greater social costs associated with accepting settlements than participants in no-fault conditions $(t$-stat $=1.62, p$-value $=0.05) . \mathrm{I}$ conclude that fault assignment was successfully manipulated. Participants in managertargeted sanction conditions perceive greater economic costs associated with accepting

\footnotetext{
${ }^{14}$ The exact language of the questions is: For economic costs - "From the standpoint of you (the manager)/the firm, if an investigation was launched and a settlement reached - the fine associated with accepting the settlement could damage your personal finances (7-strongly agree, 1-strongly disagree)". For social costs - "From the standpoint of you (the manager)/the firm, if an investigation was launched and a settlement reached - your reputation and relationships would be damaged (7-strongly agree, 1-strongly disagree)".
} 
settlements than participants in firm-targeted sanction conditions $(t$-stat $=8.82, p$-value $=0.00)$. I conclude that sanction target was successfully manipulated. Participants in strong sanction conditions perceive greater economic costs for accepting settlements than those in weak sanction conditions $(t$-stat $=1.31, p$-value $=0.10)$. I conclude that sanction strength was successfully manipulated.

\section{IV.B Descriptive Statistics}

Descriptive statistics are reported in Table 1. Panel A of Table 1 reports compliance overall and by each independent variable. Overall, $93.8 \%$ of participants choose either minimal or full compliance (53.8\% select minimal compliance, $40.0 \%$ select full compliance). On average, $39.8 \%$ of participants indicate that they perceive the case to be primarily ethical in nature. The average perceived cost of accepting a settlement is 5.18 out $7.00 .95 .9 \%$ of participants in the assigned-fault condition choose to comply with regulations ( $52.5 \%$ select minimal compliance, $43.4 \%$ select full compliance). In the no-fault condition, $91.5 \%$ choose to comply with regulations $(55.1 \%$ select minimal compliance, $33.4 \%$ select full compliance). $44.3 \%$ of participants in assigned-fault conditions describe the case as being ethical in nature, while $35.2 \%$ of participants do so in no-fault conditions. The average perceived cost of accepting a settlement is 5.38 out of 7.00 for participants in assigned-fault conditions, and 4.97 out of 7.00 for participants in no-fault conditions.

When comparing strong versus weak sanctions, $96.1 \%$ of participants in strong sanction conditions choose at least minimal compliance $(55.7 \%$ select minimal compliance, $40.4 \%$ select full compliance). $91.6 \%$ of participants faced with weak sanctions select at least minimal compliance (52.0\% select minimal compliance, 39.6\% 
select full compliance). Of participants in conditions with strong sanctions, $35.6 \%$ of participants identify their compliance as being an ethical choice, while $43.6 \%$ of participants in weak sanction conditions do so. The average perceived cost of accepting a settlement is 5.40 out of 7.00 in strong sanction conditions, and 4.96 out of 7.00 in weak sanction conditions.

When comparing manager-targeted sanction conditions to firm-targeted sanction conditions, $96.3 \%$ of participants in manager-targeted sanction conditions choose at least minimal compliance (55.6\% select minimal compliance, $40.7 \%$ select full compliance). $91.2 \%$ of participants faced with firm-targeted sanctions select at least minimal compliance (51.9\% select minimal compliance, $39.3 \%$ select full compliance). $38.2 \%$ of participants in manager-targeted sanction conditions identify their compliance as being an ethical choice, while $41.4 \%$ of participants in firm-targeted sanction conditions do so. The average perceived cost of accepting a settlement is 5.57 out of 7.00 when sanctions target managers, and 4.78 out of 7.00 when sanctions target the firm.

On the whole, univariate means are consistent with predictions that compliance is greater in assigned fault conditions, when sanctions are stronger, and when managers are targeted by sanctions. Means are also consistent with ethical frames being more prevalent among managers faced with fault-assignment and firm-targeted sanctions, and with perceived sanction strength being greater when sanctions are stronger, when they assign fault, and when they target managers.

Panel B of Table 1 reports descriptive statistics for all eight conditions. Broadly, results are consistent with fault being an important determinant of compliance when sanctions target managers, with $100.0 \%$ compliance for both conditions that assign fault 
to managers, but $93.3 \%$ (strong manager no-fault) and $91.4 \%$ (weak manager no-fault) in conditions with manager-targeted no-fault sanctions. ${ }^{15}$ Results are also consistent with sanction strength being an important determinant of compliance when sanctions target the firm, with $96.5 \%$ compliance (strong firm assigned-fault) and 94.7\% compliance (strong firm no-fault) in firm-targeted conditions with strong sanctions compared to $87.5 \%$ compliance (weak firm assigned-fault) and 86.9\% compliance (weak firm no-fault) for firm-targeted weak sanctions. This corresponds to a somewhat wider range in the cost perceptions for firm-targeted sanctions (4.01 of 7.00 for weak firm no-fault sanctions, compared to 5.35 of 7.00 for strong firm assigned-fault sanctions) than for managertargeted sanctions (5.43 of 7.00 for strong manager no-fault sanctions, compared to 5.85 of 7.00 for strong manager assigned fault sanctions). Ethical perceptions in managertargeted conditions are $26.7 \%$ and $31.0 \%$ for strong and weak no-fault sanctions respectively, but $41.1 \%$ and $52.2 \%$ for strong and weak assigned fault sanctions respectively.

Panel C of Table 1 reports participants' compliance choices by their decision frame. $98.4 \%$ of participants reporting an ethical decision frame comply with regulations (33.0\% select minimal compliance, $65.4 \%$ select full compliance). Of participants adopting business or legal decision frames, $90.0 \%$ choose to comply $(71.4 \%$ select minimal compliance, $17.6 \%$ select full compliance). These findings are consistent with ethical frame, resulting in both more and higher quality compliance.

\footnotetext{
${ }^{15}$ Logistic regression analyses of compliance in conditions that exhibit $100 \%$ compliance rates rely on bootstrapping to estimate effects. Bootstrapping iterations randomly select and replace the compliance choices of 2 compliant participants (1 weak manager-targeted assigned-fault observation and 1 strong manager-targeted assigned-fault condition) with a non-compliant choice indicator.
} 
TABLE 1: DESCRIPTIVE STATISTICS

Mean

(Std. Dev)

Panel A: By Independent Variable

\begin{tabular}{|c|c|c|c|c|c|c|c|c|c|c|c|}
\hline & $\mathbf{n}$ & $\begin{array}{l}\text { Ethical } \\
\text { Frame }\end{array}$ & $\begin{array}{c}\text { Business } \\
\text { or Legal } \\
\text { Frame } \\
\end{array}$ & $\begin{array}{c}\text { Perceived } \\
\text { Costs }\end{array}$ & $\begin{array}{c}\text { Non- } \\
\text { Compliant }\end{array}$ & $\begin{array}{c}\text { Minimal } \\
\text { Compliance }\end{array}$ & $\begin{array}{c}\text { Full } \\
\text { Compliance }\end{array}$ & $\begin{array}{c}\text { Total } \\
\text { Compliance }\end{array}$ & Age & Gender & $\begin{array}{r}\text { Collat'l } \\
\text { Consequ. }\end{array}$ \\
\hline Overall & 480 & $39.8 \%$ & $47.3 \%$ & $\begin{array}{c}5.18 \\
(1.49)\end{array}$ & $6.3 \%$ & $53.8 \%$ & $40.0 \%$ & $93.8 \%$ & $\begin{array}{c}36.4 \\
(11.1)\end{array}$ & $48.5 \%$ & $\begin{array}{l}-0.04 \\
(1.02)\end{array}$ \\
\hline Fault & 244 & $44.3 \%$ & $44.3 \%$ & $\begin{array}{c}5.38 \\
(1.32)\end{array}$ & $4.1 \%$ & $52.5 \%$ & $43.4 \%$ & $95.9 \%$ & $\begin{array}{c}36.6 \\
(11.1)\end{array}$ & $48.8 \%$ & $\begin{array}{l}-0.03 \\
(0.97)\end{array}$ \\
\hline No-Fault & 236 & $35.2 \%$ & $50.4 \%$ & $\begin{array}{c}4.97 \\
(1.61)\end{array}$ & $8.5 \%$ & $55.1 \%$ & $36.4 \%$ & $91.5 \%$ & $\begin{array}{c}36.3 \\
(11.1)\end{array}$ & $48.3 \%$ & $\begin{array}{l}-0.05 \\
(1.06)\end{array}$ \\
\hline Strong & 230 & $35.6 \%$ & $50.0 \%$ & $\begin{array}{c}5.40 \\
(1.35)\end{array}$ & $3.9 \%$ & $55.7 \%$ & $40.4 \%$ & $96.1 \%$ & $\begin{array}{c}36.4 \\
(11.6)\end{array}$ & $52.2 \%$ & $\begin{array}{c}0.03 \\
(0.96)\end{array}$ \\
\hline Weak & 250 & $43.6 \%$ & $44.8 \%$ & $\begin{array}{c}4.96 \\
(1.58)\end{array}$ & $8.4 \%$ & $52.0 \%$ & $39.6 \%$ & $91.6 \%$ & $\begin{array}{c}36.5 \\
(10.5)\end{array}$ & $45.2 \%$ & $\begin{array}{l}-0.10 \\
(1.06)\end{array}$ \\
\hline Manager & 241 & $38.2 \%$ & $49.4 \%$ & $\begin{array}{c}5.57 \\
(1.39)\end{array}$ & $3.7 \%$ & $55.6 \%$ & $40.7 \%$ & $96.3 \%$ & $\begin{array}{c}36.4 \\
(10.9)\end{array}$ & $45.2 \%$ & $\begin{array}{l}-0.09 \\
(1.02)\end{array}$ \\
\hline Firm & 239 & $41.4 \%$ & $45.2 \%$ & $\begin{array}{c}4.78 \\
(1.48)\end{array}$ & $8.8 \%$ & $51.9 \%$ & $39.3 \%$ & $91.2 \%$ & $\begin{array}{c}36.4 \\
(11.2)\end{array}$ & $51.9 \%$ & $\begin{array}{c}0.01 \\
(1.01)\end{array}$ \\
\hline
\end{tabular}


TABLE 1 (continued)

Panel B: By Condition

\begin{tabular}{|c|c|c|c|c|c|c|c|c|c|c|c|}
\hline & $\mathbf{n}$ & $\begin{array}{l}\text { Ethical } \\
\text { Frame }\end{array}$ & $\begin{array}{c}\text { Business } \\
\text { or Legal } \\
\text { Frame }\end{array}$ & $\begin{array}{c}\text { Perceived } \\
\text { Costs } \\
\end{array}$ & $\begin{array}{c}\text { Non- } \\
\text { Compliant }\end{array}$ & $\begin{array}{c}\text { Minimal } \\
\text { Compliance }\end{array}$ & $\begin{array}{c}\text { Full } \\
\text { Compliance }\end{array}$ & $\begin{array}{c}\text { Total } \\
\text { Compliance }\end{array}$ & Age & Gender & $\begin{array}{r}\text { Collat'l } \\
\text { Consequ. }\end{array}$ \\
\hline $\begin{array}{l}\text { Manager } \\
\text { Strong } \\
\text { Fault }\end{array}$ & 56 & $41.1 \%$ & $51.8 \%$ & $\begin{array}{c}5.85 \\
(1.09)\end{array}$ & $0.0 \%$ & $51.8 \%$ & $48.2 \%$ & $100.0 \%$ & $\begin{array}{c}36.9 \\
(11.8)\end{array}$ & $48.2 \%$ & $\begin{array}{c}0.17 \\
(0.92)\end{array}$ \\
\hline $\begin{array}{l}\text { Manager } \\
\text { Weak } \\
\text { Fault }\end{array}$ & 67 & $52.2 \%$ & $40.3 \%$ & $\begin{array}{c}5.54 \\
(1.39)\end{array}$ & $0.0 \%$ & $50.7 \%$ & $49.3 \%$ & $100.0 \%$ & $\begin{array}{c}37.4 \\
(11.7)\end{array}$ & $37.3 \%$ & $\begin{array}{l}-0.25 \\
(0.98)\end{array}$ \\
\hline $\begin{array}{l}\text { Manager } \\
\text { Strong } \\
\text { No-Fault }\end{array}$ & 60 & $26.7 \%$ & $56.7 \%$ & $\begin{array}{c}5.43 \\
(1.55)\end{array}$ & $6.7 \%$ & $60.0 \%$ & $33.3 \%$ & $93.3 \%$ & $\begin{array}{c}35.8 \\
(10.5)\end{array}$ & $43.3 \%$ & $\begin{array}{l}-0.07 \\
(1.01)\end{array}$ \\
\hline $\begin{array}{l}\text { Manager } \\
\text { Weak } \\
\text { No-Fault }\end{array}$ & 58 & $31.0 \%$ & $50.0 \%$ & $\begin{array}{c}5.47 \\
(1.45)\end{array}$ & $8.6 \%$ & $60.3 \%$ & $31.0 \%$ & $91.4 \%$ & $\begin{array}{l}35.5 \\
(9.6)\end{array}$ & $53.4 \%$ & $\begin{array}{l}-0.18 \\
(1.11)\end{array}$ \\
\hline $\begin{array}{l}\text { Firm } \\
\text { Strong } \\
\text { Fault }\end{array}$ & 57 & $38.6 \%$ & $42.1 \%$ & $\begin{array}{c}5.35 \\
(1.23)\end{array}$ & $3.5 \%$ & $57.9 \%$ & $38.6 \%$ & $96.5 \%$ & $\begin{array}{c}36.3 \\
(10.9)\end{array}$ & $63.2 \%$ & $\begin{array}{c}0.00 \\
(0.88)\end{array}$ \\
\hline $\begin{array}{l}\text { Firm } \\
\text { Weak } \\
\text { Fault }\end{array}$ & 64 & $43.8 \%$ & $43.8 \%$ & $\begin{array}{c}4.81 \\
(1.34)\end{array}$ & $12.5 \%$ & $50.0 \%$ & $37.5 \%$ & $87.5 \%$ & $\begin{array}{l}35.5 \\
(9.8)\end{array}$ & $48.4 \%$ & $\begin{array}{l}-0.00 \\
(1.05)\end{array}$ \\
\hline $\begin{array}{l}\text { Firm } \\
\text { Strong } \\
\text { No-Fault }\end{array}$ & 57 & $36.8 \%$ & $49.1 \%$ & $\begin{array}{c}5.00 \\
(1.36)\end{array}$ & $5.3 \%$ & $52.6 \%$ & $42.1 \%$ & $94.7 \%$ & $\begin{array}{c}36.6 \\
(13.4)\end{array}$ & $54.4 \%$ & $\begin{array}{c}0.02 \\
(1.03)\end{array}$ \\
\hline $\begin{array}{l}\text { Firm } \\
\text { Weak } \\
\text { No-Fault }\end{array}$ & 61 & $45.9 \%$ & $45.9 \%$ & $\begin{array}{c}4.01 \\
(1.65)\end{array}$ & $13.1 \%$ & $47.5 \%$ & $39.3 \%$ & $86.9 \%$ & $\begin{array}{c}37.2 \\
(10.7)\end{array}$ & $42.6 \%$ & $\begin{array}{c}0.03 \\
(1.11)\end{array}$ \\
\hline
\end{tabular}


TABLE 1 (continued)

Panel C: By Decision Frame

\begin{tabular}{|c|c|c|c|c|c|c|c|c|c|c|c|}
\hline & n & $\begin{array}{l}\text { Ethical } \\
\text { Frame }\end{array}$ & $\begin{array}{c}\text { Business } \\
\text { or Legal } \\
\text { Frame }\end{array}$ & $\begin{array}{l}\text { Perceived } \\
\text { Costs }\end{array}$ & $\begin{array}{c}\text { Non- } \\
\text { Compliant }\end{array}$ & $\begin{array}{c}\text { Minimal } \\
\text { Compliance }\end{array}$ & $\begin{array}{c}\text { Full } \\
\text { Compliance }\end{array}$ & $\begin{array}{c}\text { Total } \\
\text { Compliance }\end{array}$ & Age & Gender & $\begin{array}{c}\text { Collat'l } \\
\text { Consequ }\end{array}$ \\
\hline $\begin{array}{l}\text { Ethical } \\
\text { Frame }\end{array}$ & 191 & $100.0 \%$ & $0.0 \%$ & $\begin{array}{c}5.20 \\
(1.50)\end{array}$ & $1.6 \%$ & $33.0 \%$ & $65.4 \%$ & $98.4 \%$ & $\begin{array}{c}38.3 \\
(11.9)\end{array}$ & $45.0 \%$ & $\begin{array}{l}-0.25 \\
(0.93)\end{array}$ \\
\hline $\begin{array}{l}\text { Business or } \\
\text { Legal Frame }\end{array}$ & 227 & $0.0 \%$ & $100.0 \%$ & $\begin{array}{c}5.16 \\
(1.46)\end{array}$ & $11.0 \%$ & $71.4 \%$ & $17.6 \%$ & $90.0 \%$ & $\begin{array}{c}35.8 \\
(10.4)\end{array}$ & $52.0 \%$ & $\begin{array}{c}0.18 \\
(1.02)\end{array}$ \\
\hline Other & 62 & $0.0 \%$ & $0.0 \%$ & $\begin{array}{c}5.13 \\
(1.54)\end{array}$ & $3.2 \%$ & $53.2 \%$ & $43.5 \%$ & $96.7 \%$ & $\begin{array}{l}33.2 \\
(9.7)\end{array}$ & $46.8 \%$ & $\begin{array}{l}-0.21 \\
(1.13)\end{array}$ \\
\hline
\end{tabular}

Panel D: By Case

\begin{tabular}{|c|c|c|c|c|c|c|c|c|c|c|c|}
\hline & $\mathrm{n}$ & $\begin{array}{l}\text { Ethical } \\
\text { Frame }\end{array}$ & $\begin{array}{c}\text { Business } \\
\text { or Legal } \\
\text { Frame }\end{array}$ & $\begin{array}{l}\text { Perceived } \\
\text { Costs }\end{array}$ & $\begin{array}{c}\text { Non- } \\
\text { Compliant }\end{array}$ & $\begin{array}{c}\text { Minimal } \\
\text { Compliance }\end{array}$ & $\begin{array}{c}\text { Full } \\
\text { Compliance }\end{array}$ & $\begin{array}{c}\text { Total } \\
\text { Compliance }\end{array}$ & Age & Gender & $\begin{array}{c}\text { Collat'l } \\
\text { Consequ }\end{array}$ \\
\hline $\begin{array}{l}\text { Financial } \\
\text { Case }\end{array}$ & 229 & $52.0 \%$ & $39.3 \%$ & $\begin{array}{c}5.20 \\
(1.48)\end{array}$ & $4.4 \%$ & $38.4 \%$ & $57.2 \%$ & $95.6 \%$ & $\begin{array}{c}36.2 \\
(11.0)\end{array}$ & $45.9 \%$ & $\begin{array}{c}0.11 \\
(0.98)\end{array}$ \\
\hline $\begin{array}{l}\text { Managerial } \\
\text { Case }\end{array}$ & 251 & $28.7 \%$ & $54.6 \%$ & $\begin{array}{c}5.16 \\
(1.49)\end{array}$ & $8.0 \%$ & $67.7 \%$ & $24.3 \%$ & $92.0 \%$ & $\begin{array}{c}36.6 \\
(11.2)\end{array}$ & $51.0 \%$ & $\begin{array}{l}-0.18 \\
(1.03)\end{array}$ \\
\hline
\end{tabular}

FAULT is a dichotomous variable set to 1 when participants' case indicates that settlements offered to violators require admission of fault, 0 when the case indicates that violators are neither permitted to admit nor deny fault in the settlement. STRENGTH is a dichotomous variable set to 1 when risk-weighted settlement financial penalties exceed the financial gains of violation (in increased profit and/or bonus pay), 0 when the financial gains of violation exceed the financial penalties imposed by settlements. TARGET is a dichotomous variable set to 1 when sanctions are described as targeting the manager, or 0 when sanctions are described as targeting the manager's firm. ETHICAL FRAME is a dichotomous variable set to 1 when participants indicate that their case choice is primarily an ethical choice, 0 otherwise. BUSINESS OR LEGAL FRAME is a dichotomous variable set to 1 when participants indicate that their case choice is primarily a business choice or primarily a legal choice, 0 otherwise. PERCEIVED COST is the average of participants' responses to two 7-pt Likert questions reflecting agreement that overall costs for the firm (1) and manager (2) are high. MINIMAL COMPLIANCE is a dichotomous variable set to 1 when participants select either minimal disclosure, 0 when participants select no disclosure. FULL COMPLIANCE is a dichotomous variable set to 1 when participants select full disclosure, 0 when participants select either minimal or no disclosure. TOTAL COMPLIANCE is the sum of minimal and full compliance. AGE is the number of years from 2015 (the year the data was collected) to the year that participants indicated they were born in. GENDER is a dichotomous variable set to 0 when participants' self-report their gender as female, 1 when participants' self-report their gender as male. COLLATERAL CONSEQUENCES is the average of participants' decision weights assigned to two possible decision factors: a) possibility of subsequent litigation, b) possibility of job loss. 
TABLE 2: CORRELATION MATRIX Pearson's Correlations

\begin{tabular}{|c|c|c|c|c|c|c|c|c|c|c|c|}
\hline & Fault & Target & Strength & $\begin{array}{c}\text { Comply } \\
\text { Level }\end{array}$ & $\begin{array}{c}\text { No } \\
\text { Comply } \\
\end{array}$ & $\begin{array}{l}\text { Minimal } \\
\text { Comply }\end{array}$ & $\begin{array}{c}\text { Full } \\
\text { Comply }\end{array}$ & $\begin{array}{l}\text { Ethical } \\
\text { Frame }\end{array}$ & $\begin{array}{c}\text { Perceived } \\
\text { Costs }\end{array}$ & Gender & Age \\
\hline $\begin{array}{c}\text { Comply } \\
\text { Level }\end{array}$ & $0.099 * *$ & 0.056 & 0.043 & & & & & & & & \\
\hline $\begin{array}{c}\text { No } \\
\text { Comply }\end{array}$ & $-0.090 * *$ & $-0.104 * *$ & $-0.092 * *$ & $-0.585 * * *$ & & & & & & & \\
\hline $\begin{array}{l}\text { Minimal } \\
\text { Comply }\end{array}$ & -0.026 & 0.037 & 0.037 & $-0.615 * * *$ & $-0.278 * * *$ & & & & & & \\
\hline $\begin{array}{c}\text { Full } \\
\text { Comply }\end{array}$ & $0.072 *$ & 0.014 & 0.009 & $0.916^{* * *}$ & $-0.211 * * *$ & $-0.880 * * *$ & & & & & \\
\hline $\begin{array}{l}\text { Ethical } \\
\text { Frame }\end{array}$ & $0.093^{* *}$ & -0.033 & $-0.081^{*}$ & $0.413 * * *$ & $-0.157 * * *$ & $-0.339 * * *$ & $0.422 * * *$ & & & & \\
\hline $\begin{array}{c}\text { Perceived } \\
\text { Costs }\end{array}$ & $0.137^{* * *}$ & $0.265^{* * *}$ & $0.148 * * *$ & $0.191 * * *$ & $-0.280 * * *$ & 0.043 & $0.094 * *$ & 0.016 & & & \\
\hline Gender & 0.005 & -0.067 & 0.070 & $-0.080 *$ & $0.094 * *$ & 0.006 & -0.053 & -0.057 & $-0.130 * * *$ & & \\
\hline Age & 0.012 & 0.002 & -0.003 & $0.134 * * *$ & $-0.113 * *$ & -0.047 & $0.103 * *$ & $0.135 * * *$ & 0.060 & -0.033 & \\
\hline
\end{tabular}

$* * *, * * *$ - indicates statistical significance at the $0.01,0.05$, and 0.10 , levels, respectively

FAULT is a dichotomous variable set to 1 when participants' case indicates that settlements offered to violators require admission of fault, 0 when the case indicates that violators are neither permitted to admit nor deny fault in the settlement. STRENGTH is a dichotomous variable set to 1 when risk-weighted settlement financial penalties exceed the financial gains of violation (in increased profit and/or bonus pay), 0 when the financial gains of violation exceed the financial penalties imposed by settlements. TARGET is a dichotomous variable set to 1 when sanctions are described as targeting the manager, or 0 when sanctions are described as targeting the manager's firm. ETHICAL FRAME is a dichotomous variable set to 1 when participants indicate that their case choice is primarily an ethical choice, 0 otherwise. BUSINESS OR LEGAL FRAME is a dichotomous variable set to 1 when participants indicate that their case choice is primarily a business choice or primarily a legal choice, 0 otherwise. PERCEIVED COST is the average of participants' responses to two 7-pt Likert questions reflecting agreement that overall costs for the firm (1) and manager (2) are high. MINIMAL COMPLIANCE is a dichotomous variable set to 1 when participants select either minimal disclosure, 0 when participants select no disclosure. FULL COMPLIANCE is a dichotomous variable set to 1 when participants select full disclosure, 0 when participants select either minimal or no disclosure. TOTAL COMPLIANCE is the sum of minimal and full compliance. AGE is the number of years from 2015 (the year the data was collected) to the year that participants indicated they were born in. COMPLY LEVEL is an ordinal variable set to 0 for participants who do not comply with regulations, 1 for participants who minimally comply, and 2 for participants who select full compliance. GENDER is a dichotomous variable set to 0 when participants' self-report their gender as female, 1 when participants' self-report their gender as male. COLLATERAL CONSEQUENCES is the average of participants' decision weights assigned to two possible decision factors: a) possibility of subsequent litigation, b) possibility of job loss. 
Panel D of Table 1 reports compliance choices by the managerial or financial case scenario. $52.0 \%$ of participants completing the financial case indicate that the scenario is ethical in nature, while $28.7 \%$ of participants completing the managerial case do so. $95.6 \%$ of participants completing the financial scenario comply at some level $(38.4 \%$ select minimal compliance, $57.2 \%$ select full compliance). $92.0 \%$ of participants completing the managerial scenario select either minimal or full compliance $(67.7 \%$ select minimal compliance, $24.3 \%$ select full compliance). Because compliance level differs by case ( $z$ score: 4.86, p-value: $<0.01)$, I include a control variable for case in my analysis.

Table 2 presents Pearson's correlations for the primary independent, dependent and control measures used in the study. All three primary independent variables are positively associated with measures of managers' cost perceptions (fault $r=0.137, p<$ 0.01 ; target $r=0.265, p<0.01$; strength $r=0.148, p=0.01$ ). However, only two independent variables are associated with managers' ethical decision frames - (fault $r=$ 0.093, $p=0.04$; strength $r=-0.081, p=0.08$ ).

Measures of managers' cost perceptions and ethical decision frames show no univariate association with one another $(r=0.016, p=0.73)$. Measures of managers' cost perceptions and ethical decision frames are each positively correlated with managers' compliance level (ethical frame $r=0.413, p<0.01$; cost perceptions $r=0.191, p<0.01$ ) and compliance frequency (ethical frame $r=0.157, p<0.01$; cost perceptions $r=-0.280$, $p<0.01$ ). Lastly, control variables correlate with both mediating variables (managers' ethical decision frame and cost perceptions) and compliance choices (compliance frequency and compliance level), but demonstrate no correlation with my independent variables. 


\section{IV.C Hypothesis Tests}

\section{The Effects of Fault on Perceived Costs (H1a) and Ethical Frames (H1b)}

Hypothesis 1a predicts that managers will perceive the costs of accepting a settlement to be greater when settlements include fault assignment. I test H1a by examining the coefficient on fault in an OLS regression with managers' perceived costs as the primary dependent variable, indicator variables for my primary independent variables (fault, strength, target) and their interactions, and control variables for participants' selfreported gender, perceived collateral consequences, and received case as described in Section III.

Results are reported in Table 3, Model 1. Consistent with H1a, the coefficient on fault is positively and significantly associated with my measure of cost perceptions ( $t$-stat: 3.37, $p$-value: $<0.01) .{ }^{16}$ I conclude that H1a is supported, suggesting that managers perceive the costs of accepting a settlement to be greater when settlements include fault assignment.

Hypothesis $1 \mathrm{~b}$ predicts that managers will be more likely to invoke ethical decision frames when settlements include fault assignment. I test H1b by examining the coefficient on fault in a logistic regression with managers' ethical frame as the primary dependent variable, indicator variables for my primary independent variables (fault, strength, target) and their interactions, and control variables for participants' self-reported gender, perceived collateral consequences, and received case as described in Section III. Results are reported in Table 4, Model 1. Inconsistent with H1b, the coefficient on fault is not significantly associated with greater frequencies of ethical decision frames ( $z$-score: -0.17 , p-value: 0.86). I conclude that $\mathrm{H} 1 \mathrm{~b}$ is not supported.

\footnotetext{
${ }^{16}$ All reported p-values are one-tailed, except where noted otherwise.
} 


\section{The Effects of Sanction Strength on Perceived Costs and Ethical Frames (RQ1)}

Research Question 1 investigates the possibility that sanction strength may influence managers' ethical perceptions by signaling either/both of managers' descriptive norms for non-compliance or/and regulators' injunctive norms of compliance. I test RQ1 by examining the coefficient on strength in a logistic regression with managers' ethical frame as the primary dependent variable, indicator variables for my primary independent variables (fault, strength, target) and their interactions, and control variables for participants' self-reported gender, perceived collateral consequences, and received case as described in Section III. Results are reported in Table 4, Model 1. The coefficient on strength is not significantly associated with greater frequencies of ethical decision frames ( $z$-score: $-1.18, p$-value: 0.24$).$ I conclude that the association between sanction strength and managers' ethical decision frames is not statistically significant.

\section{The Effects of Sanction Target on Perceived Costs (H2a) and Ethical Frames (H2b)}

Hypothesis 2a predicts that managers will perceive the costs of accepting a settlement to be greater when settlements target managers. I test H2a by examining the coefficient on target in an OLS regression with managers' perceived costs as the primary dependent variable, indicator variables for my primary independent variables (fault, strength, target) and their interactions, and control variables for participants' self- reported gender, perceived collateral consequences, and received case as described in Section III. Results are reported in Table 3, Model 1. Consistent with H2a, the coefficient on target is positively and significantly associated with greater cost perceptions ( $t$-stat: $6.08, p$-value: $<0.01$ ). I conclude that $\mathrm{H} 2 \mathrm{a}$ is supported, suggesting that managers perceive the costs of accepting a settlement to be greater when settlements target managers rather than firms. 


\section{TABLE 3: MEDIATOR - COST PERCEPTIONS (“PROCESSING”)}

Coefficient (OLS) or Odds Ratio (Logistic / Ordered Logistic) (t-stat or z-score)

\begin{tabular}{ccc} 
Link 1 & Links 2\& 5 & Links $2 \& 5$ \\
\hline Perceived & Total & Comply \\
Costs & Comply & Level
\end{tabular}

\begin{tabular}{|c|c|c|c|}
\hline & (1) OLS & (2) LOGIT & (3) OLOGIT \\
\hline Perceived Costs & & $\begin{array}{c}1.96 * * * \\
(4.78)\end{array}$ & $\begin{array}{c}1.34 * * * \\
(4.02)\end{array}$ \\
\hline Fault $(H 1 a)$ & $\begin{array}{c}0.83 * * * \\
(3.37)\end{array}$ & $\begin{array}{c}0.50 \\
(-1.14)\end{array}$ & $\begin{array}{c}0.77 \\
(-0.68)\end{array}$ \\
\hline Strength & $\begin{array}{c}1.05^{* * *} \\
(4.11)\end{array}$ & $\begin{array}{l}1.28 \\
(0.32)\end{array}$ & $\begin{array}{l}1.01 \\
(0.03)\end{array}$ \\
\hline Target $(H 2 a)$ & $\begin{array}{c}1.54^{* * * *} \\
(6.08)\end{array}$ & $\begin{array}{c}0.54 \\
(-0.88)\end{array}$ & $\begin{array}{l}0.54^{*} \\
(-1.52)\end{array}$ \\
\hline Target*Fault & $\begin{array}{c}-0.83 * * * \\
(-2.36)\end{array}$ & $\begin{array}{c}13.10^{* *} \\
(1.94)\end{array}$ & $\begin{array}{l}2.89 * * \\
(1.96)\end{array}$ \\
\hline Target*Strength $(H 4)$ & $\begin{array}{c}-1.15 * * * \\
(-3.20)\end{array}$ & $\begin{array}{l}1.04 \\
(0.04)\end{array}$ & $\begin{array}{l}1.25 \\
(0.41)\end{array}$ \\
\hline Fault*Strength $(H 5)$ & $\begin{array}{l}-0.44 \\
(-1.23)\end{array}$ & $\begin{array}{l}2.33 \\
(0.75)\end{array}$ & $\begin{array}{l}1.02 \\
(0.04)\end{array}$ \\
\hline Fault*Target*Strength & $\begin{array}{l}0.84 * * \\
(1.67)\end{array}$ & $\begin{array}{c}0.21 \\
(-0.79)\end{array}$ & $\begin{array}{c}0.86 \\
(-0.19)\end{array}$ \\
\hline Gender & $\begin{array}{c}-0.43 * * * \\
(-3.38)\end{array}$ & $\begin{array}{c}0.76 \\
(-0.65)\end{array}$ & $\begin{array}{c}0.95 \\
(-0.28)\end{array}$ \\
\hline $\begin{array}{l}\text { Collateral } \\
\text { Consequences }\end{array}$ & $\begin{array}{l}0.15^{* *} \\
(2.26)\end{array}$ & $\begin{array}{c}0.54 * * * \\
(-2.86)\end{array}$ & $\begin{array}{c}0.61 * * * \\
(-4.69)\end{array}$ \\
\hline Case & $\begin{array}{l}-0.03 \\
(-0.22)\end{array}$ & $\begin{array}{l}2.75 * * \\
(2.27)\end{array}$ & $\begin{array}{l}4.68 * * * \\
(7.51)\end{array}$ \\
\hline $\begin{array}{c}n \\
\text { Adj. or Pseudo R-Square }\end{array}$ & $\begin{array}{c}480 \\
0.141\end{array}$ & $\begin{array}{c}480 \\
0.210\end{array}$ & $\begin{array}{c}480 \\
0.117\end{array}$ \\
\hline
\end{tabular}

$* * *, * *, *$ - indicates statistical significance at the 0.01, 0.05, and 0.10 , levels, respectively

$\S$ - Managers in manager-targeted, assigned-fault conditions demonstrate $100 \%$ compliance. To facilitate data analysis, bootstrapping is conducted where observations were randomly assigned non-compliance. 2 observations were assigned non-compliance per iteration, 1 weak-sanction, manager-targeted, assigned fault observation and 1 strongsanction, manager-targeted, assigned-fault observation. 


\section{TABLE 4: MEDIATOR - DECISION FRAME (“SIGNALING”)}

Odds Ratio

(z-score)

\begin{tabular}{|c|c|c|}
\hline Link 3 & Links $4 \& 5$ & Links $4 \& 5$ \\
\hline $\begin{array}{l}\text { Ethical } \\
\text { Frame }\end{array}$ & $\begin{array}{c}\text { Total } \\
\text { Comply }\end{array}$ & $\begin{array}{c}\text { Comply } \\
\text { Level }\end{array}$ \\
\hline (1) LOGIT & (2) LOGIT & $c$ \\
\hline
\end{tabular}

\begin{tabular}{|c|c|c|c|}
\hline Ethical Frame & & $\begin{array}{c}4.39 * * * \\
(2.60)\end{array}$ & $\begin{array}{c}5.07 * * * \\
(7.45)\end{array}$ \\
\hline Fault $(H 1 b)$ & $\begin{array}{c}0.94 \\
(-0.17)\end{array}$ & $\begin{array}{l}1.08 \\
(0.16)\end{array}$ & $\begin{array}{l}1.03 \\
(0.09)\end{array}$ \\
\hline Strength $(R Q 1)$ & $\begin{array}{c}0.63 \\
(-1.18)\end{array}$ & $\begin{array}{l}3.22 * \\
(1.61)\end{array}$ & $\begin{array}{l}1.74^{*} \\
(1.38)\end{array}$ \\
\hline Target $(H 2 b)$ & $\begin{array}{l}0.46 * * \\
(-1.92)\end{array}$ & $\begin{array}{l}2.05 \\
(1.15)\end{array}$ & $\begin{array}{l}1.16 \\
(0.36)\end{array}$ \\
\hline Target*Fault $(H 3)$ & $\begin{array}{c}2.57 * * \\
(1.71)\end{array}$ & $\begin{array}{l}4.27 \\
(1.16)\end{array}$ & $\begin{array}{l}1.65 \\
(0.91)\end{array}$ \\
\hline Target*Strength & $\begin{array}{l}1.39 \\
(0.56)\end{array}$ & $\begin{array}{c}0.41 \\
(-0.87)\end{array}$ & $\begin{array}{c}0.72 \\
(-0.58)\end{array}$ \\
\hline Fault*Strength & $\begin{array}{l}1.11 \\
(0.19)\end{array}$ & $\begin{array}{l}1.53 \\
(0.39)\end{array}$ & $\begin{array}{c}0.82 \\
(-0.36)\end{array}$ \\
\hline Fault*Target ${ }^{*}$ Strength & $\begin{array}{c}0.80 \\
(-0.28)\end{array}$ & $\begin{array}{c}0.52 \\
(-0.34)\end{array}$ & $\begin{array}{l}1.33 \\
(0.36)\end{array}$ \\
\hline Gender & $\begin{array}{c}0.89 \\
(-0.58)\end{array}$ & $\begin{array}{l}0.56 * \\
(-1.47)\end{array}$ & $\begin{array}{c}0.85 \\
(-0.79)\end{array}$ \\
\hline $\begin{array}{l}\text { Collateral } \\
\text { Consequences }\end{array}$ & $\begin{array}{c}0.61 * * * \\
(-4.50)\end{array}$ & $\begin{array}{c}0.81 \\
(-1.15)\end{array}$ & $\begin{array}{c}0.73 * * * \\
(-2.86)\end{array}$ \\
\hline Case & $\begin{array}{l}3.24 * * * \\
\quad(5.67)\end{array}$ & $\begin{array}{c}1.68 \\
(1.23)\end{array}$ & $\begin{array}{c}3.49 * * * \\
(5.89)\end{array}$ \\
\hline $\mathbf{n}$ & 480 & 480 & 480 \\
\hline Pseudo R-Square & 0.095 & 0.140 & 0.168 \\
\hline
\end{tabular}

***, **, * - indicates statistical significance at the 0.01, 0.05, and 0.10, levels, respectively

FAULT is a dichotomous variable set to 1 for participants in assigned fault conditions, 0 for participants in no-fault conditions. TARGET is a dichotomous variable set to 1 for participants in manager-targeted sanction conditions, or 0 for participants in firm-targeted sanction conditions. STRENGTH is a dichotomous variable set to 1 for participants in conditions where the risk-weighted settlement financial penalties exceed the financial gains of violation (in increased bonus pay), 0 when otherwise. PERCEIVED COST is the average of participants' responses to two 7-pt Likert questions reflecting agreement that overall costs for the firm (1) and manager (2) are high. ETHICAL FRAME is a dichotomous variable set to 1 when participants indicate the case choice is an ethical choice, 0 otherwise. TOTAL COMPLY is a dichotomous variable set to 1 if the participant selected either minimal or full compliance, 0 otherwise. COMPLY LEVEL is an ordinal variable set to 0 for participants who do not comply with regulations, 1 for participants who select minimal compliance, and 2 for participants who select full compliance. GENDER is a dichotomous variable set to 0 when participants self-report their gender as female, 1 when participants self-report their gender as male.

COLLATERAL CONSEQUENCES is the average of participants' decision weights assigned to two possible decision 
factors: a) possibility of subsequent litigation, b) possibility of job loss. CASE is an indicator variable set to 1 for participants who completed the financial scenario.

Hypothesis $2 \mathrm{~b}$ predicts that managers will be more likely to invoke ethical decision frames when settlements target firms rather than managers. I test $\mathrm{H} 2 \mathrm{~b}$ by examining the coefficient on target in a logistic regression with managers' ethical frame as the primary dependent variable, indicator variables for my primary independent variables (fault, strength, target) and their interactions, and control variables for participants' self-reported gender, perceived collateral consequences, and received case as described in Section III. Results are reported in Table 4, Model 1. Consistent with H2b, the coefficient on target is negative and statistically significant ( $z$-score: $-1.92, p$-value: 0.06$)$. I conclude that $\mathrm{H} 2 \mathrm{~b}$ is supported, suggesting that managers are more likely to invoke ethical decision frames when sanctions target the firm than when they target managers.

\section{The Interactive Effects of Fault and Sanction Target on Ethical Frames (H3)}

Hypothesis 3 predicts that the effects of fault assignment and sanction target on managers' ethical decision frames will be greater in combination than alone. I test H3 by examining the coefficient on target ${ }^{*}$ fault in a logistic regression with managers' ethical frame as the primary dependent variable, indicator variables for my primary independent variables (fault, strength, target) and their interactions, and control variables for participants' self-reported gender, perceived collateral consequences, and received case as described in Section III. Results are reported in Table 4, Model 1. Consistent with H3, the coefficient on $\operatorname{target}^{*}$ fault is positive and weakly statistically significant ( $z$-score: 1.71 , p-value: 0.09$)$. I conclude that $\mathrm{H} 3$ is supported, suggesting that managers are more likely to invoke ethical decision frames when sanctions target managers with fault. 


\section{The Interactive Effects of Sanction Strength and Sanction Target on Perceived Costs}

(H4)

Hypothesis 4 predicts that managers' cost perceptions will be more sensitive to differences in sanction strength when settlements target managers. I test H4 by examining the coefficient on target* strength in an OLS regression with managers' perceived costs as the primary dependent variable, indicator variables for my primary independent variables (fault, strength, target) and their interactions, and control variables for participants' selfreported gender, perceived collateral consequences, and received case as described in Section III. Results are reported in Table 3, Model 1. Inconsistent with H4, the coefficient on target ${ }^{*}$ strength is negatively and significantly associated with my measure of cost perceptions ( $t$-stat: $-3.20, p$-value: $<0.01)$. One interpretation of this finding is that sanction strength and sanction target may act as partial substitutes with regards to managers' cost perceptions. In light of the negative and statistically significant coefficient on target $^{*}$ fault, an alternative interpretation of this finding is that managers' cost perceptions are non-linear, resulting in decreasing marginal benefits for adding additional costs to sanctions.

\section{The Interactive Effects of Fault and Sanction Strength on Perceived Costs (H5)}

Hypothesis 5 predicts that the cost perceptions triggered by assigning fault in sanctions will substitute for cost perceptions triggered by strong sanctions. I test H5 by examining the coefficient on fault* strength in an OLS regression with managers' cost perceptions as the primary dependent variable, indicator variables for my primary independent variables (fault, strength, target) and their interactions, and control variables for participants' self-reported gender, perceived collateral consequences, and received 
case as described in Section III. Results are reported in Table 3, Model 1. Inconsistent with $\mathrm{H} 5$, the coefficient on fault* strength is not statistically significantly related to managers cost perceptions ( $t$-stat: $-1.23, p$-value: 0.22$)$. I conclude that H5 is not supported.

\section{The Effects of Perceived Costs and Ethical Frames on Managers' Compliance}

\section{Frequency (H6a) and Compliance Level (H6b)}

Hypothesis $6 \mathrm{a}$ predicts that managers cost perceptions and ethical perceptions will be associated with greater frequencies of compliance. I test H6a by examining the coefficients on perceived costs and ethical frame in a logistic regression with total compliance as the primary dependent variable. I include measures of my mediating variables perceived costs and ethical frame, and also include controls for my manipulated variables (fault, strength, target) and their interactions. Lastly, I also control for participants' self-reported gender, perceived collateral consequences, and received case as described in Section III. Results are reported in Table 5, Panel B Model 1. Consistent with H6a, the coefficient on perceived costs is positive and statistically significant (zscore: $4.55, p$-value: $<0.01)$; the coefficient on ethical frame is also positive and statistically significant ( $z$-score: $2.30, p$-value: 0.02$)$. I conclude that H6a is supported, suggesting that managers are more likely to select at least minimum compliance when they perceive costs to be greater and when they perceive their compliance choice to be ethical in nature.

Hypothesis $6 \mathrm{~b}$ predicts that managers cost perceptions and ethical perceptions will be associated with greater levels of compliance. I test H6b by examining the coefficients on perceived costs and ethical frame in an ordered logistic regression with compliance 
TABLE 5: FULL MODEL

Panel A: Without Mediators

Odds Ratio

(z-score)

\begin{tabular}{cc} 
All Links & All Links \\
\hline Total & Comply \\
Comply & Level \\
(1) LOGIT & (2) OLOGIT
\end{tabular}

\begin{tabular}{|c|c|c|}
\hline Fault & $\begin{array}{l}1.08 \\
(0.15)\end{array}$ & $\begin{array}{c}0.96 \\
(-0.10)\end{array}$ \\
\hline Strength & $\begin{array}{l}2.92 * \\
(1.50)\end{array}$ & $\begin{array}{l}1.30 \\
(0.67)\end{array}$ \\
\hline Target & $\begin{array}{l}1.71 \\
(0.87)\end{array}$ & $\begin{array}{c}0.84 \\
(-0.45)\end{array}$ \\
\hline Target $*$ Fault & $\begin{array}{l}4.92 * \\
(1.28)\end{array}$ & $\begin{array}{l}2.20 * \\
(1.48)\end{array}$ \\
\hline Target*Strength & $\begin{array}{c}0.43 \\
(-0.83)\end{array}$ & $\begin{array}{c}0.90 \\
(-0.18)\end{array}$ \\
\hline Fault*Strength & $\begin{array}{l}1.38 \\
(0.30)\end{array}$ & $\begin{array}{c}0.91 \\
(-0.18)\end{array}$ \\
\hline Fault*Target*Strength & $\begin{array}{c}0.59 \\
(-0.27)\end{array}$ & $\begin{array}{l}1.13 \\
(0.16)\end{array}$ \\
\hline Gender & $\begin{array}{l}0.56^{*} \\
(-1.49)\end{array}$ & $\begin{array}{c}0.85 \\
(-0.83)\end{array}$ \\
\hline Collateral Consequences & $\begin{array}{c}0.71 * * \\
(-1.84)\end{array}$ & $\begin{array}{c}0.64 * * * \\
(-4.31)\end{array}$ \\
\hline Case & $\begin{array}{c}2.20^{* *} \\
(1.93)\end{array}$ & $\begin{array}{c}4.43 * * * \\
(7.35)\end{array}$ \\
\hline $\begin{array}{c}\mathbf{n} \\
\text { Pseudo R-Square }\end{array}$ & $\begin{array}{c}480 \\
0.103\end{array}$ & $\begin{array}{c}480 \\
0.097\end{array}$ \\
\hline
\end{tabular}

***, **, *-indicates statistical significance at the 0.01,0.05, and 0.10, levels, respectively

$\S$ - Managers in manager-targeted, assigned-fault conditions demonstrate $100 \%$ compliance. To facilitate data analysis, bootstrapping is conducted where observations were randomly assigned non-compliance. 2 observations were assigned non-compliance per iteration, 1 weak-sanction, manager-targeted, assigned fault observation and 1 strongsanction, manager-targeted, assigned-fault observation. 
TABLE 5 (continued)

\section{Panel B: With Mediators}

Odds Ratio

(z-score)

\begin{tabular}{|c|c|c|c|}
\hline All Lin & & $\begin{array}{c}\text { Comply } \\
\text { Level, }\end{array}$ & $\begin{array}{c}\text { Comply } \\
\text { Level, }\end{array}$ \\
\hline & Com & Ethical & Econ/Legal \\
\hline & $\begin{array}{l}\text { Level } \\
\text { (2) }\end{array}$ & Frame & $\begin{array}{l}\text { Frame } \\
\text { (4) }\end{array}$ \\
\hline
\end{tabular}

\begin{tabular}{|c|c|c|c|c|}
\hline & & & & \\
\hline Perceived Costs $(H 6)$ & $\begin{array}{c}1.91 * * * \\
(4.55)\end{array}$ & $\begin{array}{c}1.36^{* * * *} \\
(4.06)\end{array}$ & $\begin{array}{c}1.18 \\
(1.23)\end{array}$ & $\begin{array}{c}1.73 * * * \\
(4.43)\end{array}$ \\
\hline Ethical Frame $(H 6)$ & $\begin{array}{c}3.84 * * \\
(2.30)\end{array}$ & $\begin{array}{c}5.22 * * * \\
(7.46)\end{array}$ & & \\
\hline Fault & $\begin{array}{c}0.55 \\
(-0.95)\end{array}$ & $\begin{array}{c}0.81 \\
(-0.55)\end{array}$ & $\begin{array}{l}1.05 \\
(0.07)\end{array}$ & $\begin{array}{c}0.61 \\
(-0.80)\end{array}$ \\
\hline Strength & $\begin{array}{l}1.48 \\
(0.50)\end{array}$ & $\begin{array}{l}1.31 \\
(0.66)\end{array}$ & $\begin{array}{c}0.54 \\
(-0.86)\end{array}$ & $\begin{array}{l}2.87 * \\
(1.63)\end{array}$ \\
\hline Target & $\begin{array}{c}0.67 \\
(-0.55)\end{array}$ & $\begin{array}{c}0.72 \\
(-0.77)\end{array}$ & $\begin{array}{c}0.63 \\
(-0.57)\end{array}$ & $\begin{array}{l}1.06 \\
(0.10)\end{array}$ \\
\hline Target*Fault & $\begin{array}{c}9.60 * * \\
(1.70)\end{array}$ & $\begin{array}{l}2.20^{*} \\
(1.40)\end{array}$ & $\begin{array}{l}1.11 \\
(0.10)\end{array}$ & $\begin{array}{l}4.20^{*} \\
(1.62)\end{array}$ \\
\hline Target*Strength & $\begin{array}{c}0.97 \\
(-0.03)\end{array}$ & $\begin{array}{c}1.02 \\
(0.04)\end{array}$ & $\begin{array}{l}1.81 \\
(0.52)\end{array}$ & $\begin{array}{l}0.23 * * \\
(-1.64)\end{array}$ \\
\hline Fault*Strength & $\begin{array}{l}2.37 \\
(0.75)\end{array}$ & $\begin{array}{c}0.94 \\
(-0.10)\end{array}$ & $\begin{array}{c}0.52 \\
(-0.67)\end{array}$ & $\begin{array}{c}0.84 \\
(-0.19)\end{array}$ \\
\hline $\begin{array}{l}\text { Fault*'Target* } \\
\text { Strength }\end{array}$ & $\begin{array}{c}0.20 \\
(-0.79)\end{array}$ & $\begin{array}{c}1.00 \\
(0.00)\end{array}$ & $\begin{array}{c}2.34 \\
(0.56)\end{array}$ & $\begin{array}{l}2.30 \\
(0.67)\end{array}$ \\
\hline Gender & $\begin{array}{c}0.75 \\
(-0.67)\end{array}$ & $\begin{array}{c}0.95 \\
(-0.23)\end{array}$ & $\begin{array}{c}1.32 \\
(0.74)\end{array}$ & $\begin{array}{l}0.56 * * \\
(-1.77)\end{array}$ \\
\hline $\begin{array}{l}\text { Collateral } \\
\text { Consequences }\end{array}$ & $\begin{array}{l}0.63 * * \\
(-2.15)\end{array}$ & $\begin{array}{c}0.70 * * * \\
(-3.24)\end{array}$ & $\begin{array}{l}0.71 * \\
(-1.55)\end{array}$ & $\begin{array}{l}0.77 * * \\
(-1.64)\end{array}$ \\
\hline Case & $\begin{array}{l}2.11 * \\
(1.64)\end{array}$ & $\begin{array}{c}3.68 * * * \\
(6.07)\end{array}$ & $\begin{array}{c}13.47 * * * \\
(6.47)\end{array}$ & $\begin{array}{c}3.24 * * * \\
(3.51)\end{array}$ \\
\hline $\mathbf{n}$ & 480 & 480 & 191 & 227 \\
\hline Pseudo R-Square & 0.238 & 0.189 & 0.209 & 0.208 \\
\hline
\end{tabular}

***, **, * - indicates statistical significance at the 0.01, 0.05, and 0.10, levels, respectively 
PERCEIVED COSTS is the average of participants' responses to two 7-pt Likert questions reflecting agreement that overall costs for the firm (1) and manager (2) are high. ETHICAL FRAME is a dichotomous variable set to 1 when participants indicate the case choice is an ethical choice, 0 otherwise. FAULT is a dichotomous variable set to 1 for participants in assigned fault conditions, 0 for participants in no-fault conditions. TARGET is a dichotomous variable set to 1 for participants in manager-targeted sanction conditions, or 0 for participants in firm-targeted sanction conditions. STRENGTH is a dichotomous variable set to 1 for participants in conditions where the risk-weighted settlement financial penalties exceed the financial gains of violation (in increased bonus pay), 0 when otherwise. TOTAL COMPLY is a dichotomous variable set to 1 if the participant selected either minimal or full compliance, 0 otherwise. COMPLY LEVEL is an ordinal variable set to 0 for participants who do not comply with regulations, 1 for participants who select minimal compliance, and 2 for participants who select full compliance. GENDER is a dichotomous variable set to 0 when participants self-report their gender as female, 1 when participants self-report their gender as male. COLLATERAL CONSEQUENCES is the average of participants' decision weights assigned to two possible decision factors: a) possibility of subsequent litigation, b) possibility of job loss. CASE is an indicator variable set to 1 for participants who completed the financial scenario.

level as the primary dependent variable. I include measures of my mediating variables perceived costs and ethical frame, and also include controls for my manipulated variables and participants' self-reported gender, perceived collateral consequences, and received case as described in Section III. Results are reported in Table 5, Panel B Model 2. Consistent with $\mathrm{H} 6 \mathrm{~b}$, the coefficient on perceived costs is positive and statistically significant ( $z$-score: $4.06, p$-value: $<0.01$ ); the coefficient on ethical frame is also positive and statistically significant ( $z$-score: $7.46, p$-value: $<0.01)$. I conclude that $\mathrm{H} 6 \mathrm{~b}$ is supported, suggesting that managers select higher quality compliance both when they perceive costs to be greater and when they perceive their compliance choice to be ethical in nature.

Lastly, in ordered logistic regressions on subsamples of participants indicating ethical decision frames (Table 5, Panel B Model 3) or economic/legal decision frames (Table 5, Panel B Model 4) I additionally observe that perceived costs is only a determinant of compliance level among participants adopting economic/legal decision frames ( $z$-score: $4.43, p$-value: $<0.01)$, but not among participants adopting ethical decision frames ( $z$-score: $1.23, p$-value: 0.22$)$. This is consistent with theory regarding 
decision frames, which predicts that managers' cost perceptions are not emphasized by individuals adopting ethical decision frames (Tenbrunsel \& Messick 1999).

\section{IV.D SUPPLEMENTARY ANALYSIS}

\section{'Dark Triad' Personality Traits}

Prior research suggests that the senior-most managers most likely to have decision responsibility for compliance choices demonstrate high levels of dark triad personality traits associated with self-interested choice (O'Reilly et al. 2014). I therefore investigate the sensitivity of my findings to subsamples of participants who demonstrate either high levels of dark triad personality traits ('high triads') or low levels of dark triad personality traits ('low triads'). Arguments hold alternatively that high triads, who may be less sensitive to others' concerns, will also be less concerned with avoiding social penalties such as fault assignment. Or, alternatively that high triads - who tend to be more narcissistic - may be more rather than less concerned with reputational signals that threaten self-image, such as fault assignment. Similarly, it may also be that low triads are less sensitive to social cues in the sense that their compliance is consistently high, even without fault.

To investigate the sensitivity of my results to high or low levels of dark triad personality traits, I partition my sample based on the standardized average of participants' scores to three psychometric scales measuring machiavellianism (Mach-IV scale, Christie \& Geiss 1970), narcissism (NPI scale, Raskin \& Hall 1981), and descriptive statistics for participants' ethical decision frames and compliance by dark triad partition. Descriptive statistics are directionally consistent with the high triad subsample being both less likely to perceive compliance as an ethical choice (32.0\% for high triads, $47.0 \%$ for low triads) and 
less likely to comply with regulation ( $10.8 \%$ of high triads do not comply, $2.0 \%$ of low triads do not comply).

In subsamples of high triad and low triad participants I examine the effects of sanction attributes on managers' perceived costs (Table 6, Panel B Models 1 and 2), ethical decision frames (Table 6, Panel B Models 3 and 4), and compliance level (Table 6, Panel B Models 5 and 6). In an OLS regression with perceived cost as the primary dependent variable, specified as in Table 3 Model 1, I observe that interactions of sanction attributes are generally statistically significant for low triad participants (Table 6, Panel B Model 2 target*fault $t$-stat: $-2.24, p$-value: 0.03 ; target*strength $t$-stat: $-2.75, p$-value: 0.01 ; fault*strength $t$-stat: $-1.29, p$-value: 0.20 ; fault*target*strength $t$-stat: $2.05, p$-value: 0.04 ) but not significant for high triad participants (Table 6, Panel B Model 1target*fault $t$-stat: 1.17, $p$-value: 0.24 ; target*strength $t$-stat: $-1.71, p$-value: 0.09 ; fault*strength $t$-stat: -0.44 , $p$-value: 0.66 ; fault*target*strength $t$-stat: $0.29, p$-value: 0.77$)$. This suggests that high triads perceive less cost substitution from sanction attributes than do low triads, which may partly reflect less non-linearity in their perceived cost function. In a logistic regression with ethical frame as the primary dependent variable, specified as in Table 4 Model 1, I observe that coefficients on target and target*fault are statistically significant determinants among high triads (Table 6, Panel B Model 3 target $z$-score: - 2.52, $p$-value: 0.01; target*fault $z$-score: $2.31, p$-value: 0.02 ) but not among low triads (Table 6, Panel B Model 4 target $z$-score: $-0.21, p$-value: 0.83 ; target*fault $z$-score: $-0.29, p$-value: 0.78$)$.

Lastly, in an logistic regression with compliance level as the primary dependent variable, specified as in Table 5 Panel B Model 2, I observe that coefficients on perceived costs and target*fault are statistically significant determinants among high triads (Table 6, 
TABLE 6: SUPPLEMENTAL ANALYSIS: BY DARK TRIAD PARTITION

Panel A: Descriptive Statistics By Dark Triad Partition

\begin{tabular}{lc|cccccccc}
\multicolumn{1}{c}{$\begin{array}{c}\text { Ethical } \\
\text { Frame }\end{array}$} & $\begin{array}{c}\text { Business } \\
\text { or Legal } \\
\text { Frame }\end{array}$ & $\begin{array}{c}\text { Perceived } \\
\text { Costs }\end{array}$ & $\begin{array}{c}\text { Non- } \\
\text { Compliant }\end{array}$ & $\begin{array}{c}\text { Minimal } \\
\text { Comply }\end{array}$ & $\begin{array}{c}\text { Full } \\
\text { Comply }\end{array}$ & $\begin{array}{c}\text { Total } \\
\text { Comply }\end{array}$ \\
\hline $\begin{array}{l}\text { High } \\
\text { Triad }\end{array}$ & 231 & $32.0 \%$ & $56.7 \%$ & $\begin{array}{c}5.15 \\
(1.56)\end{array}$ & $10.8 \%$ & $56.3 \%$ & $32.9 \%$ & $89.2 \%$ \\
$\begin{array}{l}\text { Low } \\
\text { Triad }\end{array}$ & 249 & $47.0 \%$ & $38.6 \%$ & $\begin{array}{c}5.20 \\
(1.42)\end{array}$ & $2.0 \%$ & $51.4 \%$ & $46.6 \%$ & $98.0 \%$
\end{tabular}

Panel B: Mediating Variables (Processing, Signaling), by Triad Partition

Coefficient (OLS) or Odds Ratio (Logistic and Ordered Logistic)

(t-stat or z-score)

$\begin{array}{cccc}\begin{array}{c}\text { Perceived Costs } \\ \text { High Triad }\end{array} & \begin{array}{c}\text { Perceived Costs } \\ \text { Low Triad }\end{array} & \begin{array}{c}\text { Ethical Frame } \\ \text { High Triad }\end{array} & \begin{array}{c}\text { Ethical Frame } \\ \text { Low Triad }\end{array}\end{array}$

\begin{tabular}{|c|c|c|c|c|}
\hline & (1) OLS & (2) OLS & (3) LOGIT & (4) LOGIT \\
\hline Fault & $\begin{array}{c}0.82 * * * \\
(2.18)\end{array}$ & $\begin{array}{c}0.86 * * * \\
(2.64)\end{array}$ & $\begin{array}{c}0.52 \\
(-1.20)\end{array}$ & $\begin{array}{l}2.02 \\
(1.26)\end{array}$ \\
\hline Strength & $\begin{array}{c}1.11 * * * \\
(2.90)\end{array}$ & $\begin{array}{c}1.03 * * * \\
(2.97)\end{array}$ & $\begin{array}{c}0.57 \\
(-0.99)\end{array}$ & $\begin{array}{c}0.69 \\
(-0.64)\end{array}$ \\
\hline Target & $\begin{array}{c}1.49 * * * \\
(3.70)\end{array}$ & $\begin{array}{c}1.59 * * * \\
(4.86)\end{array}$ & $\begin{array}{c}0.17 * * * \\
(-2.52)\end{array}$ & $\begin{array}{c}0.89 \\
(-0.21)\end{array}$ \\
\hline Target*Fault & $\begin{array}{l}-0.64 \\
(-1.17)\end{array}$ & $\begin{array}{c}-1.04^{* *} \\
(-2.24)\end{array}$ & $\begin{array}{l}7.96 * * \\
(2.31)\end{array}$ & $\begin{array}{c}0.87 \\
(-0.19)\end{array}$ \\
\hline Target*Strength & $\begin{array}{c}-0.96^{* *} \\
(-1.71)\end{array}$ & $\begin{array}{c}-1.31 * * * \\
(-2.75)\end{array}$ & $\begin{array}{c}2.99 \\
(1.14)\end{array}$ & $\begin{array}{c}0.80 \\
(-0.29)\end{array}$ \\
\hline Fault*Strength & $\begin{array}{l}-0.24 \\
(-0.44)\end{array}$ & $\begin{array}{l}-0.63^{*} \\
(-1.29)\end{array}$ & $\begin{array}{c}0.86 \\
(-0.18)\end{array}$ & $\begin{array}{c}1.00 \\
(-0.00)\end{array}$ \\
\hline $\begin{array}{l}\text { Fault*Target* } \\
\text { Strength }\end{array}$ & $\begin{array}{c}0.22 \\
(0.29)\end{array}$ & $\begin{array}{l}1.40 * * \\
(2.05)\end{array}$ & $\begin{array}{c}0.92 \\
(-0.07)\end{array}$ & $\begin{array}{l}-0.17 \\
(-0.14)\end{array}$ \\
\hline Gender & $\begin{array}{c}-0.61 * * * \\
(-3.02)\end{array}$ & $\begin{array}{c}-0.30 * * \\
(-1.74)\end{array}$ & $\begin{array}{c}0.84 \\
(-0.56)\end{array}$ & $\begin{array}{l}1.11 \\
(0.36)\end{array}$ \\
\hline $\begin{array}{l}\text { Collateral } \\
\text { Consequences }\end{array}$ & $\begin{array}{l}0.16^{*} \\
(1.62)\end{array}$ & $\begin{array}{l}0.13 * \\
(1.47)\end{array}$ & $\begin{array}{l}0.70 * * \\
(-2.16)\end{array}$ & $\begin{array}{c}0.51 * * * \\
(-4.14)\end{array}$ \\
\hline Case & $\begin{array}{l}-0.13 \\
(-0.65)\end{array}$ & $\begin{array}{c}0.03 \\
(0.19)\end{array}$ & $\begin{array}{c}3.14 * * * \\
(3.56)\end{array}$ & $\begin{array}{c}4.92 * * * \\
(5.12)\end{array}$ \\
\hline \multirow{2}{*}{$\begin{array}{c}\text { n } \\
\text { Adj. / Pseudo R- } \\
\text { Square }\end{array}$} & 231 & 249 & 231 & 249 \\
\hline & 0.130 & 0.126 & 0.097 & 0.145 \\
\hline
\end{tabular}


Panel C: Dependent Variable (Compliance), by Triad Partition

Coefficient

(z-score)

Comply Level Comply Level

High Triad Low Triad

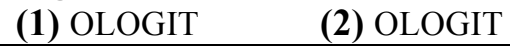

\begin{tabular}{|c|c|c|}
\hline Perceived Costs & $\begin{array}{c}1.64 * * * \\
(4.65)\end{array}$ & $\begin{array}{c}1.09 \\
(0.77)\end{array}$ \\
\hline Ethical Frame & $\begin{array}{c}6.52 * * * \\
(5.46)\end{array}$ & $\begin{array}{c}3.33 * * * \\
(3.89)\end{array}$ \\
\hline Fault & $\begin{array}{c}0.68 \\
(-0.70)\end{array}$ & $\begin{array}{l}1.30 \\
(0.45)\end{array}$ \\
\hline Strength & $\begin{array}{l}1.29 \\
(0.41)\end{array}$ & $\begin{array}{l}1.44 \\
(0.59)\end{array}$ \\
\hline Target & $\begin{array}{c}0.47 \\
(-1.20)\end{array}$ & $\begin{array}{l}1.22 \\
(0.34)\end{array}$ \\
\hline Target*Fault & $\begin{array}{l}2.98^{*} \\
(1.33)\end{array}$ & $\begin{array}{l}1.18 \\
(0.21)\end{array}$ \\
\hline Target*Strength & $\begin{array}{c}0.94 \\
(-0.07)\end{array}$ & $\begin{array}{c}0.84 \\
(-0.21)\end{array}$ \\
\hline Fault*Strength & $\begin{array}{c}0.89 \\
(-0.15)\end{array}$ & $\begin{array}{c}0.81 \\
(-0.25)\end{array}$ \\
\hline $\begin{array}{l}\text { Fault*Target* } \\
\text { Strength }\end{array}$ & $\begin{array}{l}1.46 \\
(0.33)\end{array}$ & $\begin{array}{l}1.10 \\
(0.08)\end{array}$ \\
\hline Gender & $\begin{array}{l}1.10 \\
(0.32)\end{array}$ & $\begin{array}{c}1.03 \\
(0.11)\end{array}$ \\
\hline $\begin{array}{l}\text { Collateral } \\
\text { Consequences }\end{array}$ & $\begin{array}{l}0.75 * * \\
(-1.89)\end{array}$ & $\begin{array}{c}0.62 * * * \\
(-2.84)\end{array}$ \\
\hline Case & $\begin{array}{c}2.95^{* * *} \\
(3.50)\end{array}$ & $\begin{array}{c}6.41 * * * \\
(5.65)\end{array}$ \\
\hline $\mathbf{n}$ & 231 & 249 \\
\hline Pseudo R-Square & 0.204 & 0.208 \\
\hline
\end{tabular}

$* * *, * *, *-$ indicates statistical significance at the $.01, .05$, and .10 levels, respectively

TRIAD partitions sample based on their averaged and standardized score to 3 psychometric scales, as described in Section V. HIGH TRIAD contains participants with above-median dark triad scores; LOW TRIAD contains participants with below-median dark triad scores. FAULT is a dichotomous variable set to 1 for participants in assigned fault conditions, 0 for participants in no-fault conditions. TARGET is a dichotomous variable set to 1 for participants in manager-targeted sanction conditions, or 0 for participants in firm-targeted sanction conditions. STRENGTH is a dichotomous variable set to 1 for participants in conditions where the risk-weighted settlement financial penalties 
exceed the financial gains of violation (in increased bonus pay), 0 when otherwise. ETHICAL FRAME is a dichotomous variable set to 1 when participants indicate the case choice is an ethical choice, 0 otherwise. PERCEIVED COST is the average of participants' responses to two 7-pt Likert questions reflecting agreement that overall costs for the firm (1) and manager (2) are high. TOTAL COMPLY is a dichotomous variable set to 1 if the participant selected either minimal or full compliance, 0 otherwise. COMPLY LEVEL is an ordinal variable set to 0 for participants who do not comply with regulations, 1 for participants who select minimal compliance, and 2 for participants who select full compliance. GENDER is a dichotomous variable set to 0 when participants self-report their gender as female, 1 when participants self-report their gender as male. COLLATERAL CONSEQUENCES is the average of participants' decision weights assigned to two possible decision factors: a) possibility of subsequent litigation, b) possibility of job loss. CASE is an indicator variable set to 1 for participants who completed the financial scenario.

Panel C Model 1 perceived costs $z$-score: 4.65, $p$-value: $<0.01$; target*fault $z$-score: 1.33 , p-value: 0.18) but not among low triads (Table 6, Panel B Model 4 perceived costs $z$ score: $0.77, p$-value: 0.44 ; target*fault $z$-score: $0.21, p$-value: 0.84$)$. These findings are consistent with the observed effects of sanction attributes (e.g., fault, sanction strength, sanction target) being more pronounced in the high triad subsample than the low triad subsample.

\section{Cost Source and Compliance Level}

Although much of the policy debate regarding sanction strength focuses on the magnitude of financial penalties imposed in sanctions, sociology and criminology research suggests that social motivations are at least as important in motivating compliance (Pratt \& Cullen 2005). I therefore decompose managers' cost perceptions into their economic and social cost bases, investigating whether the source of managers' cost perceptions (economic versus social) are differently associated managers' compliance frequency and compliance level. In Table 7 I employ logistic regressions of managers' minimal compliance (Table 8, Model 1), full compliance (Table 7, Model 2), total compliance (Table 7, Model 3), and compliance level (Table 7, Model 4 - ordered logistic) as the primary dependent variable. Models are specified as in Table 5, Panel B, with managers' perceived costs and ethical frame as mediating variables in regressions that include controls for manipulated variables and their interactions and for gender, collateral 
consequences and case. However, in the present analysis I replace managers' perceived costs with two variables, reflecting managers' perceived economic costs, and perceived social costs (see Section III, Manipulation Check for exact language).

I observe that the coefficient on perceived economic costs is positively and statistically significantly related to minimal compliance (z-score: $2.66, p$-value: 0.01$)$ and total compliance (z-score: $2.52, p$-value: 0.01 ), but negatively related to full compliance (z-score: -1.31, p-value: 0.19), and not related to compliance level ( $z$-score: $-0.17, p$-value: 0.86). This suggests that managers' perceptions of economic costs may increase overall compliance, but does so in part by reducing the prevalence of high quality compliance. I observe that the coefficient on perceived social costs is positive and statistically significantly related to full compliance (z-score: $3.95, p$-value: $<0.01)$, total compliance $(z$ score: 2.38 , $p$-value: 0.02 ), and compliance level ( $z$-score: 4.89, $p$-value: $<0.01)$. However, perceived social costs are negatively and statistically significantly related to minimal compliance (z-score: $-2.29, p$-value: 0.02$)$. This is consistent with a positive association between perceived social costs and both the frequency and the quality of compliance.

\section{Pairwise Comparisons of Regulatory Regimes}

Regulators may be constrained in their ability to advocate for changes to existing regulatory regimes because regimes are path dependent with institutional changes requiring advocacy, political capital, and career risk. Consequently, regulators may be interested in better understanding which 'regulatory lever(s)' is/are most likely to yield increases in compliance for any given initial regulatory state. In Table 8, I report the results of pairwise comparisons of regulatory regimes that differ by one attribute, to 
TABLE 7: SUPPLEMENTAL ANALYSIS: SOURCE OF PERCEIVED COSTS

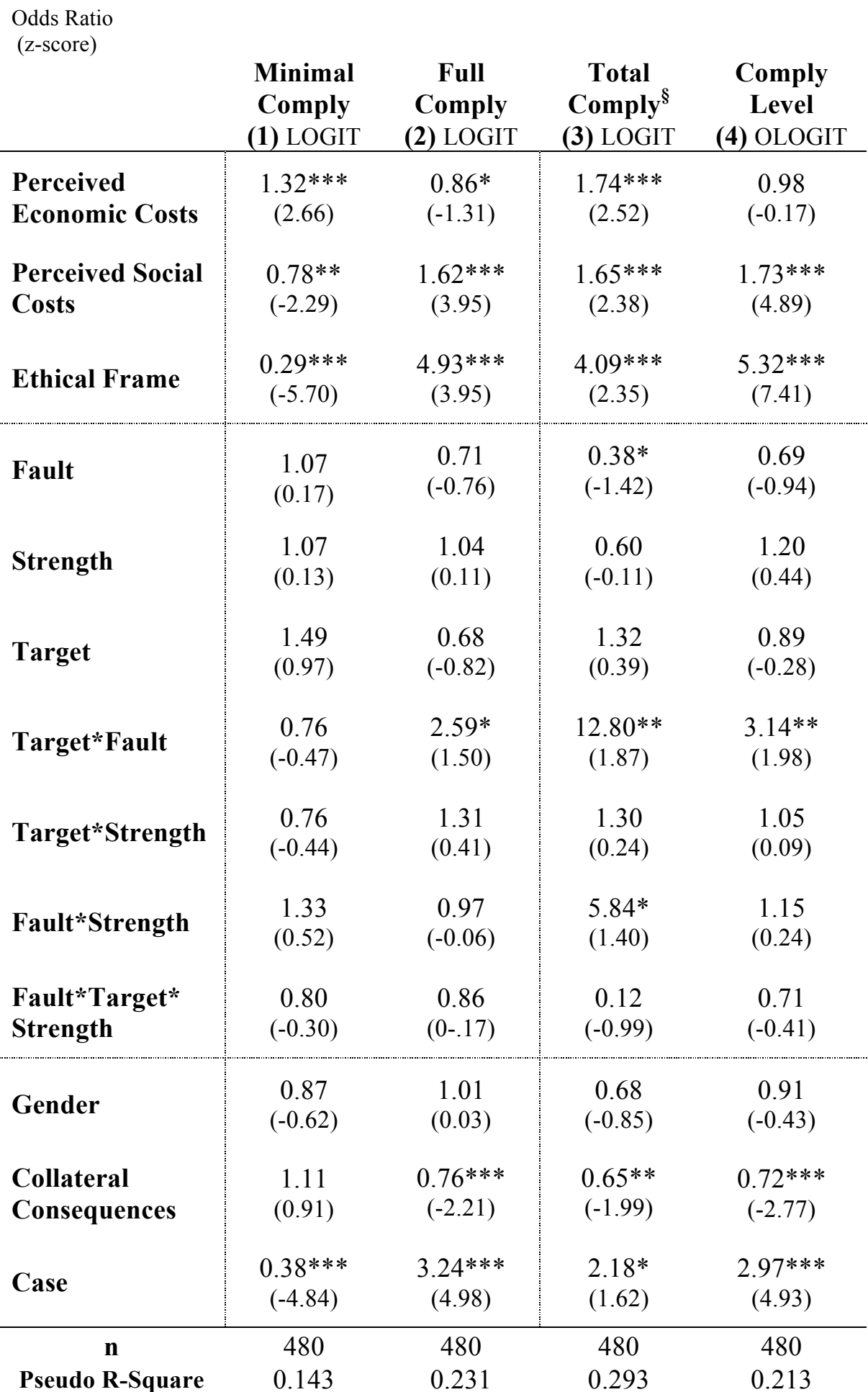

***, **, * - indicates statistical significance at the 0.01, 0.05, and 0.10, levels, respectively

PERCEIVED ECONOMIC COSTS is the average of participants' responses to two 7-pt Likert questions reflecting agreement that accepting a settlement could damage the finances of the firm (1) and manager (2). PERCEIVED 
SOCIAL COSTS is the average of participants' responses to two 7-pt Likert questions reflecting agreement that accepting a settlement could damage the reputation and relationships of the firm (1) and manager (2). ETHICAL FRAME is a dichotomous variable set to 1 when participants indicate the case choice is an ethical choice, 0 otherwise. MINIMAL COMPLIANCE is a dichotomous variable set to 1 when participants select either minimal disclosure, 0 when participants select no disclosure. FULL COMPLIANCE is a dichotomous variable set to 1 when participants select full disclosure, 0 when participants select either minimal or no disclosure. TOTAL COMPLY is a dichotomous variable set to 1 if the participant selected either minimal or full compliance, 0 otherwise. COMPLY LEVEL is an ordinal variable set to 0 for participants who do not comply with regulations, 1 for participants who select minimal compliance, and 2 for participants who select full compliance. FAULT is a dichotomous variable set to 1 for participants in assigned fault conditions, 0 for participants in no-fault conditions. TARGET is a dichotomous variable set to 1 for participants in manager-targeted sanction conditions, or 0 for participants in firm-targeted sanction conditions. STRENGTH is a dichotomous variable set to 1 for participants in conditions where the risk-weighted settlement financial penalties exceed the financial gains of violation (in increased bonus pay), 0 when otherwise. GENDER is a dichotomous variable set to 0 when participants self-report their gender as female, 1 when participants self-report their gender as male. COLLATERAL CONSEQUENCES is the average of participants' decision weights assigned to two possible decision factors: a) possibility of subsequent litigation, b) possibility of job loss. CASE is an indicator variable set to 1 for participants who completed the financial scenario.

$\S$ - Managers in manager-targeted, assigned-fault conditions demonstrate 100\% compliance. To facilitate data analysis, bootstrapping is conducted where observations were randomly assigned non-compliance. 2 observations were assigned non-compliance per iteration, 1 weak-sanction, manager-targeted, assigned fault observation and 1 strongsanction, manager-targeted, assigned-fault observation.

simulate the potential benefits of pulling single 'regulatory levers' for initial regulatory states.

I observe that adding fault to manager-targeted regimes increases managers' cost perceptions in the presence of strong sanctions ( $t$-stat: $2.17, p$-value: 0.02$)$ and increases managers' ethical frames for both weak and strong sanctions (weak sanctions $z$-score: 2.04, $p$-value: 0.02 ; strong sanctions $z$-score: $1.90, p$-value: 0.06$)$. This results in greater in greater compliance level in both conditions (weak sanctions $z$-score: $2.17, p$-value: 0.02; strong sanctions $z$-score: $2.06, p$-value: 0.02 ), and greater compliance frequency in both strong and weak sanction conditions (weak sanctions $z$-score: 1.53, p-value: 0.06; strong sanctions $z$-score: $1.26, p$-value: 0.10$)$. This is consistent with fault yielding incremental benefits to compliance in regimes that primarily target managers. I also observe that increasing the strength of sanctions in firm-targeted regimes increases managers' cost perceptions in the presence of both fault and no-fault sanctions 


\section{TABLE 8: SUPPLEMENTAL ANALYSIS: PAIRWISE COMPARISONS}

Coefficient - Compliance Level

[ Coefficient - Compliance Frequency ]

\begin{tabular}{|c|c|c|c|}
\hline & Add Fault & $\begin{array}{l}\text { Increase } \\
\text { Strength }\end{array}$ & $\begin{array}{c}\text { Target } \\
\text { Manager }\end{array}$ \\
\hline No-Fault, Weak, Firm-Targeted & $\begin{array}{l}-0.02^{\S} \\
{[0.09]}\end{array}$ & $\begin{array}{c}0.22^{\S} \\
{\left[\mathbf{1 . 1 3}{ }^{*+*}\right]}\end{array}$ & $\begin{array}{c}-0.11^{\S} \\
{[0.60]}\end{array}$ \\
\hline No-Fault, Weak, Manager-Targeted & $\begin{array}{l}0.83^{* *} \star \\
{\left[1.72^{*}\right]}\end{array}$ & $\begin{array}{c}0.12 \\
{[0.15]}\end{array}$ & \\
\hline No-Fault, Strong, Firm-Targeted & $\begin{array}{l}-0.14 \S \\
{[0.19]}\end{array}$ & & $\begin{array}{c}-0.28^{\S} \\
{[-0.52]}\end{array}$ \\
\hline No-Fault, Strong, Manager-Targeted & $\begin{array}{c}0.82^{* *} \S \star \\
{\left[1.46^{*}\right]}\end{array}$ & & \\
\hline Fault, Weak, Firm-Targeted & & $\begin{array}{c}0.15^{\S} \\
{[\mathbf{1 . 3 6}]}\end{array}$ & $\begin{array}{c}0.62^{* \S} \\
{\left[2.17^{* *}\right]}\end{array}$ \\
\hline Fault, Weak, Manager-Targeted & & $\begin{array}{c}0.08^{\S} \\
{\left[\mathrm{n} / \mathrm{a}^{\mathrm{f}}\right]}\end{array}$ & \\
\hline Fault, Strong, Firm-Targeted & & & $\begin{array}{l}\mathbf{0 . 6 0} \mathbf{0}^{*} \\
{[1.06]}\end{array}$ \\
\hline Fault, Strong, Manager-Targeted & & & \\
\hline
\end{tabular}

\footnotetext{
***, **, * - indicates statistical significance at the 0.01, 0.05, and 0.10 , levels, respectively

$\S_{-}$- indicates managers' cost perceptions significantly greater at $p<0.10$ level

* - indicates managers' ethical frames significantly greater at $p<0.10$ level

- indicates managers' ethical frames significantly lower at $p<0.10$ level

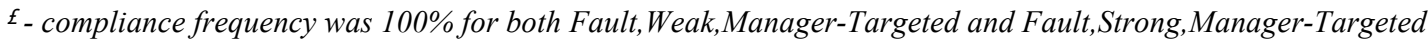
conditions
}

Conditions are as described above. FAULT is a dichotomous variable set to 1 for participants in assigned fault conditions, 0 for participants in no-fault conditions. TARGET is a dichotomous variable set to 1 for participants in manager-targeted sanction conditions, or 0 for participants in firm-targeted sanction conditions. STRENGTH is a dichotomous variable set to 1 for participants in conditions where the risk-weighted settlement financial penalties exceed the financial gains of violation (in increased bonus pay), 0 when otherwise. TOTAL COMPLY is a dichotomous variable set to 1 if the participant selected either minimal or full compliance, 0 otherwise. COMPLY LEVEL is an ordinal variable set to 0 for participants who do not comply with regulations, 1 for participants who select minimal compliance, and 2 for participants who select full compliance.

Each cell represents the incremental benefit in increased compliance frequency 'TOTAL COMPLY' or compliance quality 'COMPLY LEVEL' that is gained from adding the sanction attribute indicated in the top row.

(assigned-fault $t$-stat: 2.17, $p$-value: 0.02 ; no-fault $t$-stat: $3.80, p$-value: $<0.01$ ). However, increasing the strength of firm-targeted sanctions does not influence the prevalence of 
managers' ethical frames in a statistically significant manner (assigned-fault $z$-score: $0.66, p$-value: 0.27 ; no-fault $z$-score: $-1.20, p$-value: 0.12$)$. Nevertheless, increasing the strength of firm-targeted sanctions results in greater compliance frequencies (assignedfault $z$-score: $1.59, p$-value: 0.06 ; no-fault $z$-score: $1.53, p$-value: 0.07$)$, but does not result in greater compliance level (assigned-fault $z$-score: 0.38, $p$-value: 0.35; no-fault $z$-score: $0.56, p$-value: 0.28$)$. This is consistent with increased sanction strength yielding incremental benefits to compliance in regimes that primarily target firms.

\section{Private Fault}

Lastly, I investigate which portion of managers' compliance is attributable to fault assignment per se, in the absence of public disclosure. I employ a condition with weak manager-target sanctions where investigations and settlements are described as being private in nature. Research suggests that social concerns are generally heightened when social signals are made public, but persist also when kept private (Tafkov 2012, Smith et al. 2002). This corresponds with notions of guilt, a loss of self-respect versus shame, reflecting a loss of respect in the eyes of others (Smith et al. 2002, Grasmick \& Bursik 1990, Williams \& Hawkins 1989).

In Table 9, I examine the relationship between private fault and managers' ethical decision frames and compliance in four comparisons. I first examine if fault and/or private investigations influence the primary mediating variables, perceived costs (Table 9 , Model 1) and ethical frame (Table 9, Model 2). In an OLS regression with managers' perceived costs as the primary dependent variable, indicator variables for fault and private enforcement, and controls for gender, collateral consequences and case as discussed in Section IV, I find no statistically significant relationship of fault assignment or the 
TABLE 9: SUPPLEMENTAL ANALYSIS - PRIVATE FAULT

Coefficient (OLS) or Odds Ratio (Logistic and Ordered Logistic)

(t-stat and z-score)

\begin{tabular}{cccc}
$\begin{array}{c}\text { Perceived } \\
\text { Costs }\end{array}$ & $\begin{array}{c}\text { Ethical } \\
\text { Frame }\end{array}$ & $\begin{array}{c}\text { Comply } \\
\text { Level }\end{array}$ & $\begin{array}{c}\text { Comply } \\
\text { Level }\end{array}$ \\
(1) OLS & (2) LOGIT & (3) OLOGIT & (4) OLOGIT \\
\hline
\end{tabular}

\begin{tabular}{|c|c|c|c|c|}
\hline \multicolumn{3}{|l|}{ Perceived Costs } & & \multirow{2}{*}{$\begin{array}{c}1.32 * * \\
(2.04) \\
4.88 * * * \\
(4.37)\end{array}$} \\
\hline Ethical Frame & & & & \\
\hline Fault & $\begin{array}{l}-0.02 \\
(-0.08)\end{array}$ & $\begin{array}{c}2.35^{* *} \\
(2.11)\end{array}$ & $\begin{array}{c}2.24 * * \\
(2.10)\end{array}$ & $\begin{array}{l}1.90^{*} \\
(1.57)\end{array}$ \\
\hline Private & $\begin{array}{c}0.30 \\
(1.25)\end{array}$ & $\begin{array}{c}0.83 \\
(-0.45)\end{array}$ & $\begin{array}{l}0.57^{*} \\
(-1.46)\end{array}$ & $\begin{array}{l}0.52^{*} \\
(-1.60)\end{array}$ \\
\hline Gender & $\begin{array}{c}-0.76 * * * \\
(-3.88)\end{array}$ & $\begin{array}{c}0.75 \\
(-0.88)\end{array}$ & $\begin{array}{l}1.03 \\
(0.10)\end{array}$ & $\begin{array}{l}1.41 \\
(0.97)\end{array}$ \\
\hline $\begin{array}{l}\text { Collateral } \\
\text { Consequences }\end{array}$ & $\begin{array}{c}0.08 \\
(0.84)\end{array}$ & $\begin{array}{c}0.64 * * * \\
(-2.54)\end{array}$ & $\begin{array}{l}0.72 * * \\
(-2.05)\end{array}$ & $\begin{array}{l}0.79^{*} \\
(-1.37)\end{array}$ \\
\hline Case & $\begin{array}{c}-0.46 * * * \\
(-2.37)\end{array}$ & $\begin{array}{c}3.97 * * * \\
(4.11)\end{array}$ & $\begin{array}{c}3.42 * * * \\
(3.81)\end{array}$ & $\begin{array}{c}2.77 * * * \\
(2.87)\end{array}$ \\
\hline $\mathbf{n}$ & 177 & 177 & 177 & 177 \\
\hline $\begin{array}{l}\text { Adj. / Pseudo R- } \\
\text { Square }\end{array}$ & 0.088 & 0.129 & 0.087 & 0.168 \\
\hline
\end{tabular}

NOTE: EMPLOYS ONLY MANAGER-TARGETED, WEAK SANCTIONS, WITH ASCRIBED FAULT.

$* * *, * *, *$ - indicates statistical significance at the $0.01,0.05$, and 0.10 levels, respectively

FAULT is a dichotomous variable set to 1 when participants' case indicates that settlements offered to violators require admission of fault, 0 when the case indicates that violators are neither permitted to admit nor deny fault in the settlement. PRIVATE is a dichotomous variable set to 1 when participants' case indicates that settlements are privately recorded, known only by the regulator, 0 when the settlement (including any admission of fault) is described as being part of the public record, in a publicly searchable database. MINIMAL COMPLY is a dichotomous variable set to 1 when participants select either minimal or full disclosure, 0 when participants select no disclosure. FULL COMPLY is a dichotomous variable set to 1 when participants select full disclosure, 0 when participants select either minimal or no disclosure. PERCEIVED COSTS is the average of participants' responses to two 7-pt Likert questions reflecting agreement that overall costs for the firm (1) and manager (2) are high. ETHICAL FRAME is a dichotomous variable set to 1 when participants indicate the case choice is an ethical choice. ETHICAL FRAME is a dichotomous variable set to 1 when participants indicate that their case choice is primarily an ethical choice, 0 otherwise. CASE is an indicator variable set to 1 for participants who completed the financial scenario.

public/private disclosure of enforcement to managers' perceived costs (fault $t$-stat: -0.08 , $p$-value 0.93 ; private assignment $t$-stat: $1.25, p$-value 0.21$)$. In a logistic regression with 
managers' ethical decision frame as the primary dependent variable, I find that fault assignment is positively and significantly associated with ethical decision frames (z-score: 2.11, $p$-value 0.04$)$, but my indicator for privately assigned fault does not load ( $z$-score: $0.45, p$-value 0.65$)$. This is consistent with fault assignment functioning as a social penalty even when privately assigned, because fault is associated with guilt, a self-mediated social penalty (Smith et al. 2002, Grasmick \& Bursik 1990, Williams \& Hawkins 1989).

However, in ordered logistic regressions with compliance level as the primary dependent variable (Model 3 and Model 4, without and with mediators respectively), I observe that the positive effects of fault assignment (without mediators, odds-ratio: 2.24; with mediators, odds-ratio: 1.90) are approximately offset by the negative effects of private enforcement (without mediators, odds-ratio: 0.57; with mediators, odds-ratio:

0.52). This suggests that the increased ethical perceptions facilitated by fault may be less likely to translate into increased compliance without public records of enforcement.

\section{CONCLUSION, LIMITATIONS, \& FUTURE RESEARCH}

In this study, I report the results of an experiment where individuals face a costly compliance choice in the presence of sanctions that may either be strong or weak, may target managers or firms, and may also include fault assignment. This study observes that individuals faced with fault assignment in manager-targeted sanctions are more likely to perceive their compliance as an ethical dilemma and consequently comply more frequently and at a higher level than managers faced with no-fault sanctions. Thus, fault conditionally demonstrates a relationship to managers' compliance and ethical perceptions, and - ultimately - to their compliance. 
These findings compliment recent research investigating the complex interactions effects of sanctioning systems with compliance (Tayler \& Bloomfield 2011, Gneezy \& Rustichini 2000, Tenbrunsel \& Messick 1999). While several studies find that sanctions crowd-out cooperation and social concerns, my findings suggest that fault fosters ethical decision frames in the presence of sanctions. One interpretation of my evidence is that sanctions may include both economic and social dimensions, with social sanctions such as fault tending to reinforce ethical decision frames. Prior studies that examined the effects of economic sanctions typically did so in the absence of social sanctions (Tayler \& Bloomfield 2011, Gneezy \& Rustichini 2000, Tenbrunsel \& Messick 1999), which may be operative in many compliance decisions. Lastly, my study also allows for participants to exceed minimal levels of compliance, finding that the compliance associated with economic decision frames differs from the compliance associated with ethical decision frames. This contributes to discussions of compliance and discussing 'letter of the law' compliance.

This study is subject to several limitations meriting discussion. Because I employ experimental methods, I am able to test for directions of effects but am unable to estimate the sanction levels that would be appropriate for use in practice (e.g. the sanction level that would offset decreases in voluntary compliance caused by removing fault). Likewise, because participants in my study make compliance choices without putting actual economic resources at risk, my study is limited in its ability to inform the potential consequences of policies that do impose actual economic consequences. Additionally, the reputation concerns elicited from a case that is completed individually via computer may differ from the concerns evoked in a natural setting, where managers interact with many 
others, across many groups. Lastly, this study tests individuals' compliance with disclosure regulations in stylized scenarios. While the study does capture essential elements of the choice, it is undoubtedly less rich than the decision setting that individuals might actually face.

Future research may extend my findings in several important ways. First, future research may add to insights yielded from my supplemental analysis suggesting that sanction attributes such as fault are more effective at influencing the social perceptions and compliance of individuals who are high in 'dark triad' personality traits. Future research may further investigate whether high triad individuals perceive costs differently than low triad individuals, for instance - by reacting less severely to small penalties; and, future research may further investigate whether high triads' ethical framing is reacting more to ego threats evoked by the reputation stigma of the fault label, or to the threat of social consequences stemming from isolation and relationship loss. Additionally, results in my managerial scenario include a minority of managers who choose 'costly noncompliance' consistent with intentional 'narrow misses' compliance thresholds by incurring virtually all of the costs of compliance but deliberately falling short of the enforced threshold. This behavior is interesting and important to understanding the full spectrum of compliance. In particular, intentional 'narrow misses' appear to be probing the boundary of ethically defensible actions, while also attempting to extracting benefits from non-compliance. It would be beneficial to better understand what structural and person factors contribute to and/or this probing behavior. Copyright (C) Matt Sooy 2016 


\section{APPENDIX A: EXPERIMENT INSTRUMENT}

\section{Panel A: Managerial Scenario}

\section{Background}

In this scenario, you will assume the role of a plant manager who supervises a moderate-sized manufacturing plant. Like other manufacturers in this industry, you are faced with the problem of dealing with a toxic gas (VS-1) that is created as a by-product of the manufacturing process.

Environmentalists have become increasingly concerned about the problem and have proposed that all of your plant's smokestacks be equipped with 'scrubbers' that would completely eliminate the toxic gas if they operated $100 \%$ of the time.

The scrubbers are relatively expensive, which would reduce plant profit and - accordingly - both a) your division's performance, relative to others and b) your performance-based bonus compensation. The choice of if and how much to run the scrubbers is solely your responsibility.

\section{Regulatory Environment}

Environmentalists have recently threatened to lobby for increased legislation that would require manufacturers to purchase and run the scrubbers $100 \%$ of the time, and would additionally require manufacturers to comply with strict regulatory reporting requirements. Running the scrubbers $100 \%$ of the time would cost about $\$ 1.5 \mathrm{M}$ annually, and the costs of complying with additional regulatory oversight would be about $\$ 3.0 \mathrm{M}$.

With the potential threat of the environmentalists lobbying for increased legislation, all of the manufacturers in the industry have come together and reached an agreement in which all manufacturers would install scrubbers and run them $80 \%$ of the time. This solution is acceptable to the environmentalists because it eliminates all of the major health and environmental safety concerns. It is desirable from the manufacturers' standpoint because it avoids increased legislation and the costs of associated compliance.

If most (at least $80 \%$ ) of the manufacturers in the industry comply with agreement, the environmentalists will be satisfied with the solution. However, if fewer than $80 \%$ of the manufacturers in the industry comply with the agreement, then environmentalists will revive the increased legislation and you (and the other manufacturers) will be forced to incur compliance costs.

[MANAGER WEAK FAULT] Enforcement of the agreement is limited because regulators have limited resources. Regulators conduct random checks of about $5 \%$ of manufacturing plants each year. Regulators open investigations of plant managers (e.g. you) they suspect of violations. Investigated plant managers may ultimately be proven innocent, but most investigated managers choose to settle cases - to avoid a long and costly legal defense. Settlements entail a small fine of around $\$ 50,000$ payable by the manager, who must also admit fault in the matter. Settlements do not carry criminal consequences. Investigations and their outcomes (including settlements) are recorded in a publicly accessible database.

[FIRM STRONG NO-FAULT] Enforcement of the agreement is strong because regulators have many resources. Regulators conduct random checks of about $80 \%$ of manufacturing plants each year. Regulators open investigations of firms they suspect of violations. Investigated firms may ultimately be proven innocent, but most investigated firms choose to settle cases - to avoid a long and costly legal defense. Settlements entail a large fine of around $\$ 2,000,000$ payable by the firm, which neither admits nor denies fault in the matter. Settlements do not carry criminal 
consequences. Investigations and their outcomes (including settlements) are recorded in a publicly accessible database.

Knowledge Check 1 of 8 : What is your role in the case?

O Dropdown options: Plant Manager, Regulator, Unclear or not stated in the case

Knowledge Check 2 of 8 : What $\%$ of the time must your plant run its pollution control equipment ('scrubbers') to fully eliminate the toxic gas (VS-1) it generates in the manufacturing process?

O Dropdown options: $0 \%, 20 \%, 40 \%, 60 \%, 80 \%, \underline{\mathbf{1 0 0} \%}$, Unclear or not stated in case

Knowledge Check 3 of 8: How much would it cost your plant to run the pollution control scrubbers $100 \%$ of the time?

O Dropdown options: $\$ 0, \$ 50,000, \$ 500,000, \$ 1,000,000, \mathbf{\$ 1 , 5 0 0 , 0 0 0}, \$ 2,000,000, \$ 2,500,000$, $\$ 3,000,000$, Unclear or not stated in case

Knowledge Check 4 of 8 : What \% of manufacturers must comply with the agreement to avoid increased legislation?

Dropdown options: $0 \%, 20 \%, 40 \%, 60 \%, \mathbf{8 0 \%}, 100 \%$, Unclear or not stated in the case

Knowledge Check 5 of 8 : What $\%$ of manufacturing plants do regulators randomly check each year?

O Dropdown options: $0 \%, \underline{\mathbf{5} \%}, 10 \%, 15 \%, 20 \%, 25 \%, 30 \%, 35 \%, 40 \%, 45 \%, \underline{\mathbf{5 0} \%+}$

Knowledge Check 6 of 8: If you accepted a settlement with regulators, what is the fine associated with the settlement?

O Dropdown options: $\$ 0$ (No Fine), $\$ \mathbf{5 0 , 0 0 0}, \$ 250,000, \$ 500,000, \$ 1,000,000, \$ 1,500,000$, \$2,000,000, $\$ 2,500,000, \$ 3,000,000$

Knowledge Check 7 of 8: If you accepted a settlement with regulators, who would pay the settlement fine?

Dropdown options: You (the manager), Your firm, Unknown or not stated in the case

Knowledge Check 8 of 8 : If you accepted a settlement with regulators, would you be required to admit fault in the matter?

O Dropdown options: Yes, No, Unclear or not stated in the case

\section{Case - (continued)}

You are trying to decide how much you should run the pollution control scrubbers. You estimate that: The scrubbers cost $\$ 0.3 \mathrm{M}$ for every increment of $20 \%$ of the time that they are run $(\$ 0.3 \mathrm{M}$ for $20 \%, \$ 0.6 \mathrm{M}$ for $40 \%, \$ 0.9 \mathrm{M}$ for $60 \%$, etc. (See table below).

Other manufacturers are also making the same choice - they are choosing what percentage of total time that they should operate their own scrubbers.

As noted previously, your perception is that if most of the other manufacturers in your industry abide by the agreement then you do not expect increased legislation or increased compliance costs 
(\$3.0M per year); but if most other manufacturers do not abide by the agreement, then you do expect increased legislation.

TABLE: Pollution Control Scrubber Costs

\begin{tabular}{ccccc|c}
$\begin{array}{c}\text { Ammount of } \\
\text { Time You } \\
\text { Operate } \\
\text { Scrubbers }\end{array}$ & $\begin{array}{c}\text { Increased } \\
\text { Legislation }\end{array}$ & $\begin{array}{c}\text { Operating } \\
\text { Costs }\end{array}$ & $\begin{array}{c}\text { Compliance } \\
\text { Costs }\end{array}$ & Total Costs \\
\hline Cyyyy & No & $\begin{array}{c}\$ 1.2 \mathrm{M}-\$ 1.5 \mathrm{M} \\
(80 \%-100 \% \text { operation })\end{array}$ & $\$ 0$ & $\$ 1.2 \mathrm{M}-\$ 1.5 \mathrm{M}$ \\
\hline Less than $80 \%$ & No & $\begin{array}{c}\$ 0.0 \mathrm{M}-\$ 1.2 \mathrm{M} \\
(0 \%-80 \% \text { operation })\end{array}$ & $\$ 0$ & $\$ 0.0 \mathrm{M}-\$ 1.2 \mathrm{M}$ \\
\hline $80 \%$ or more & Yes & $\begin{array}{c}\$ 1.2 \mathrm{M}-\$ 1.5 \mathrm{M} \\
(80 \%-100 \% \text { operation })\end{array}$ & $\$ 3 \mathrm{M}$ & $\$ 4.2 \mathrm{M}-\$ 4.5 \mathrm{M}$ \\
\hline Less than $80 \%$ & Yes & $\begin{array}{c}\$ 0.0 \mathrm{M}-\$ 1.2 \mathrm{M} \\
(0 \%-80 \% \text { operation })\end{array}$ & $\$ 3 \mathrm{M}$ & $\$ 3.0-\$ 4.2 \mathrm{M}$ \\
\hline
\end{tabular}

Please indicate what choices you would make as plant manager:

Slider bar: What percent (\%) of the time would you operate the pollution control scrubbers? $(0 \%$ / $\$ 0$ vs. $100 \% / \$ 1.5 \mathrm{M})$

In a few sentences, explain the basis for your pollution control scrubber decision (why did you make the decision that you did)? (Text Input)

Your decision in the scenario is best described as:

O Dropdown options (random ordering): A Personal Decision, An Ethical Decision, A Business Decision, An Environmental Decision, A Legal Decision

What $\%$ of other plant managers would operate the scrubbers at least $80 \%$ of the time?

O Dropdown options: $0 \%$ (all other managers would violate the agreement), 5\%, 10\%, 15\%, $20 \%, 25 \%, 30 \%, 35 \%, 40 \%, 45 \%, 50 \%, 55 \%, 60 \%, 65 \%, 70 \%, 75 \%, 80 \%, 85 \%, 90 \%, 95 \%$, $100 \%$ (all other managers would comply with the agreement)

How much environmental damage will be caused if the scrubbers were operated less than $80 \%$ of the time?

Dropdown options: None, A little, A moderate amount, A large amount, Do not know, Does not matter

Slider bar: What is the plant manager's responsibility? (to run the plant profitability vs. to protect the environment)

Please allocate 100 points among the following 11 factors based on how important different factors were in your case choice. Please allocate points based on the factors you actually 
considered in your decision-making. (Note: to facilitate ease of use, respondents not constrained to 100 points)

Slider Options, randomly ordered: Probability of being caught, Magnitude of fines, Your plant's profit, The possibility that other manufacturers might/might not comply, What was 'the right thing to do', What complied with the law, What others might think (family, friends, colleagues, etc), My regret for harming others, Possibility of being sued if caught, Possibility that my career may be damaged, Possibility of getting fired

Please indicate your agreement with each of the following statements by selecting the option that most closely corresponds to your beliefs. (7pt Likert - Strongly Disagree / Strongly Agree)

Considering all of the possible risks and costs - the potential downside of violating pollution control regulations is high for you (the plant manager).

Considering all of the possible risks and costs - the potential downside of violating pollution control regulations is high for your firm.

Please indicate your agreement with each of the following statements by selecting the option that most closely corresponds to your beliefs. (7pt Likert - Strongly Disagree / Strongly Agree)

From your standpoint (the plant manager): If an investigation was launched and a settlement reached - the fine associated with accepting the settlement could damage your personal finances.

From your standpoint (the plant manager): If an investigation was launched and a settlement reached - your reputation and relationships would be damaged.

From your standpoint (the plant manager): If an investigation was launched and a settlement reached - you would think less of yourself.

From the standpoint of the firm: If an investigation was launched and a settlement reached - the fine associated with accepting the settlement could damage the firm's finances.

From the standpoint of the firm: If an investigation was launched and a settlement reached - the firm's reputation and relationships would be damaged.

Please indicate your agreement with each of the following statements by selecting the option that most closely corresponds to your beliefs. (7pt Likert - Strongly Disagree / Strongly Agree)

The likelihood of being caught violating environmental regulations is high

The consequences of violating environmental regulations are not my problem

The consequences of accepting a settlement are not my problem

If I accepted a settlement, people would think that I was guilty

Have you completed a similar case/survey by the same requester in the past week?

Dropdown options: Yes, No

Was anything unclear or missing from the case? (write below)

Do you have any other thoughts about the case or this HIT? 
The following questions are to confirm your retention of case facts. Please attempt to recall the case facts as much as possible. Your survey will not be held up or cancelled by incorrect answers.

Retention Check 1: What is your role in the case?

Dropdown options: Plant Manager, Regulator, Unclear or not stated in the case

Retention Check 2: What \% of the time must your plant run its pollution control equipment ('scrubbers') to fully eliminate the toxic gas (VS-1) it generates in the manufacturing process?

O Dropdown options: $0 \%, 20 \%, 40 \%, 60 \%, 80 \%, 100 \%$, Unclear or not stated in case

Retention Check 3: What \% of manufacturers must comply with the agreement to avoid increased legislation?

O Dropdown options: $0 \%, 20 \%, 40 \%, 60 \%, \underline{\mathbf{8 0} \%}, 100 \%$, Unclear or not stated in the case

Retention Check 4: What \% of manufacturing plants do regulators randomly check each year?

Dropdown options: $0 \%, \underline{\mathbf{5 \%}}, 10 \%, 15 \%, 20 \%, 25 \%, 30 \%, 35 \%, 40 \%, 45 \%, \underline{\mathbf{5 0} \%+}$

Retention Check 5: Which is greater - the settlement fine or the cost of running the scrubbers at least $80 \%$ of the time?

O Dropdown options: The settlement fine is greater, The cost of running the scrubbers is greater, The costs are equal, Unclear or not stated in the case

Retention Check 6: If you/your firm accepted a settlement with regulators, who would pay the settlement fine?

O Dropdown options: You (the manager), Your firm, Unknown or not stated in the case

Retention Check 7: If you/your firm accepted a settlement with regulators, would you be required to admit fault in the matter?

O Dropdown options: Yes, No, Unclear or not stated in the case 


\section{Panel B: Financial Case}

\section{Background}

In this scenario, you will assume the role of an underwriting manager in a financial services firm. Your group underwrites stock sales such as IPOs ('Initial Public Offerings') - when companies wish to issue stocks or bonds, they come to your group. Your group facilitates the issuance by finding investors for the IPO shares.

As compensation for underwriting an IPO, your group typically receives cash or stock that is increasing in the price that the IPO realizes - the higher the share price you achieve for your clients, the greater the revenue that your group receives. As group manager, you receive a salary and a profit-sharing bonus that depends on your group's performance. Thus, both your group's profit and your bonus depend on your ability to achieve higher IPO share prices for the securities that your group underwrites.

\section{The Investment Prospectus}

In a typical IPO, the underwriter (e.g. you) hires outside consultants to generate performance projections. The outside consultants compute performance projections based on the company's past performance. An important part of your job is to compile this information into a prospectus an investment report - that investors will rely on when deciding what price they are willing to pay per IPO share. And, you must identify investors who may be interested in the IPO (e.g. by sector, industry, region or other profile). Creating and updating the prospectus is the underwriter's sole responsibility.

Generally speaking, higher performance forecasts result in higher IPO share prices.

\section{Regulations}

There is a time lag of around 3 months between when the consultants complete their performance projections and when the IPO is first made available for sale. In some situations, circumstances may change at either the IPO firm and/or in the economy that leads the performance projections in the investment prospectus to become inaccurate / unreliable.

Because investors rely on these performance projections, regulations require that the investment prospectus be updated whenever the underwriter becomes aware that economic circumstances have changed. Because the investment prospectus is the underwriter's sole responsibility (no one else will update or is expected to update the information), updating the prospectus is solely the underwriter's responsibility.

Failing to update new circumstances / performance projections is considered 'misrepresentation' by regulators, a violation of securities regulations. This is because - without updating the projections - the investment prospectus (which investors use to decide on an appropriate price) forecasts higher performance than the underwriter knows to be true. When this happens, investors will experience losses when the share price eventually drops to its true value. Collectively, investor losses can easily total in the millions of dollars, or more.

Updated performance projections typically take one of two forms: either a 'full update' - which meets both the legal requirements and the intent of the regulations. Or, a 'minimal update' - which meets only the legal requirements outlined in the regulation, but is intentionally designed to be difficult for investors to fully comprehend (e.g. using fine print, 'legalese', etc.). With full updates, most investors appear to understand the updated information, leading the IPO price to fully reflect the new information. This lowers bonus compensation. Typically, many investors have trouble processing minimal updates, leading the IPO price to change in the expected direction, but in a smaller amount (it will not fully reflect the true information). 
[MANAGER WEAK FAULT] Enforcement of misrepresentation cases is limited because regulators have limited resources and cases of misrepresentation are difficult to prove. Regulators must prove that the underwriter (e.g. you) possessed, but did not update 'material new information.' Consequently, about $5 \%$ of IPO investment prospectuses are investigated. Regulators open investigations of underwriting managers they suspect of misrepresentation violations. Investigated underwriting managers may ultimately be proven innocent, but most investigated managers choose to settle cases - to avoid a long and costly legal

defense. Settlements entail a fine of around $\$ 25,000$ payable by the manager, who must also admit fault in the matter. Settlements do not carry criminal consequences. Investigations an their outcomes (including settlements) are recorded in a publicly accessible database.

[FIRM STRONG NO-FAULT] Enforcement of misrepresentation cases is strong because regulators have committed resources to identifying cases of misrepresentation. Regulators must prove that the underwriter (e.g. you) possessed, but did not update 'material new information.' Consequently, at least $50 \%$ of IPO investment prospectuses are investigated. Regulators open investigations of underwriting firms they suspect of misrepresentation violations. Investigated underwriting firms may ultimately be proven innocent, but most investigated firms choose to settle cases - to avoid a long and costly legal defense. Settlements entail a fine of around $\$ 2,000,000$ payable by the firm, which neither admits nor denies fault in the matter. Settlements do not carry criminal consequences. Investigations an their outcomes (including settlements) are recorded in a publicly accessible database.

Knowledge Check 1 of 8 : What is your role in the case?

O Dropdown options: Underwriting Manager, Investor, Regulator, CEO of an IPO Firm, Unclear or not stated in the case

Knowledge Check 2 of 8: When new information about the IPO firm or the economy become available to underwriter, who should update the investment prospectus (to ensure that the prospectus accurately reflects performance projections).

Underwriting Manager, Investors, Regulators, Unclear or not stated in case

Knowledge Check 3 of 8: Who is ultimately harmed when an IPO prospectus overstates the performance projections of the IPO firm?

O Underwriters, Investors, Regulators, Unclear or not stated in case

Knowledge Check 4 of 8: Updating the prospectus with new unfavorable information will cause the following changes:

\begin{tabular}{|c|c|c|c|}
\hline & Increase & No Change & Decrease \\
\hline IPO Share Price & 0 & $\bigcirc$ & $\bigcirc[\mathbf{X}]$ \\
Underwriter's Profit \& & 0 & 0 & $\bigcirc[\mathbf{X}]$ \\
Bonus Pay & 0 & 0 & $\bigcirc[\mathbf{X}]$ \\
\hline Investor Losses & 0 \\
\hline
\end{tabular}


Knowledge Check 5 of 8: What \% of IPO investment prospectuses do regulators check?

Dropdown options: $0 \%, \underline{\mathbf{5 \%}}, 10 \%, 15 \%, 20 \%, 25 \%, 30 \%, 35 \%, 40 \%, 45 \%, \underline{\mathbf{5 0} \%+}$

Knowledge Check 6 of 8: If you accepted a settlement with regulators, what is the fine associated with the settlement?

O Dropdown options: $\$ 0$ (No Fine), $\$ \mathbf{2 5 , 0 0 0}, \$ 50,000, \$ 250,000, \$ 500,000, \$ 1,000,000$, $\$ 1,500,000, \$ 2,000,000, \$ 2,500,000$

Knowledge Check 7 of 8: If you accepted a settlement with regulators, who would pay the settlement fine?

Dropdown options: You (the underwriting manager), Your firm, Unknown or not stated in the case

Knowledge Check 8 of 8: If you accepted a settlement with regulators, would you be required to admit fault in the matter?

O Dropdown options: Yes, No, Unclear or not stated in the case

\section{Current Issue}

Your group has been engaged to underwrite a securities issue for Digifacture - a moderate-sized high-tech manufacturing firm. As part of the underwriting agreement, your group will receive a small fee, and will receive substantial performance-based revenue if the selling price of Digifacture's stock offering exceeds $\$ 15$ per share.

Based on Digifacture's audited past performance, reputable financial consultants have independently generated performance projections that value each share at $\$ 20$. At that price, your bonus compensation tied to the deal would be substantial - approximately $\$ 50,000$ from this deal alone.

However, you have recently become aware of changing economic conditions in the industry that have not yet been publicly reported (a public report will be made about one week after the stock offering). Based on your personal knowledge, you believe that Digifacture's performance projections should now be revised down, to $\$ 15$ per share. You have verified the information through other sources and you are confident that it is true and complete.

\section{You are trying to decide if and/or how you should disclose the updated information. You estimate that:}

FULL UPDATE: If you make a full update, you will achieve an average selling price of $\$ 15.00$ per share (corresponding to a $\$ 0$ bonus for you). Because your update complies with regulations, you will face no additional legal or regulatory risks. Because your update fully communicates your private information, Digifacture investors will not suffer predictable losses - the issue price will equal its fundamental value.

MINIMAL UPDATE: If you make a minimal update, you will achieve an average selling price of $\$ 17.50$ per share (corresponding to a $\$ 25,000$ bonus for you). Because your update complies with regulations, you will face no additional legal or regulatory risks. Because many Digifacture investors will have trouble understanding the disclosed information, many are likely to pay more for the stock than it is actually worth. You predict that they will be surprised when the price 
declines to $\$ 15.00$ per share (expected to occur 7 days later, when the government releases economic results).

NO UPDATE: If you make no update, you will achieve an average selling price of $\$ 20.00$ per share (corresponding to a $\$ 50,000$ bonus for you). This choice does not comply with regulations. And, if prosecuted, you would face a fine $(\$ 25,000)$ and would not be required to admit or be permitted to deny fault. The majority of fines $(95 \%)$ are settled in this manner. Because you have not disclosed the economic information, Digifacture investors are likely to pay more than the stock is actually worth. You predict that they will be surprised when the price declines to $\$ 15.00$ per share (expected to occur 7 days later, when the government releases economic results).

TABLE: Updating Options

\begin{tabular}{|c|c|c|c|c|c|}
\hline Option & $\begin{array}{c}\text { Meets } \\
\text { Legal } \\
\text { Minimum? }\end{array}$ & $\begin{array}{c}\text { Potential } \\
\text { Penalty? }\end{array}$ & $\begin{array}{c}\text { Investors } \\
\text { Harmed }\end{array}$ & $\begin{array}{c}\text { Price } \\
\text { Correction }\end{array}$ & $\begin{array}{c}\text { Your } \\
\text { Expected } \\
\text { Bonus }\end{array}$ \\
\hline Full Update & Yes & No & None & Full & $\$ 0$ \\
\hline Minimal Update & Yes & No & Many & Half & $\$ 25,000$ \\
\hline No Update & No & Yes & All & None & $\$ 50,000$ \\
\hline
\end{tabular}

Please indicate what choice you would make as underwriting manager

O Dropdown options: I would make NO UPDATE to the investment prospectus, I would MINIMALLY UPDATE the investment prospectus, I would FULLY UPDATE the investment prospectus

Acknowledging that decisions like this (updating investment prospectus) are seldom black and white, if you could choose exactly how much you update the prospectus, what amount of updating would you choose? (use the slider to adjust the level of updating)

Slider bar What amount of updating would you choose? (Minimal Update vs. Full Update)

In a few sentences, explain the basis for your prospectus updating decision (why did you make the decision that you did)?

This choice in the scenario is best described as:

O Dropdown options (ordered randomly): A Personal Decision, An Ethical Decision, A Business Decision, An Environmental Decision, A Legal Decision

How much harm will investors experience if the prospectus is not updated?

O Dropdown options: None, A little, A moderate amount, A large amount, Do not know, Does not matter 
What is the underwriting manager's responsibility?

Slider bar: The underwriting manager's responsibility is... (to run the group profitably vs. to protect investors from harm)

Please allocate points among the following 10 factors based on how important different factors were in your case choice. Please allocate points based on the factors you actually considered in your decision-making. (Note: to facilitate ease of use, respondents not constrained to 100 points)

Options, ordered randomly: Probability of being caught, Magnitude of fines, Your group's profit, What was 'the right thing to do', What complied with the law, What others might think (family, friends, colleagues, etc), My regret for harming others, Possibility of being sued if caught, Possibility that my career may be damaged, Possibility of getting fired

Please indicate your agreement with each of the following statements by selecting the option that most closely corresponds to your beliefs. $7 p t$ Likert (Strongly Disagree, Strongly Agree)

Considering all of the possible risks and costs - the potential downside of violating misrepresentation regulations is high for you (the underwriting manager).

Considering all of the possible risks and costs - the potential downside of violating misrepresentation regulations is high for your firm.

Please indicate your agreement with each of the following statements by selecting the option that most closely corresponds to your beliefs. $7 p t$ Likert (Strongly Disagree, Strongly Agree)

From your standpoint (the underwriting manager): If an investigation was launched and a settlement reached - the fine associated with accepting the settlement could damage your personal finances.

From your standpoint (the underwriting manager): If an investigation was launched and a settlement reached - your reputation and relationships would be damaged.

From your standpoint (the underwriting manager): If an investigation was launched and a settlement reached - you would think less of yourself.

From the standpoint of the firm: If an investigation was launched and a settlement reached - the fine associated with accepting the settlement could damage the firm's finances.

From the standpoint of the firm: If an investigation was launched and a settlement reached - the firm's reputation and relationships would be damaged.

Please indicate your agreement with each of the following statements by selecting the option that most closely corresponds to your beliefs. 7pt Likert (Strongly Disagree, Strongly Agree)

The likelihood of being caught violating misrepresentation regulations is high

The consequences of misrepresentation regulations are not my problem

The consequences of accepting a settlement are not my problem

If I accepted a settlement, people would think that I was guilty 
Please indicate your agreement with each of the following statements by selecting the option that most closely corresponds to your beliefs. $7 p t$ Likert (Strongly Disagree, Strongly Agree)

The case was realistic

The case was easy to understand

I would recommend this HIT to others

The following questions are to confirm your retention of case facts. Please attempt to recall the case facts as much as possible. Your survey will not be held up or cancelled by incorrect answers.

Retention Check 1: What is your role in the case?

Dropdown options: Underwriting Manager, Investor, Regulator, CEO of an IPO Firm, Unclear or not stated in the case

Retention Check 2: When new information about the IPO firm or the economy become available to underwriter, who should update the investment prospectus (to ensure that the prospectus accurately reflects performance projections).

O Dropdown options: Underwriting Manager, Investors, Regulators, Unclear or not stated in case

Retention Check 3: Who is ultimately harmed when an IPO prospectus overstates the performance projections of the IPO firm?

O Dropdown options: Underwriters, Investors, Regulators, Unclear or not stated in case

Retention Check 4: What \% of IPO investment prospectuses do regulators check?

Dropdown options: $0 \%, \underline{\mathbf{5 \%}}, 10 \%, 15 \%, 20 \%, 25 \%, 30 \%, 35 \%, 40 \%, 45 \%, \underline{\mathbf{5 0} \%+}$

Retention Check 5: Which is greater - the bonus you would earn from the IPO or the fine you would face for violating misrepresentation regulations?

O Dropdown options: The potential fine is greater, The potential bonus is greater, The potential fine and bonus are equal, Unclear or not stated

Retention Check 6: If you/your firm accepted a settlement with regulators, who would pay the settlement fine?

O Dropdown options: You (the underwriting manager), Your firm, Unknown or not stated in the case

Retention Check 7: If you/your firm accepted a settlement with regulators, would you/your firm be required to admit fault in the matter?

O Dropdown options: Yes, No, Unclear or not stated in the case 


\section{Panel C: Exit Questions}

Demographic Questions

What is your gender:

O Dropdown options: Male, Female

What year were you born?

O Dropdown options: $1920-2000$

In which country do you reside?

O Dropdown options: All countries listed.

Are you a parent?

Dropdown options: Yes, No

What is the highest level of education you have completed?

O Dropdown option: Less than High School, High School / GED, Some College, 2-year College Degree, 4-year College Degree, Masters Degree, Doctoral Degree, Professional Degree (JD, MD)

How many college-level courses in business (accounting, finance, marketing, management, etc.) have you completed?

How many years of full-time work experience have you completed?

In what industry(s) is your full-time work expense?

Have you ever acted as a supervisor or manager for other employees?

O Dropdown options: Yes, No

\section{General Questions (Set 1 of 4)}

For each question, please select 'True' if the statement accurately describes you; please select 'False' if the statement does not accurately describe you. True / False

I find it hard to imitate the behavior of other people

At parties and social gatherings, I do not attempt to do or say things that others will like

I can only argue for ideas which I already believe

I guess I put on a show to impress or entertain others

I would probably make a good actor

In a group of people I am rarely the center of attention

In different situations and with different people, I often act like very different persons 
I am not particularly good at making other people like me

I'm not always the person I appear to be

I would not change my opinions (or the way I do things) in order to please someone or win their favor

I have considered being an entertainer

I have never been good at games like charades or improvisational acting

I have trouble changing my behavior to suit different people and different situations

At a party I let others keep the jokes and stories going

I feel a bit awkward in public and do not show up quite as well as I should

I can look anyone in the eye and tell a lie with a straight face (if for a good reason)

I may deceive people by being friendly when I really dislike them

\section{General Questions (Set 2 of 4)}

For each question, please select 'True' if the statement accurately describes you; please select 'False' if the statement does not accurately describe you. True/False

I have a natural talent for influencing people

Modesty doesn't suit me

I would do almost anything on a dare

I know that I am good because everybody keeps telling me so

If I ruled the world it would be a much better place

I can usually talk my way out of anything

I like to be the center of attention

I will be a success

I think I am a special person

I see myself as a good leader

I am assertive

I like to have authority over other people

I find it easy to manipulate people

I insist on getting the respect that I am due

I like to show off my body

I can read people like a book

I like to take responsibility for making decisions

I want to amount to something in the world

I am likely to show off if I get the chance

I always know what I am doing 
For each question, please select 'True' if the statement accurately describes you; please select 'False' if the statement does not accurately describe you. True/False

\section{Please select 'True' (option not bolded in actual instrument)}

I rarely depend on anyone else to get things done

Everybody likes to hear my stories

I expect a great deal from other people

I won't be satisfied until I get all that I deserve

I like to be complimented

I have a strong will to power

I like to start new trends and fashions

I like to look at myself in the mirror

I really like to be the center of attention

I can live my life in any way I want to

People always seem to recognize my authority

I would prefer to be a leader

I am going to be a great person

I can make anybody believe anything I want them to

I am a born leader

I wish somebody would someday write my biography

I get upset when people don't notice how I look when I go out in public

I am more capable than other people

I am an extra ordinary person

I like to look at my body

\section{General Questions (Set 3 of 4)}

Please indicate your agreement with each of the following statements by selecting the option that most closely corresponds to your beliefs. 7pt Likert (Strongly Disagree, Strongly Agree)

Never tell anyone the real reason you did something unless it is useful to do so

The best way to handle people is to tell them what they want to hear

One should take action only when they are sure it is morally right

Most people are basically good and kind

Please select 'Agree' (option not bolded in actual instrument)

Honestly is the best policy in all cases

There is no excuse for lying to someone else 
It is hard to get ahead without cutting corners here and there

All in all, it is better to be humble and honest than important and dishonest

When you ask someone to do something for you, it is best to give the real reasons for wanting it rather than giving reasons that carry more weight

Most people who get ahead in the world lead clean, moral lives

Please indicate your agreement with each of the following statements by selecting the option that most closely corresponds to your beliefs. 7pt Likert (Strongly Disagree, Strongly Agree)

Anyone who completely trusts anyone else is asking for trouble (

The biggest difference between most criminals and other people is that criminals are stupid enough to get caught

Most people are brave

It is wise to flatter important people

It is possible to be good in all respects

Barnum was very wrong when he said that there's a sucker burn every minute

Generally speaking, people won't work hard unless they're forced to

People suffering from incurable diseases should have the choice of being painlessly put to death

People more easily forget the death of a parent than the loss of their property

It is safest to assume that all people have a vicious streak and it will come out when they are given a chance

\section{General Questions (Set 4 of 4)}

Please indicate your agreement with each of the following statements by selecting the option that most closely corresponds to your beliefs. $7 p t$ Likert (Strongly Disagree, Strongly Agree)

I don't think of myself as tricky or sly

I get a kick out of 'conning' someone

I got in a lot of trouble at school

I enjoy gambling for large stakes

It's sometimes fun to see how far you can push someone before they catch on

I can be fairly cunning if I have to be

I think of myself as self-assured and confident

I usually feel quite confident when meeting new people

I would NOT describe myself as shy or timid

I wish I were more assertive

I often worry unnecessarily 
Please select 'Disagree' (option not bolded in actual instrument)

I worry a lot about possible misfortunes

I didn't get into much trouble in school

I am very good at most things I try to do 


\section{REFERENCES}

Ackerman, A. 2014. "SEC Waives 'Bad Actor' Restrictions on Citigroup". Wall Street Journal. October 1, 2014.

Ackerman, A., \& C. Rexrode. 2014. 'SEC Splits on BofA Business Curbs; 'Bad Actor' Waivers Deadlock Regulator". Wall Street Journal. October 27, 2014.

Baker, C. R., \& Hayes, R. 2004. "Reflecting form over substance: the case of Enron Corp". Critical Perspectives on Accounting, 15, 6: pp. 767-785.

Bandura, A. 1991. Social cognitive theory of self-regulation. Organizational behavior and human decision processes. Vol. 50, 2: pp. 248-287.

Bandura, A. 1999. "Moral Disengagement in the Perpetration of Inhumanities". Personality and Social Psychology Review. Vol 3, 3: pp. 193 - 209.

Beeson, E. 2015. "CFTC Needs Sharper Enforcement Teeth, Massad Tells Sens.”. Law360. May 14, 2015.

Bersoff, D. 1999. "Why Good People Sometimes Do Bad Things: Motivated Reasoning and Unethical Behavior". Personality and Social Psychology Bulletin. Vol. 25, 1: pp. $28-39$.

Bicchierei, C. \& E. Xiao. 2009. "Do the Right Thing: But Only if Others Do So." Journal of Behavioral Decision Making. Vol. 22: pp. 191 - 208.

Biel, A. \& J. Thorgensen. 2007. "Activation of social norms in social dilemmas: A review of the evidence and reflections on the implications for environmental behavior." Journal of Economic Psychology. Vol 28: pp. 93 - 112.

Bowen, R. M., Call, A. C., \& Rajgopal, S. 2010. "Whistle-blowing: Target firm characteristics and economic consequences". The Accounting Review. Vol. 85, 4: pp. 1239-1271.

Bray, C., \& J. Eaglesham. 2011. "SEC-Citi Pact Rejected by Judge Rakoff". Wall Street Journal. November 28, 2011.

Brehm, J. W. 1972. Responses to the loss of freedom: A theory of psychological reactance. General Learning Press.

Charness, G., \& Rustichini, A. 2011. "Gender differences in cooperation with group membership". Games and Economic Behavior. Vol 72, 1: pp. 77-85.

Christ, M.H. 2013. "An Experimental Investigation of the Interactions among Intentions, Reciprocity, and Control”. Journal of Management Accounting Research. Vol. 25: pp. $169-197$. 
Christ, M.H., K.L. Sedatole, \& K.L Towry. 2012. "Sticks and Carrots: The Effect of Contract Frame on Effort in Incomplete Contracts". The Accounting Review. Vol. 87, 6: pp. $1913-1938$.

Christie, R. and Geis, F.L. 1970. Studies in Machiavellianism. Academic Press, New York.

Cialdini, R.B. 1996. "Social Influence and the triple tumor structure of organizational dishonesty." Codes of conduct: Behavioral research into business ethics. pp. $44-58$.

Cialdini, R.B., P.K. Petrova, \& N.J. Goldstein. 2004. "The Hidden Costs of Organizational Dishonesty". MIT Sloan Management Review. Vol. 45, 3: pp. 67 73.

Cochran, J.K, M.B. Chamlin, P.B. Wood, \& C.S. Sellers. 1999. "Shame, Embarrassment, and Formal Sanction Threats: Extending the Deterrence/Rational Choice Model to Academic Dishonesty". Sociological Inquiry. Vol. 69, 1: pp. $91-105$.

Coffee, jr., J.C. 2007. "Law and the Market: The Impact of Enforcement". University of Pennsylvania Law Review. Vol. 156, 2: pp. $229-311$.

Coletti, A.L., K.L. Sedatole, K.L. Towry. 2005. "The Effect of Control Systems on Trust and Cooperation in Collaborative Environments". The Accounting Review. Vol. 80, 2: pp. $477-500$.

Combs, D. J., Campbell, G., Jackson, M., \& Smith, R. H. (2010). Exploring the consequences of humiliating a moral transgressor. Basic and Applied Social Psychology, Vol. 32, 2: pp 128-143.

Cooter, R. 2000. "Do Good Laws Make Good Citizens? An Economic Analysis of Internalized Norms". Virginia Law Review. Vol. 86, 8: pp. 1577 - 1601.

Cornelissen, G., M.R. Bashur, J. Rode, \& M. Le Menestrel. 2013. "Rules or Consequences? The Role of Ethical Mind-Sets in Moral Dynamics". Psychological Science. Vol. 24, 4: pp. $482-488$.

Croson, R., \& Gneezy, U. 2009. Gender differences in preferences. Journal of Economic literature, 448-474.

Dana, J., Weber, R. A., \& Kuang, J. X. 2007. Exploiting moral wiggle room: experiments demonstrating an illusory preference for fairness. Economic Theory, Vol. 33, 1: pp. 67-80.

Desai, H., Hogan, C. E., \& Wilkins, M. S. 2006. "The reputational penalty for aggressive accounting: Earnings restatements and management turnover". The Accounting Review. Vol. 81, 1: 83-112. 
Dugar, S. 2010. "Nonmonetary sanctions and rewards in an experimental coordination game". Journal of Economic Behavior \& Organization. Vol. 73: pp. 377 - 386.

Eaglesham, J., \& A. Ackerman. 2013. "SEC Seeks Admissions of Fault”. Wall Street Journal. June 19, 2013.

Falk, A. \& M. Kosfeld. 2006. "The Hidden Costs of Control". American Economic Review. Vol 96, 5: pp. $1611-1630$.

Fehr, E. \& B. Rockenbach. 2003. "Detrimental effects of sanctions on human altruism". Nature. Vol. 422, 13 March: pp. 137 - 140.

Folger, R., and M.A. Konovsky. 1989. "Effects of Procedural and Distributive Justice on Reactions to Pay Raise Decisions". Academy of Management Journal. Vol. 32,1: pp. $115-130$.

Forte, A. 2005. "Locus of Control and the Moral Reasoning of Managers". Journal of Business Ethics. Vol. 58, 1/3: pp. 65- 77.

Frey, B. S. 1997. "A constitution for knaves crowds out civic virtues*”. The Economic Journal. Vol 107, 443: pp. 1043-1053.

Garcia, S. M., Chen, P., \& Gordon, M. T. 2014. "The letter versus the spirit of the law: A lay perspective on culpability". Judgment and Decision Making, Vol. 9, 5: pp. 479 490 .

Gneezy, U., \& Rustichini, A. 2000. “A fine is a price”. Journal of Legal Studies. Vol. 29, 1: pp. 1 - 17.

Grasmick, H.G., \& R.J. Bursik, Jr. 1990. "Conscience, Significant Others, and Rational Choice: Extending the Deterrence Model”. Law \& Society Review. Vol. 24, 3: pp. $837-862$.

Grasmick, H.G., \& G.J. Bryjak. 1980. "The Deterrent Effect of Perceived Severity of Punishment”. Social Forces. Vol. 59, 2: pp. $471-491$.

Hannan, R.L, F.W. Rankin, \& K.L. Towry. 2006. "The Effect of Information Systems on Honesty in Managerial Reporting: A Behavioral Perspective". Contemporary Accounting Research. Vol. 23, 4: pp. 885 -918.

Hare, R.D. 1991. The Hare Psychopathy Checklist-Revised PCL-R. Multi-Health Systems, Toronto, Ontario.

Hartmann, F. \& S. Slapnicar. 2009. "How formal performance evaluation affects trust between superior and subordinate managers". Accounting, Organizations, and Society. Vol. 34: pp. 722 - 737. 
Hennes, K. M., Leone, A. J., \& Miller, B. P. 2008. “The importance of distinguishing errors from irregularities in restatement research: The case of restatements and CEO/CFO turnover". The Accounting Review. Vol. 83, 6: pp. 1487-1519.

Holthausen, R.W. 2009. "Accounting Standards, Financial Reporting Outcomes, and Enforcement". Journal of Accounting Research. Vol. 47, 2: pp. 447 - 458.

Karpoff, J.M., D.S. Lee, \& G.S. Martin. 2008a. "The consequences to managers of financial misrepresentation". Journal of Financial Economics. Vol. 88: pp. 193 215.

Karpoff, J. M., Lee, D. S., \& Martin, G. S. 2008b. "The cost to firms of cooking the books". Journal of Financial and Quantitative Analysis, Vol. 43, 03: pp. 581-611.

Kennedy, D. 1976. Form and substance in private law adjudication. Harvard Law Review, 1685-1778.

Kerr, N.L. 1983. "Motivation Losses in Small Groups: A Social Dilemma Analysis". Interpersonal Relations and Group Processes. Vol. 45, 2: pp. 819 - 828.

Khuzami, R. 2012. "Testimony on 'Examining the Settlement Practices of U.S. Financial Regulators"'. Securities and Exchange Commission. May 17, 2012.

Latman, P. 2012. "Bear Stearns Ex-Managers to Pay \$1 Million to Settle Fraud Case". Deal B\%k. February 13, 2012.

Libby, R., Bloomfield, R., \& Nelson, M. W. 2002. Experimental research in financial accounting. Accounting, Organizations and Society. Vol. 27, 8: pp. - 775-810.

Liu, X. K., Wright, A. M., \& Wu, Y. J. 2015. “Managers' Unethical Fraudulent Financial Reporting: The Effect of Control Strength and Control Framing." Journal of Business Ethics, Vol. 129, pp. 295-310.

March, JG. 1995. “A primer on decision making”. New York, Free Press; 51.

Masclet, D., C. Noussair, S. Tucker, \& M.C. Villeval. 2003. "Monetary and Nonmonetary Punishment in the Voluntary Contributions Mechanism". American Economic Review. Vol. 93, 1: pp. $366-380$.

Matthew. C.M. 2014. "Court Says Citi Judge Went Too Far". Wall Street Journal. June 5, 2014.

Mahoney, B. 2014. "Admissions of Guilt Won't Become Norm, SEC Official Says”. Law 360. March 13, 2014.

McBarnet, D. 2001. "When compliance is not the solution but the problem: From changes in law to changes in attitude". The Australian National University Australian Taxation Office, Centre for Tax System Integrity. Working Paper No. 18. 
McBarnet, D., \& Whelan, C. 1991. "The elusive spirit of the law: Formalism and the struggle for legal control”. The Modern Law Review. Vol. 54, 6: pp. 848-873.

McKenna, F. 2011. "Judge Rakoff Indicts No-Fault Securities Settlement Syndrome”. Forbes. March 3, 2011.

Messick, D. M. 1999. Alternative logics for decision making in social settings. Journal of Economic Behavior \& Organization. Vol. 39, 1: pp. 11-28.

Milgrom, P. R., \& North, D. C. 1990. The role of institutions in the revival of trade: The law merchant, private judges, and the champagne fairs. Economics \& Politics, Vol 2, 1: pp. 1-23.

Moohr, G.S. 2007a. "On the Prospects of Deterring Corporate Crime”. Journal of Business Law \& technology. Vol. 2, 1: pp. $25-41$.

Moohr, G.S. 2006. "What The Martha Stewart Case Tells Us About White Collar Criminal Law”. Houston Law Review. Vol. 43, 3: pp. 591 - 619.

Morgenson, G. 2015. “An S.E.C. Settlement With Citigroup That Fails to Name Names". The New York Times. August 28, 2015.

Mulder, L.B., E. van Dijk, D. De Cremer, \& H.A.M. Wilke. 2006. "When Sanctions Fail to Increase Cooperation in Social Dilemmas: Considering the Presence of an Alternative Option to Defect". Personality and Social Psychology Bulletin. Vol. 32, 10: pp. $1312-1324$.

Mulder, L.B., P. Verboon, \& D. De Cramer. 2009. "Sanctions and moral judgments: The moderating effect of sanction severity and trust in authorities". European Journal of Social Psychology. Vol. 39: pp. 255-269.

Noussair, C., \& S. Tucker. 2005. "Combining Monetary and Social Sanctions to Promote Cooperation”. Economic Inquiry. Vol. 43, 3: pp. 649 - 660.

O'Fallon, M.J., \& K.D. Butterfield. 2005. "A Review of the Empirical Ethical DecisionMaking Literature: 1996-2003”. Journal of Business Ethics. Vol. 59: pp. 375 - 413.

O'Reilly, C. A., Doerr, B., Caldwell, D. F., \& Chatman, J. A. (2014). Narcissistic CEOs and executive compensation. The Leadership Quarterly, 25(2), 218-231.

Paulhus, D. L., \& Williams, K. M. 2002. The dark triad of personality: Narcissism, Machiavellianism, and psychopathy. Journal of research in personality. Vol. 36, 6: pp. 556-563.

Pierce, J.R. 2015. "Reexamining the Cost of Corporate Criminal Convictions". Journal of Management. In press. 
Pillutla, M.M., \& X.P. Chen. 1999. "Social Norms \& Cooperation in Social Dilemmas: The Effects of Context and Feedback". Organizational Behavior and Human Decision Processes. Vol. 78, 2: pp. $81-103$.

Pratt, T.C., \& F.T. Cullen. 2005. “Assessing Macro-Level Predictors and Theories of Crime: A Meta-Analysis". Crime and Justice. Vol. 32: pp. 373 - 450.

Rakoff, J.S. 2014. "Why Innocent People Plead Guilty", The New York Review of Books. November 20, 2014.

Rankin, F.W., S.T. Schwartz, R.A. Young. 2008. "The Effect of Honesty and Superior Authority on Budget Proposals". The Accounting Review. Vol. 83, 4: pp. 1083 1099.

Raskin, R., \& Hall, C. S. 1981. The Narcissistic Personality Inventory: Alternative form reliability and further evidence of construct validity. Journal of personality assessment. Vol 45, 2: pp. 159-162.

Rege, M., \& K. Telle. 2004. "The impact of social approval and framing on cooperation in public good situations". Journal of Public Economics. Vol. 88: pp. 1625 - 1644.

Robbins, T.L. 1995. "Social Loafing on Cognitive Tasks: An Examination of the 'Sucker Effect"”. Journal of Business and Psychology. Vol. 9, 3: pp. 337 - 342.

Sachdeva, S., R. Iliev, \& D.L. Medin. 2009. "Sinning Saints and Saintly Sinners: The Paradox of Moral Self-Regulation". Psychological Science. Vol. 20, 4: pp. 523 528.

Scannell, K., L. Rappaort, \& J. Bravin. 2009. “Judge Tosses Out Bonus Deal --- SEC Pact With BofA Over Merrill Is Slammed; New York Weighs Charges Against Lewis". Wall Street Journal. September 15, 2009.

Schnelder, W. \& R. Vadovic. 2009. "Legitimacy of Control". Journal of Economics \& Management Strategy. Vol. 20, 4: pp. 985 - 1009.

Securities and Exchange Commission. 2007. "Fact Sheet: President's Corporate Fraud Task Force Marks Five Years of Ensuring Corporate Integrity”. July 17, 2007.

Sefton, M., Shupp, R., \& Walker, J. M. 2007. The effect of rewards and sanctions in provision of public goods. Economic inquiry. Vol. 45, 4: pp. 671-690.

Shah, A. K. 1996. Creative compliance in financial reporting. Accounting, Organizations and Society, Vol. 21, 1: pp. 23-39.

Shalvi, S., O. Eldar, \& Y. Bereby-Meyer. 2012. "Honesty Requires Time (and Lack of Justifications)”. Psychological Science. Vol. 23, 10: pp. $1264-1270$. 
Shavell, S. 1987. "The Optimal Use of Nonmonetary Sanctions as a Deterrent". The American Economic Review. Vol. 77, 4: pp. 584 - 592.

Skarlicki, D.P. \& R. Folger. 1997. "Retaliation in the workplace: The roles of Distributive, Procedural and Interactional Justice". Journal of Applied Psychology. Vol. 82, 3: pp. $434-443$.

Smith, R. H., Webster, J. M., Parrott, W. G., \& Eyre, H. L. 2002. The role of public exposure in moral and nonmoral shame and guilt. Journal of personality and social psychology, Vol. 83, 1: pp 138.

Tafkov, I. D. 2012. "Private and public relative performance information under different compensation contracts". The Accounting Review. Vol 88, 1: pp. 327-350.

Tayler, W.B., \& R.J. Bloomfield. 2011. "Norms, Conformity, Controls”. Journal of Accounting Research. Vol. 49, 3: pp. 753 -790.

Tenbrunsel, A. E., \& Messick, D. M. 1999. "Sanctioning systems, decision frames, and cooperation.” Administrative Science Quarterly. Vol 44, 4: pp. 684 - 707.

Tenbrunsel, A.E., K.A. Wade-Benzoni, D.M. Messick, \& M.H. Bazerman. 1997. "The Dysfunctional Aspects of Environmental Standards". Environment, ethics, and behavior: The Psychology of Environmental Valuation and Degradation. pp. $105-$ 121.

Tenbrunsel, A.E., \& K. Smith-Crowe. 2008. "Ethical Decision-Making: Where We've Been and Where We're Going”. The Academy of management Annals. Vol. 2, 1: pp. $545-607$.

Towry, K.L. 2003. "Control in a Teamwork Environment: The Impact of Social Ties on the Effectiveness of Mutual Monitoring Contracts". The Accounting Review. Vol. 78, 4: pp. $1069-1095$.

Trevino, L.K., G.R. Weaver, \& S.J. Reynolds. 2006. "Behavioral Ethics in Organizations: A Review”. Journal of Management. Vol. 32, 6: pp. 951 - 990.

Trevino, L.K., \& S.A. Youngblood. 1990. "Bad Apples in Bad Barrels: A Causal Analysis of Ethical Decision-Making Behavior". Journal of Applied Psychology. Vol. 75, 4: pp. $378-385$.

Tsui, J.S.L., \& F.A. Gul. 1996. “Auditors' Behaviour In An Audit Conflict Situation: A Research Note On The Role of Locus of Control And Ethical Reasoning”. Accounting, Organizations and Society. Vol. 21, 1: pp. $41-51$.

Tyran, J.R., \& L.P. Feld. 2002. "Why People Obey the Law: Experimental Evidence From the Provision of Public Goods". CESifo Working Paper No. 651 (2). 
van Prooijen, J.W., M. Gallucci, \& G. Toeset. 2008. "Procedural justice in punishment systems: Inconsistent punishment procedures have detrimental effects on cooperation". British Journal of Social Psychology. Vol. 47: pp. 311 - 324.

Weber, J.M., S. Kopelman, \& D.M. Messick. 2004. “A Conceptual Review of Decision Making in Social Dilemmas: Applying a Logic of Appropriateness". Personality and Social Psychology Review. Vol. 8, 3: pp. $281-307$.

White, M.J. 2013. "Deploying the Full Enforcement Arsenal: Presentation made to the Council of Institutional Investors fall conference in Chicago, IL". Securities and Exchange Commission. September 26, 2013.

White, M.J., \& L.H. Gerstein. 1987. "Helping: The Influence of Anticipated Social Sanctions and Self-Monitoring". Journal of Personality. Vol. 55, 1: pp. $41-54$.

Williams, K.R., \& R. Hawkins. 1989. "The Meaning of Arrest For Wife Assault". Criminology. Vol. 27, 1: pp. $163-181$.

Xiao, E. 2013. "Profit-seeking punishment corrupts norm obedience". Games and Economic Behavior. Vol. 77: pp. 321 - 344.

Zamensky, J. 2011. "Rakoff Rejection of Citi / SEC Settlement Pierces Wall Street's Alice-in-Wonderland Thinking". Forbes. November 29, 2011. 


\section{VITA}

\section{MATTHEW T. SOOY}

EDUCATION Attended Ph.D. Program, Accounting, University of Kentucky

M.B.A., Finance \& Decision Science, Emory University

B.B.A., Accounting, Georgia State University
$2012-2016$

$2007-2009$

$2001-2005$
PROFESSIONAL PUBLICATIONS
"The Effect of Rankings on Honesty in Budget Reporting" with Jason Brown, Joe Fisher, and Geoff Sprinkle of Indiana University Accounting, Organizations, and Society, 2014, Vol. 39(4), pp. 237-246.

"The IMA Educational Case Journal: A Guide to the First Five Years: 2008 through 2012"

with Tim Miller of Xavier University, and Sean Peffer and Dan Stone of University of Kentucky

IMA Educational Case Journal, 2014, Vol. 7(1), pp. 1-17.
SCHOLASTIC HONORS
AAA / Deloitte / J. Michael Cook Doctoral Consortium Fellow (2015)

IMA Summer Doctoral Research Scholarship (2014) - for "Why Does Bonus Pay Increase With Seniority? Social Status in Compensation Contracting"
PROFESSIONAL EMPLOYMENT
Associate - State \& Local Tax, KPMG, 2005 - 2007

Dotcommer,

Interface Designer, Interland, 2000 - 2001

Interface Designer, Telephone.com, 2000

Designer, Earthlink, 1999 - 2000

Webmaster, Matrix Rehabilitation, 1997 - 1999 